NBSIR 75.716

\title{
Proceedings of Procurement Practices Symposium Federal, State and Local January 28-30, 1975
}

Sponsored by:

Experimental Technology Incentives Program

National Bureau of Standards

Washington, D. C. 20234

Federal Supply Service

General Services Administration

Washington, D. C. 20234

National Institute of Governmental Purchasing, Inc.

Washington, D. C. 20036

National Association of State Purchasing Officials

Lexington, Kentucky 40511

Final Report

May, 1975

Prepared by

Experimental Technology Incentives Program

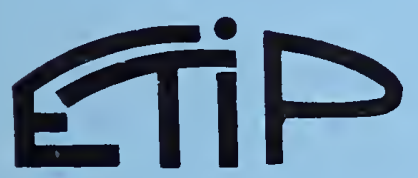



NBSIR 75-716

\section{PROCEEDINGS OF PROCUREMENT PRACTICES \\ SYMPOSIUM FEDERAL, STATE AND LOCAL \\ JANUARY 28-30, 1975}

Sponsored by:

Experimental Technology Incentives Program

National Bureau of Standards

Washington, D. C. 20234

Federal Supply Service

General Services Administration

Washington, D. C. 20234

National Institute of Governmental Purchasing, Inc.

Washington, D. C. 20036

National Association of State Purchasing Officials

Lexington, Kentucky 40511

Final Report

May, 1975

Prepared by

Experimental Technology Incentives Program

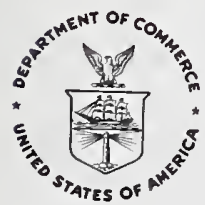

U.S. DEPARTMENT OF COMMERCE, Rogers C.B. Morton. Secretary NATIONAL BUREAU OF STANDARDS, Richerd W. Roberts. Director 

SPEECHES

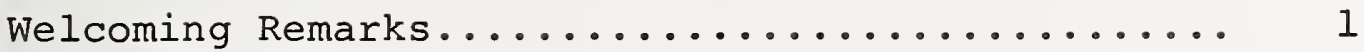
Honorable Hugh Witt

Opening Remarks.......................... 4 Honorable Arthur F. Sampson

Report of 1974 Symposium................... 5 Mr. Michael J. Timbers

Procurement Experiments Conducted by ETIP....... 8 Mr. Theodore J. Fody

Government Procurement and Technology Transfer... Mr. William T. Cavanaugh

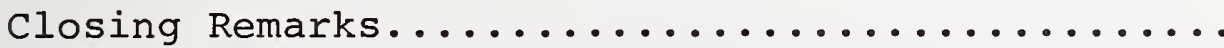

Dr. Ernest Ambler

CONCLUSIONS

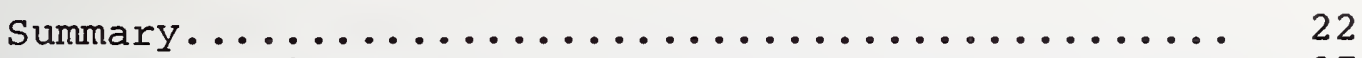

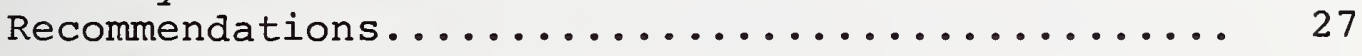

WORKSHOP REPORTS

Procurement Incentives Workshop A............. 29

Workshop B.............. 47

Interaction and Information Exchange Workshop A.. 61

Marketing, $\mathrm{R} \& \mathrm{D}$ and Government Procurement Workshop B.. 75

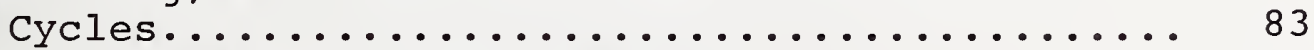

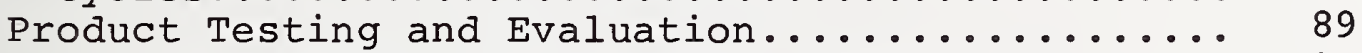

Qualified Product Lists and Bid Samples......... 95

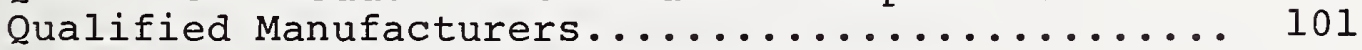

Methods and Techniques of Contracting.......... 107

ACCOMPLISHMENTS

Report on Accomplishments Based on Recommendations of the First ETIP Symposium on Procurement Prac-

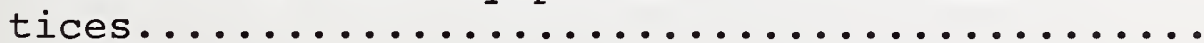

PARTICIPANTS/ATTENDEES....................... 129

PHOTOGRAPHS ........................... 
- To recommend ways to encourage information interchange and interaction between federal, state and local procurement levels and industry

- To explore the use of special incentives such as life cycle costing, value incentive clauses, and unsolicited proposals as a means to promote innovation in products purchased by all levels of government

- To establish the interrelationship between marketing, R\&D and procurement and develop approaches to acquire the latest technology through the procurement process

- To explore various product testing and evaluation efforts such as certification programs, tests by independent, company owned and association laboratories, university and government laboratories. 
SPEECHES 



\title{
PROCUREMENT PRACTICES SYMPOSIUM
}

FEDERAL, STATE AND LOCAL

\section{Sponsored by}

Experimental Technology Incentives Program (ETIP)

National Bureau of Standards, U.S. Department of Commerce

Federal Supply Service (FSS)

General Services Administration

National Association of State Purchasing Officials (NASPO)

National Institute of Governmental Purchasing (NIGP)

\author{
WELCOMING REMARKS \\ of \\ Honorable Hugh E. Witt \\ Administrator \\ Office of Federal Procurement Policy/OMB
}

Thank you Jordan. This Lewis is really an eager beaver. Even before I left my previous job as Principal Deputy Assistant Secretary of Defense, he was in my office pounding on the table telling me how important all this ETIP operation is and I had never even heard of it. There I was, just about to leave the Pentagon and step into the hallowed halls of OMB, if you will, although some people don't refer to it that way--particularly in the budget season. Before I even got over there, here was Jordan pounding the desk with great vigor, extolling the virtues of all this experimental work that is going to be palmed off upon an unsuspecting public.

I don't know how up-to-date you folks are as far as the office of Federal Procurement Policy is concerned. A number of people refer to me as the "Head Procurer," and I don't know if it's on the police blotter down at the District of Columbia or not:

Actually, what the Congress was unhappy about in the past was the fact that there was no central point where they could refer all their problems. In the Federal Government they would get one line out of NASA, another story out of GSA, and another policy pronouncement out of the Defense Department on basically the same subject. They decided to have one lightning rod so they would know where to strike, and I'm afraid you're looking at him this morning. 
We are going to have a small staff over there, hopefully about 14 professionals. I have been debating with Bob Hampton over how many supergrades I can get, and those of you in the bureaucracy know how tough it is to get new spaces out of the Civil Service commission. In addition, of course, I have already had the General Accounting office write a report saying I am not moving fast enough - me and my two people. The three of us are supposed to worry about the procurement policies for $\$ 60$ billion worth of procurement a year and that does not include the grant side of the house.

Now I have an interesting job in that first, the executive branch wasn't very happy about the job even being set up to begin with, and secondly, industry was very anxious to have it set up because like the Congress, it wants to have a focal point to concentrate on when it is unhappy about something. Herb Roback, in one of his speeches on this subject, pointed out that everybody who is unhappy could now just pick up the phone and call the Administrator for Federal Procurement Policy and tell him what the hell was wrong with procurement. Then he would have to try to straighten it out.

Well, I am not sure that it is going to work that way, but we are starting discussions with the executive agencies as to how we are going to communicate and how we are going to promulgate the policies that we set, including whether or not there should be one monstrous procurement document covering ASPR and FPRs, and so forth. These are the kinds of issues that we are going to go into as we get set up and organized, and get off the ground.

I would emphasize, however, a couple of things that are rather interesting. I am going to work for the Director of omB but I report directly to the congress. Now that is going to be pretty sporty. The other day I ran into Jack Marsh who used to be an Assistant Secretary of Defense and is now one of the counselors to the President in the White House, and he said, "I was just looking at the legislation that set up your job. Do you know who the hell you work for?" and I said, "Well, I work first for the President and second for Roy Ash and third for Congress, I think, except that any report I make has to go directly to Congress and not through the Director of OMB." Well, anyway, you can see a little bit of the dichotomy that we are facing trying to get this thing off the ground. The Director of OMB cannot take any of my funds. I have a separate appropriation which cannot be used for anything except procurement policies. So if he wants to take any of my people and put them on a special assignment that does not deal with procurement policy, the lawyers tell me, and they told him, he would be breaking the law. As you can see, working for the Director and everyone else is going to be fun. 
Well, anyway, we hope to get a better handle on the whole procurement process. We hope to have more uniformity. We hope also to meet another important responsibility that the Congress has laid on us which is something you people are particularly interested in today, and that is that I perform procurement research where I determine that there is a need. That is one reason I am here today because I certainly want to spiritually and deservedly pat Jordan Lewis on the back, as well as all of you who are involved -in these kinds of programs. In my opinion, there hasn't been enough innovation in the procurement process. There hasn't been enough new and free thinking and we need more spiritual spurs under the saddle in our business, as far as I'm concerned. I have been on the procurement side, I have been on the support side, and I have struggled with life cycle costing and integrated logistics support and all those fine words, but there are a lot of us who feel that the procurers could be doing a better job as far as coming up with new ways to procure. We also, of course, will be very cognizant of the fact that one of the six main functions and responsibilities that Congress laid on the Administrator for Federal Procurement Policy is that he perform such research as he feels necessary across the whole procurement policy spectrum. We certainly plan to do that.

I would also add that we are going to be getting a lot of help from congress. In this town you always get a lot of help from Congress. Someone told me the other day that when he asked a Congressman what he thought of ignorance and apathy, he said, "I don't know and I don't care." Well, anyway, it is going to be sporty and we do have a lot of people helping us in our business, as we all know.

I do want to thank you very much for letting me be here to help kick this thing off. Jordan has been keeping me up to speed, feeding me all sorts of documents, most of which I haven't had a chance to read yet. I do know generally the kind of programs that are involved and the kinds of areas that he is looking at and the sort of rocks you people are turning over, and all I can say is that I certainly am all for it.

I also want to thank Mike Timbers for providing transportation out here. We at OMB have a very small budget but we are trying to help everybody else with theirs, so to speak.

I would like to close with a quotation from Oliver Wendell Holmes. He said, "Knowledge and timber shouldn't be much used until they're seasoned." I am glad to be followed by a well seasoned Mike Timbers. Thank you very much. 


\section{Arthur F. Sampson \\ Administrator \\ General Services Administration \\ Statement Presented By \\ Michael J. Timbers \\ Commissioner \\ Federal Supply Service}

General Services Administration

I welcome you all to this conference. I promised Mike Timbers that I would be with you this morning to make some remarks. And I meant it because I am convinced of the worth of your efforts and assured, now, after several months since your last conference, of their real value. My schedule changed suddenly so I have asked Mike to fill in.

The procurement function in government, as you all know, is a massive one--some $\$ 57$ billion a year and the philosophy behind it--behind buying from the private sector--is sound. It's aimed at ending duplication and slowing the growth of government--which has already grown large indeed.

But the attitude toward procurement itself has not always been as progressive as it should be. All too often, in the past, procurement has been viewed as a mechanical--almost a clerical-function. A function that was seldom examined in its own right and less frequently improved. But that is changing.

The report of the Commission on Government Procurement made us newly aware of the massive, highly potent buying power of the Federal Government. It made government managers realize, perhaps for the first time, that what they bought or didn't buy or how they bought goods and services from the private sector could in very substantial ways make or break the efficiency of their programs themselves. And the procurement function, they realized, could be shaped to help those programs meet their goals--to save energy, to save dollars, and to improve the environment. Your conference and others like it that have taken place in the time since the Commission report was published are the product of that realization and the understanding that procurement can be and should be a creative part of good government.

But your conference is unique. Your's is a single purpose--to encourage the sharing of technology, and thus, the improvement of technology. In the end that comes down to the same thing-improved technology can help us save dollars, save energy ", and improve the environment.

There are two special features of this effort. Features which give it real meaning these days. One element is immediacy, as 
Mike will tell you, your recommendations have already paid off in savings--savings that we can use right now.

The second is this: the outcome of your efforts, in a general sense, is to improve the productivity of both government and business. That is, getting more for less. More for our dollars and more for our energy. Nothing could be more timely than this.

So I encourage you to be adventurous in your thinking and frank in your recommendations. With that approach, your second conference can produce even more dramatic results than your first. That is the kind of conference we are hoping for.

\author{
Report of Accomplishments \\ Based on Recommendations \\ Made at First ETIP Symposium by \\ Michael J. Timbers \\ Commissioner
}

Federal Supply Service

General Services Administration

The second part of my duties this morning is to give you a progress report on the conference which we held last spring. That is almost an impossible task. I think that we have had an incredible amount of progress since last year, but it would probably take all morning if I went into the real specifics of that progress. You also have a summary report or will be getting a summary report that I think covers it far more completely than I possibly could. I would like, however, to hit upon a couple of what I consider to be the real high points of the progress we have made based on the recommendations that were made at the last conference.

One recommendation was that we get more involved in life-cycle costing. We have made an award, for example, on air-conditioners that gave us a 21 percent energy savings over a 7-year life, and not only that, it also saved us $\$ 400,000$ in total life-cycle costing. We have also just recently made an award on water heaters, again along the life-cycle costing basis, and we have solicitations in one stage or another on lawnmowers, gas ranges, and refrigerators. So I think we are starting to make some progress as far as life-cycle costing is concerned. Another element of the life-cycle costing approach was training-training our procurement people. With the excellent help of ETIP and with the Logistics Management Institute, we have started to do some of that. We have had several training courses at Federal Supply to get our people up to snuff on the LCC concepts. We are planning to take that training and develop our own in-house capability to train our own people both within Federal Supply Service and other Government 
agencies. Hopefully, we will also be able to get our state and local procurement friends involved in these same training sessions with us. We are exploring this right now.

Another recommendation that was made last year was about organization. You recommended that we reorganize along a product manager type of concept, and we have taken some steps in that direction. The first of March, we will be establishing our National Furniture Center. This will bring all of the elements of the procurement process together including specification development, procurement, and inventory management. Our future plans include other such commodity centers in the area of tools, automotive, office and paper products, and office equipment.

We made another organizational change which I think is quite significant. We have set up a special staff office referred to as the "Experimental Technology Program Staff." This office is principally to coordinate all of the projects that we have ongoing with ETIP. It will also serve as a sort of ombudsman, if you will, for industry which may have a new concept or item that it would like to approach Federal Supply Service on. This group can serve as a kind of coordinating body.

Another recommendation that we heard out of last year's conference concerned value incentive and value management. We now will be having in all of our supply contracts in the future a Value Incentive clause so that the successful low bidder on a contract after he has been awarded a contract will have the opportunity to look for possible savings in that contract, changes in the design, and/or changes in the production process. The Government will then share the savings with the contractor. The contractor can also be assured of a royalty on the next year, if in fact, he is not the successful bidder. Under our value incentive program, we also will allow for collateral savings even if the price of the item might go up, if the life-cycle cost for that particular item goes down. Then, we will also share savings with the contractor.

Bud Brogan of our Value Management Staff at Federal Supply is here at the conference. I will ask Bud to work at the various workshops here, and give those of you who are interested a little more of the details about how the value Incentive clause will be working. I might also say one other thing to those of you from industry who are here today. If you do get involved and do submit value incentive proposals, I can assure you that we will act quickly on those proposals. I think that the worst thing to stifle a program like this is to have innovation or to have good ideas come up and not have us act on them quickly. We will act quickly: 
Another recommendation, I think is a very significant one, was the recommendation that we have a greater flow of information between the Federal, State, and local procurement people. This meeting is probably the best example of that. It not only includes our Federal, State, and local procurement people but includes the industry people as well. And another thing I might mention is the Joint Advisory Panel on Procurement and Supply. This is a Federal, State, and local panel on procurement and supply, and many of the members of that Panel are in the audience here today. This Panel, which meets three or four times a year is composed of Presidents of NASPO, NIGP, and other outstanding State and local purchasing people, will also be sponsoring in early April a 2-day Procurement Conference for Federal, State, and local procurement people.

One of the other recommendations that came out of last year's meeting was that we should do more in training our own procurement people. We have taken a number of steps in this area. One of the most significant ones, I think, is the fact that we now have a capability of video taping training sessions and disseminating them to our procurement people around the country, as well as other agencies that are interested. Many of you may have seen, in fact, a film we put together when the small purchase limitation was changed from $\$ 2,500$ to $\$ 10,000$. I think this is the kind of thing that was envisioned in the recommendation that came out of the conference last May.

There was a great interest in the multiple award schedule program at the last conference. During the last few months, we have added a number of multiple award schedules to our program including such items as storage cabinets, water purification equipment, food service, handling, refrigeration, storage and cleaning equipment, clothing, footwear and fertilizers, but we are expanding our multiple award program. One of the other problems that was mentioned is that there is not a minimum order limitation or that the minimum order limitation on many of our multiple award schedules is too small. We have issued instructions to our contracting officers to establish a small requirements limitation, in essence a minimum order limitation on our scheduled contract, tailored to the specific commodity that we are talking about.

A final thing you suggested was that we have a market and market research capability. A capability to find out what our customer agencies really want and really need so that we can serve them better. I am happy to report that since the last meeting we have established such a capability, and it is an ongoing part of our organization now.

I could probably go on, but Hugh witt reminded me when he sat down that he used, I think, 8 minutes and 45 seconds, 
so I probably have already used more than he has so I will start to finish. I think the report that you have covers the rest of the specifics very well, but I would like to do one thing. With all the difficulties that we face in the procurement process, I would like to challenge everyone here in the meeting to use your time wisely and to meet these problems head on in the next couple of days, to speak candidly and openly to question existing practices. I think we have the best talent in the procurement and supply business represented here today. Lets develop a product worthy of the attendees and the concept of ETIP. Thank you.

\section{Procurement Experiments Conducted by ETIP

\author{
Theodore J. Fody \\ Chief, Procurement Policy Area \\ Experimental Technology Incentives Program
}

Good morning. President Nixon, in his March 1972 Science and Technology and 1973 Budget Messages, called for a testing of possible partnership arrangements among various government levels, private firms and universities and the initiation of a series of experiments to find better ways of stimulating private investment in research and development. This was the birth of the Experimental Technology Incentives Program known as ETIP.

This program which is under the National Bureau of Standards is part of a continuing effort, on the part of the Federal Government, to find ways in which it can work as a more effective partner with the private sector of our society in the development, application and transfer of science and technology to strengthen the Nation's economy and improve the quality of life.

The ETIP objective is to conduct an informed inquiry into the relationship between governmental actions and technological innovation in the private sector. The purpose of the inquiry is to discover appropriate governmental policies and practices which could stimulate desirable innovation in the civilian economy and thus contribute to the solution of national problems. The general method of conducting this inquiry is to work in close cooperation with appropriate government agencies in the identification, analysis, testing, and evaluation of potential incentives for innovation. The particular question addressed will be of significant interest to the cooperating agency and will represent a general process which has application in other areas. 
This experimental program is designed to gain insight into practical problems by developing unique information from actual experience. ETIP is of course interested in fostering the adoption of the results of its inquiry, but it should be recognized, however, that responsibility for such implementation is beyond the province of ETIP.

Our mission is, if the results of our efforts are to be employed, to involve other federal agencies so closely in our work that they understand it and want to use the results. We have no authority over other agencies and if they are not interested in what we are doing, the chances of our being effective are very low. So when we go to an agency we start at the top levels of the agency that is the Administrator, the Commissioner, or the Director, explain ETIP to them and test whether they are, in fact, interested in exploring with us the possibility of getting involved in policy development. Once we obtain agreement to proceed, we then put together a project with the agency to test a theory and furnish the funds to the agency to conduct the experiment.

ETIP is made up of four areas:

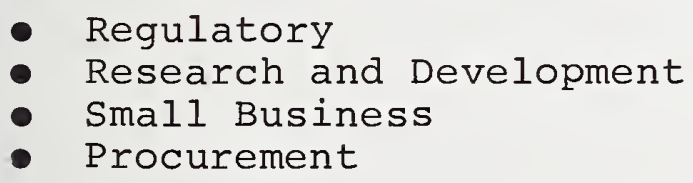

I will focus on the Procurement Area of ETIP and give you some idea of the experiments we are currently doing. The Procurement experiments are being conducted in cooperation with the General Services Administration, the Veterans Administration, and state and local governments to learn how changes in procurement policies and practices can stimulate innovation by private firms selling to the government.

The Government presently purchases most of the civilian goods and services at the lowest bid price and also to the lowest technological denominator. This procurement process tends to restrict the application of new technology because of price and other considerations. We are exploring the possibility of changing this policy to permit Government to obtain the best value for its money.

Some of the techniques being investigated through ETIP with FSS are:

- Life Cycle costing

- Value Incentive Clauses

- Increased Use of Performance Specifications 
We have Life Cycle Costing experiments with FSS covering consumer durables such as ranges, air conditioners, refrigerators and water heaters. The procurement of these items are being done on a performance-energy efficiency basis. The experiment for each of these durables is designed to last for three procurement cycles or three years. Fss has completed the first procurement cycle for window air conditioners and the following are some of the successes of this procurement:

1. FSS used a modified Life Cycle Cost approach in this procurement.

2. Bids were received from more firms in this procurement than prior to ETIP.

3. The air conditioner procurement produced an improved energy efficiency of approximately $20 \%$ on the average over 5 sizes of air conditioners.

4. FSS estimates that the savings in energy over the life of the units will be $\$ 400,000$.

We also have an experiment on lawnmowers with FSS and the objective of the experiment is to determine the effectiveness of Federal Government procurement in stimulating the introduction of noise control technology into consumer products. A quieter lawnmower was not purchased during the first procurement cycle, but we did have some successes and they are:

1. FSS modified their procurement practices from using a design specification to a modified performance specification directed toward the noise problem and provided industry with the flexibility of innovating with the power source.

2. Seven firms submitted eight technical proposals whereas previously FSS could only interest two firms in bidding.

3. FSS issued a letter of intent to procure quieter lawn mowers again next year.

4. EPA is working with FSS to develop a sliding scale incentive plan for future procurements.

Another ETIP experiment with FSS consists of developing and presenting a formal course on the theory and application of Life Cycle costing. Two workshops have already been conducted at FSS here in Washington and more are planned for each of the ten regional offices in Federal Supply. Nine additional 
products were selected for Life cycle costing as a result of these two workshops.

Another experiment ETIP has with FSS is the Value Incentive Program which you will be hearing about in the upcoming months. The thrust of this experiment is to encourage industry to challenge unrealistic government product requirements and to profit by doing so. FSS will benefit from the experience and knowledge of its contractors in the areas of cost, new materials, new techniques, and potential innovations. FSS plans to conduct government/industry seminars to implement the program and establish and coordinate internal processing procedures.

The Procurement group of ETIP is also working with the Veterans Administration to develop some experiments with them. The VA is the largest single provider of health care services operating 171 hospitals and medical centers, 206 outpatient clinics and 82 nursing homes. The VA system provides approximately 97,000 beds which is $9 \%$ of the Nation's total in patient load. Furthermore, each of the 171 hospitals are affiliated with major medical schools and participate in training one of every two physicians in the country. Our work with the VA is in its early stages and at the present time we plan to explore along three avenues:

1. Experiments in encouraging the development and procurement of innovative products and systems.

2. Experiments in new procurement policies and practices to alter some of the old practices.

3. Experiments in matching demand to supply on a more flexible basis.

This was a brief discussion of the Experimental Technology Incentives Program. We have many other projects which I have not covered with you because of the time. However, I wish to thank you for listening to our story.

Government Procurement and Technology Transfer

\author{
William T. Cavanaugh \\ Managing Director \\ American Society for Testing and Materials
}

I always enjoy being the "speaker to be announced" in the first printing of a program because this usually means that nine other people have been asked and have politely, for one 
reason or the other, declined before they got to me. Gives me a free and easy feeling.

I really feel at home this morning for many reasons not the least of which is I have had the privilege, on many occasions, to participate in programs here at the Bureau and in fact, in this lovely auditorium.

Second, as many of you may not know, ASTM is the largest developer of standards of all sorts in the world. As such we have had a great positive relationship with the Bureau since the beginning, some 77 years ago. The National Bureau of Standards has a very large cadre of its people involved in many kinds of standards developing activities in ASTM. About 200 of its people fill 860 places on our committees.

Third, and most important, I have long been associated with and have come to have tremendous respect for the National Institute of Governmental Purchasing; Albert $\mathrm{H}$. Hall and his professional associates. The same is true, but of more recent times, of the National Association of State Purchasing Officials.

Perhaps I could put it this way by saying ETIP's interest in the procurement function as an incentive or methodology or whatever in technological transfer, is great. Since we have always regarded standards development as a great mechanism for technological transfer--even before the term was invented, we look upon it as an exciting re-fueling of the tanks of programs we have very modestly under way now, with similar objectives, for about five or six years. We, therefore, of course, like the concept which is fundamental to this ETIP program-that technological transfer between the public and private sectors can have a very positive flow-over into the modern commercial marketplace and vice-versa. ASTM has been helping it happen for a long, long, time.

In fact, it may be interesting in passing to note, that's the reason, five years ago at the initiative of NIGP and ASTM, we started to try to capture more participation of professional purchasers from government in our product standards work. The basic assumption was that resulting product standards would be equally as useful in the socalled public and private sectors. Although this has not always proven to be the case, there is certainly a sufficient number of cases that indicate the validity of that assumption. ASTM's attitude still is that if we are going to crack the problem of end-use participation in product standards development then probably the largest single group of people who are not at the moment sufficiently involved are the government purchasers particularly at the state, county and municipal levels. So in ASTM on the basis 
of experience, both recent and long term, we are convinced of the validity of the concept that the development of standards for the procurement function can indeed have the effects envisioned by your program today. Let me give you several specific examples from areas that are so familiar that they are quite often overlooked.

It is impossible in the U.S., or for that matter in ninetenths of the world, to buy any petroleum product or derivative except to an ASTM standard specification or standard method of test. This is true whether we are talk-ing of gasoline, jet fuel, residual fuel, diesel fuel, road oil, asphalt, or whatever. We need to realize that the federal, state, and municipal purchasers for years and years and years (at least two generations) have been effectively involved in the ASTM activities where these specifications and test methods are developed. Thus they have had a tremendous voice in the technical improvements or technological transfer that have indeed taken place in the entire area of petroleum.

Exactly the same can be said of cement and concrete products so important, of course, in our highway programs and related interests. In passing it might be worth mentioning that there is not a single state Highway Department in the United States that is not and has not been involved in this kind of activity. There is no question that the tremendous technological transfer in these fields, much of which have been needs expressed by the State Highway Departments and their sister organizations, their municipalities, and their counties.

In passing it should be observed that historically this kind of activity has emerged almost as a natural thing based on the professional predilictions of the engineers and their colleagues involved in government who easily recognized the goals to be achieved in this kind of activity and who have turned their attention to the pursuit of these activities. There has also been for these people, developed over years, management understanding of tremendous values in this kind of activity.

In our experience such has not been the case for state and local procurement people. This is the reason that five years ago ASTM in conjunction with the National Institute of Governmental Purchasing launched a program to increase and improve the participation of state and local purchasers in certain product-oriented ASTM standards committees. Essentially, the program involved identification of product areas of priority interest to NIGP officials, followed by the identification of procurement officials available to 
participate, followed by ASTM subsidy to them, where necessary, for their travel and related out-of-pocket expenses.

What have we learned in the past four years? We learned first of all that lack of adequate involvement of non-federal procurement officials is not the result of lack of interest. NIGP, for example, has for a long time had a very progressive program in the area of professional purchasing, and, therefore, the depoliticalization of the procurement function. It has long recognized the need for product standards, not only as tools essential to the professional purchasing function but as an excellent vehicle for what is called in this program, technological transfer. We have learned, however, that there are, in spite of most progressive attitudes on the part of these folks, some very basic problems that must be identified, as we have tried to do, and attacked, as we have also tried to do, if the immense potential toward the goals of this program in the state and local purchasing function is to be realized.

This involves a greatly enlarged and appropriately integrated cadre of these people not only in activities we have in ASTM but the many other nongovernmental areas where product standards are under development.

We must candidly recognize that a very large percentage of procurement officials at the state and local levels do not have the basic resources for themselves and their colleagues to participate thoroughly in these functions. We know that many of them do not have sufficient time allowed for such participation. It is a common practice for these people, who are in fact participants in ASTM activities, to do so on their own time. They take vacation time for this purpose.

Further, we need to recognize that through no fault of their own many purchasing officials do not have technical sophistication in the form of laboratory facilities for performance validation and personnel who can participate effectively in the high technology aspects of many of these problems. They must be able to participate on a plain language performance basis that can be validated in some manner by someone else's test facilities, perhaps on contract. There is need also for a national system which will accredit those testing laboratories capable of performing the validations. Here we endorse the efforts of NBS to establish such a system.

To summarize, let me say that there is already in place, both in the federal establishment and in the private sector, a marvelous mechanism to achieve many of the goals of this conference. Standards development is possibly the most 
important mechanism for technological transfer and, therefore, the one most often overlooked. We need further to take specific steps to enlarge the input of these people in the process.

The keystone to all that must follow is a change in the right direction in the attitude of state and local government managers who simply do not understand that the resources invested in this kind of activity will return dividends immensely in excess of the original investments. It's been going on for years. It's impact needs to be expanded.

Somehow, state and local government management must be brought to a realization that the participation in national standards programs by their professionals does not constitute junketing. It is and essential element in the technological transfer aspects of standards activities.

We hope your conference can help in this regard and we hope, too, that somehow we can continue to be helpful.

\author{
Closing Remarks \\ Dr. Ernest Ambler \\ Deputy Director \\ National Bureau of Standards
}

Some of you people look mighty tired. I know our ETIP staff is! And that's a sign that this conference served its purpose as a thought provoking (and maybe sometimes just plain provoking) interchange amongst all participants.

At the opening of the Conference Michael Timbers of the Federal Supply Service focused on some of the positive responses to the recommendations made at the first Workshop. Here, we have tangible proof that ETIP and FSS can work together with business to form a better partnership in the vital process of stimulating innovation by both government and industry. That's what ETIP is all about. In brief, ETIP's goal is to act as a catalyst in stimulating technological innovation in industry. And one of those ways is via procurement, by helping develop Government procedures to make the changes worthwhile. In government, these actions would be of a policy and procedural nature, while in industry the major response would be technological. The initiatives taken by the FSS are most gratifying to us, and their impact can be widespread. In FY73 Civil Agencies alone spent about \$6.2 billion in purchasing civilian goods and services. 
While $\$ 6.2$ billion is a large number, it is dwarfed by the approximately $\$ 100$ billion a year spent by state and local governments. I know that many of the techniques developed and implemented by ETIP and its Federal Agency partners can and will be tested at the state and local level. That is why this Conference, and the positive action that it has stimulated, is an important step to all of us who seek the best buy for our dollars.

In the limited time since your workshops concluded, the ETIP staff has briefed me on your discussions and recommendations. I would like to make a few comments on both the symposium and on your recommendations.

Messages that seem to come out of several workshops are:

1. The need for a more responsive, real time information system to communicate among F'ederal, state, and local government and industry:

a. needs for innovative goods and services

b. standards, specifications and test methods

c. feedback on product performance

d. experience on "test buys" with new criteria or new policies that are the results of ETIP-type experiments

2. The need for a major educational program aimed at the appropriate levels of governmental purchaser-user groups to reflect:
a. savings potential
b. improved quality
c. reduction of procurement time and cost
d. new procurement techniques

The Life Cycle costing and Value Incentive experiments ETIP is conducting with FSS is a good start in this direction and more will be underway with state and local levels of government.

3. The need for developing more performance or cost oriented standards, specifications and test methods and to apply them on a broad scale to give the suppliers some sense of product uniformity - as part of this there is the need for quality testing and evaluation institutions to ensure compliance for the benefit of the user, purchaser and supplier - a topic of great interest to us because we are being asked to design a Laboratory Accreditation system. I am sure these and other recommendations from the workshops will be pursued in the weeks ahead. 
At this point I would like to acknowledge and thank the new Conference sponsors, the National Association of State Purchasing Officials and the National Institute of Governmental Purchasing. I trust they have found your efforts worthwhile. I hope all of you in purchasing have become more aware of what an impact you might be able to have on the various specific markets that have been discussed at this meeting. I hope that you have become interested and that you will become involved in helping us choose our next moves wisely by giving us questions to address in future experiments.

As for industry, I hope you see ETIP as your program too. We not only need your cooperation in proving out experiments, we need your guidance in deciding how to proceed. We want to proceed, and we have to proceed, in ways that will help you put research and development to more extensive and profitable use.

Now, by its very name we recognize ETIP to be an experimental program. It has the difficult but exciting challenge of providing incentives that stimulate industry to increase investments in civilian R\&D and bring new and improved products to the marketplace. This role of Governmental involvement in stimulating civilian $R \& D$ is of growing importance and one that needs to be handled carefully so that we do not further hamper private initiative. But in light of both our domestic economy and our need to better compete in foreign markets, we do need to reduce barriers and provide positive stimulation.

Technological invention and innovation have been throughout history key factors in the improvement of civilization and the estate of man. Indeed, through the application of technology, we in this country have created a standard of living that is envied throughout the world. In this present day, with our great concern for the deleterious and often unforeseen side-effects of technology, we tend to lose sight of the fact that technology has been and remains a great boon to man. Governments must, like everyone else, recognize this fact and act accordingly.

I view ETIP as an important program in this regard and the management of NBS is proud to have such an important test-bed for technology policy here. It is one to which people at many levels must contribute if it is to do its job. Industry, Federal, state and local officials must all actively participate if we are to accomplish our objectives. And that is what this Conference is all about.

While you are here, I would like to tell you about some other NBS programs that may be of direct interest to state and local governments. We provide essential central support for the 
most basic of all consumer protection through our office of Weights and Measures. We do this by working closely with the National Conference on Weights and Measures - which represents all 50 states - to help assure a fair measure in the marketplace. Our contributions range from training to developing and distributing new state standards to helping formulate model codes and regulations. The success of this effort is reflected in widespread consumer confidence that a pound is indeed a pound, or a kilogram a kilogram, or a gallon a true gallon, or a liter a liter. I was happy to learn that a workshop of this conference suggested this arrangement as a model to emulate, because we are pursuing this same idea in areas other than the one of Government procurement that you are suggesting.

We also serve as the secretariat and work closely with the National Conference of States on Building Codes and Standards, a group that seeks to foster innovation in building through development of more uniform building codes. Here again is an area where new technology could be used if proper mechanisms can be developed to foster its introduction. For example, if a building code called for a wall strength, and provided at the same time a method for testing and evaluation, rather than prescribing exactly how it is to be built, then innovation and economies could be introduced. The impact would affect official buildings as well as homes, and would give greater latitude in your building contracts.

We have a Law Enforcement Standards Laboratory that develops standards and test methods for the Law Enforcement Assistance Administration for purchase of police equipment. These standards formulated under this program are available to all jurisdictions and provide a rational basis for purchase decisions. Standards for such items as protective armor, handcuffs, and communications equipment have been published, and are available for use by all agencies of government.

I could go on, but I only want to indicate that there may be a number of activities at NBS of interest to you, on which we would be glad to give you more information. In continuing the work you started here, I encourage you to utilize not only the ETIP program, but all that may be useful to you at NBS.

We enjoyed having you here with us. I am much encouraged by the reports I heard. I am impressed with the depth of coverage of such broad subjects, the insights into how government and industry can foster their new partnership, and with the large number of new questions to be addressed by ETIP experiments. 
We hope both industry representatives and public purchasing officials will continue to look upon ETIP and all of NBS as resources to help you in your respective jobs. And we hope that you will continue to take an active part in promoting the much-needed dialogue on government-industry business practices.

Let me wish you good luck in continuing the work you started here, and I look forward to seeing you again soon. 

CONCLUSIONS 
The symposium was the second in a projected series of conferences held as part of the continuing joint governmentindustry effort to find means of accelerating the development and application of innovative technology through incentives in public procurement.

At the first conference, held May 29-31, 1974, workshops conducted in nine product areas produced a series of recommendations for modifying prevailing government procurement practices. Suggestions were made that government specifications be more flexible, with emphasis on performance of products rather than design, and for broader use of the life cycle costing concept. There were a number of suggestions for increasing the exchange of ideas between government and industry and among federal, state and local government to improve nationwide procurement techniques.

\section{FEDERAL SUPPLY SERVICE ACTIONS}

Actions taken by the Federal Supply Service relating to comments and recommendations of the first symposium were in four general categories:

\section{Procurement}

Solicitations containing Life Cycle Costing provisions have been issued in several product categories. Awards were made for air conditioners and were pending on water heaters, refrigerators and gas ranges. Use of the multiple award schedule program was expanded.

A program of on-the-job training has been initiated for procurement personnel, both at headquarters and in regional offices. Planning is underway to make training programs available to state and local procurement personnel. Other initiatives have been undertaken to provide incentives for innovation on the part of procurement personnel as well as suppliers.

\section{Specifications, Standards and Quality Control}

Steps have been taken to improve laboratory facilities and equipment for testing, and some of the resources have been centralized to insure optimum utilization of expensive equipment. The system of feedback of results of testing has been made more effective and is responsive both to product acceptance and to customer complaints. 
FSS is expanding the use of panels of experts for subjective evaluation of products in which it is not feasible to develop performance specifications and where design specifications are not practicable.

\section{Communications}

The Federal Supply Service has recruited a specialist to develop a program to channel procurement information to trade journals, national publications such as the Wall street Journal, and trade association newsletters. The program also will be designed to stimulate a greater flow of information among the federal, state and local governments and to sponsor more joint seminars.

\section{Organization}

A market research group has been established to work to obtain data on open market procurements and to ascertain customer satisfaction or dissatisfaction with items currently availabie in the supply system. A policy and planning group has been established to continuously reassess programs and policies and make changes as necessary to maintain the most costeffective material management organization.

The complete report of the Federal Supply Service on its accomplishments is included in a later section.

\section{WORKSHOPS ORGANIZED FUNCTIONALLY}

The same format was used at the second symposium that was used in the first. Initial speeches provided orientation and direction for workshops that addressed specific aspects of procurement and reported to the final plenary session. Whereas at the first conference the workshops were productoriented, this time they were organized to address functional problems. The seven workshops and their topics were:

1. Procurement Incentives Workshop. (Two workshops) These groups concentrated on special incentives to promote innovations in products purchased by all levels of government with emphasis on life cycle costing, value incentive clauses and unsolicited proposals.

2. Interaction and Information Exchange. (Two workshops) These workshops attempted to identify those elements of the total procurement process that are susceptible to interaction between federal, state and local procurement levels and industry both in development and maintenance stages. 
3. Marketing, $R \& D$ and Government Procurement Cycles. This panel attempted to develop approaches through which the procurement process can more effectively interface with industry cycles to acquire the latest technology in commercial items and encourage the transfer of technological innovations to commercial products.

4. Product Testing and Evaluation. This workshop considered product testing and evaluation efforts such as certification programs, tests by independent company-owned and association laboratories, university and government laboratories. The purpose was to devise approaches to achieve maximum utilization of tests and evaluations and minimize overlap and duplication.

5. Qualified Product Lists and Bid Samples. This group explored techniques to augment performance specifications to provide greater latitude for technological innovation, including possible new criteria for Qualified Product Lists and Bid Samples.

6. Qualified Manufacturers. This workshop examined the technique of certifying manufacturers as qualified to supply to the government from the standpoint of advantages and disadvantages and possible guidelines.

7. Methods and Techniques of Contracting. This panel reviewed the many aspects of contracting with a view toward development of criteria for use in selecting the best combinations of specifications, contracting and administrative techniques for various acquisition situations.

An underlying theme that surfaced in the general sessions and in many of the workshop discussions was the desirability of close interchange at all stages of procurement among federal, state and local procurement levels and marketing and engineering personnel in both government and industry. Discussions tended to reinforce many of the recommendations that resulted from the first symposium and added suggestions for refinements of techniques.

In the following paragraphs the most significant discussions of the workshops are summarized.

\section{INTERCHANGE OF INFORMATION}

A consensus emerged from numerous discussions that the current interchange among all participants in the procurement process is inadequate. Procurement officers at any level, it was 
thought, often find that the kind of information they require on products and services is not available in a conveniently usable form. Industry sometimes finds it difficult to provide data that is responsive to complex specifications. Valuable sources exist for information needed by both industry and procurement officials, but they are not fully exploited because they are not widely known.

Procurement officials at the federal, state and local level need to interact more closely with one another so that they can become familiar with mechanisms, policies and guidelines used in other jurisdictions. State and local governments often operate under differing legal structures, causing unnecessary and undesirable inconsistencies. These might be reduced if a model procurement statute were devised as an authoritative guideline. Cooperative purchasing programs among state and local governments could be encouraged in order to foster greater uniformity of procedures.

In seeking greater interchange, it was thought, the resources of existing organizations such as the National Association of Purchasing Management, the National Association of State Purchasing Officials, the National Association of Counties and the International City Management Association should be used to the maximum extent possible.

The kinds of information that could profitably be exchanged include:

1. Processes, procedures and procurement techniques.

2. Specifications and requirements for products.

3. Data on the manner in which specific products have performed.

4. Information on technological breakthroughs.

\section{LIFE CYCLE COSTING}

This concept was discussed in several of the workshops as well as in the general sessions, with virtually unanimous agreement that it should be utilized to a greater extent and that procurement officers should be trained to think in terms of total cost including operating, maintenance, and replacement costs. The technical and contractual aspects of life cycle costing, it was noted, are not well understood by a great many buying agencies and their suppliers. 
It was suggested that commodity groups suitable for use of the life cycle costing technique could be identified by a market research study. It was strongly emphasized that information on life cycle costing should be made available to state and local procurement personnel through brochures and regional workshops as well as through publicity in trade journals and association newsletters.

\section{UNSOLICITED PROPOSALS}

The New Item Introductory Schedule of the Federal Supply Service provides for acceptance of unsolicited proposals when they are considered mutually advantageous to user and supplier. However, it was noted that the application of the policy varies considerably in different agencies. This program, it was thought, should be publicized more widely to increase industry participation, and efforts should be made to achieve a uniform federal policy that can be used as a guide by state and local governments.

\section{QUALIFIED PRODUCTS LISTS}

Although it was conceded that Qualified Product Lists and Bid Samples serve a useful purpose, it was concluded that in their present form they do not provide incentives for product innovation. They tend to become obsolete and should be reviewed at specific intervals to eliminate old products and add new ones.

The high cost of testing in order to qualify products is another disadvantage. Greater acceptance of testing accomplished at industry facilities would tend to reduce the cost.

\section{QUALIFIED MANUFACTURERS}

The procurement process in many areas could be speeded and simplified, it was thought, if a procedure were established to certify manufacturers as qualified to provide certain products. A master list of qualified manufacturers might be developed, it was suggested, and a mechanism devised to inform the public. It was strongly suggested that a single government agency be assigned the task of evaluating and approving individual manufacturers.

\section{MULTI-YEAR CONTRACTS}

The disadvantages of contracts limited to a single year were noted in several discussions. If a contract is ended after one year the contractor's profits can be greatly reduced because of high non-recurring costs. Legislation 
that would enable federal, state and local governments to enter into contracts beyond one year would allow contractors to amortize start-up and other non-recurring costs over a longer period of time.

\section{RECOMMENDATIONS}

Detailed recommendations are included in the reports of each of the workshops. The following are the principal recommendations that appeared to be endorsed by a preponderance of symposium participants.

1. Form a government-industry task force to explore the feasibility of establishing an independent organization to develop and disseminate information concerning products and procurement practices.

a. Develop a model procurement statute as a guideline for state and local governments.

b. Establish industry advisory councils on a productgroup basis and hold annual conferences bringing together manufacturers, buyers and users as represented by both marketing and technical personnel.

2. Undertake a broad program of publicizing the merits of life cycle costing to all procurement levels and of training procurement officers in its use.

3. Request the Office of Federal Procurement Policy to issue a directive on unsolicited proposals that will establish uniform federal procedures. Make the directive available as guidance to state and local governments.

4. Review Qualified Product Lists at specified periods to eliminate obsolete items and qualify new ones.

a. Accept test results from contractors having facilities and methods of demonstrated proficiency.

5. Organize a panel of federal, state and local procurement officials to explore the possibility of establishing a procedure to certify manufacturers as qualified to supply to governments.

6. Introduce legislation to enable federal, state and local governments to enter into contracts that extend beyond one year. 
WORKSHOP REPORTS 
PROCUREMENT INCENTIVES

WORKSHOP NO. IA 
Mr. Arnold H. Brogan

Co-Chairman

Director, Value Management

Office of Management Planning \&

Program Analysis

General Services Administration, FSS

Crystal Mall Building 4

Washington, D.C. 20406

$703 / 557-1583$

Mr. S. D. Zemansky

Co-Chairman

City Purchasing Agent

Bureau of Purchases

Department of Finance

City of Baltimore

lll N. Calvert Street

Baltimore, Maryland 21202

301/396-5700

Mr. D. L. Anthony

Purchasing Agent

Township of Cherry Hill

820 Mercer Street

Cherry Hill, New Jersey 08002

609/665-6500

Mr. Raymond L. Bancroft

Managing Editor

Nation's Cities

National League of Cities

1620 Eye Street, N.W.

Washington, D.C. 20006

202/293-6799

Mr. Richard T. Cheslow

Project Director

Logistics Management Institute

4701 Sangamore Road

Washington, D.C. 20016

301/229-1000

Mr. Alfred A Cooke

Senior Subcontract Specialist

Westinghouse Electric Corp., ESSD

llll Schilling Road

Hunt Valley, Maryland 21031

301/667-5421 
Mr. Raymond S. Cooper

Director, Design Innovations Task Force

Department of Supply and Services

Canadian Government

Room 616, MacDonald Building

Ottawa, Canada

KIA OH 5

613/992-9094

Mr. James E. Doremus

Deputy Purchasing Agent

Central Services - Prince George's County

Purchasing Division

Court House Annex

Upper Marlboro, Maryland

301/627-3000 Ext. 535

Mr. James H. Durfee

Senior Scientist

Braddock, Dunn and McDonald, Inc.

1920 Aline Avenue

Vienna, Virginia 22180

703/893-0750

Mr. Gerald G. Geer

Director, Division of Purchasing

The State of Washington

216 General Administration Building

Olympia, Washington 98504

206/753-6461

Mr. Ray Hill

Acting Director, Procurement Policy \&

Procedures Division

Federal Supply Service

General Services Administration

Crystal Mall Building 4

Washington, D.C. 20406

$703 / 557-8543$

Mr. Philip S. Johnson

Electronic Engineer

Institute of Computer Science \& Technology

National Bureau of Standards

Washington, D.C. 20234

$301 / 921-3724$ 
Ms. Emily A. MacFall

Economist

Public Building Service/Special studies

General Services Administration

18th \& F Streets, N.W.

Washington, D.C. 20405

202/343-3821

Mr. R. C. Newton

Marketing Manager

Appliances \& Building Materials

Governmental, Dept. 733G

Sears, Roebuck and Company

Sears Tower

Chicago, Illinois 60684

$312 / 875-6932$

Mr. Myron A. Olstein

Public Technology, Inc.

1140 Connecticut Avenue, N.W.

Washington, D.C. 20036

202/223-8240

Mr. Philip Wittenstein

Deputy Superintendent

Bureau of Supplies

Board of Education-City of New York

44-36 Vernon Boulevard

Long Island City, N.Y. 11101

212/STillwell 6-8800

RECORDER

Ms. Marlene Lueders

Federal Supply Service

General Services Administration

Crystal Mall Building \#4

Washington, D.C. 20406 


\section{PROCUREMENT INCENTIVES \\ WORKSHOP NO. IA}

\section{INTRODUCTION:}

This summary is intended to synthesize the contributions of the participants as noted in the roster for this workshop. Without going into too detailed an analysis, that summary follows herewith.

\section{$\star \star \star$}

This workshop is intended to focus on special incentives that will promote innovations in products purchased by all levels of government. It must be recognized, however, that there must be a correlation of the benefits to industry with the benefits to be derived by the using agencies of the government. The procurement activity, on all levels of government, must provide the impetus to industry if industry is to be expected to meet the ever expanding needs of the government. Conversely, the procurement activity cannot lose sight of its fiduciary responsibilities. The usual procurement techniques must be continually refined and expanded in order to keep pace with a changing economy as well as the many technological advances of industry.

It should be noted that one of the principal concerns of industry today is the economy generally, and specifically the accelerated pace of inflation. Inflation is not new, but the current rate of inflation exceeds that experienced in the country since the Civil War. Businesses of all types, all levels of government, labor and the household consumer are all affected by and are a part of the constantly changing business environment. The problems created by the current rate of inflation have a significant impact on all sectors of the economy.

It is important that both the sellers of goods and services as well as those involved in the procurement activity understand the effects of inflation on their respective organizations and that they both individually and collectively seek to identify specific ideas that will serve to minimize the problems of doing business associated with this new environment. Accelerated inflation is but one of the current problems of the business community. Others that must also be given consideration by business managers, on both sides of the table, are shortages of materials and energy, the lack of investment capital and resultant high interest rates, government social mandates which require new or improved pollution control measures, simplification of the procurement process, product safety for consumers, minimum wage rates and 
expanded pension benefits, and finally although to a lesser degree the pressures of various politically or sociologically motivated groups or organizations with primarily self-serving interests.

There are two (2) basic incentives for industry that will promote the development of new products or any improvements in quality or reductions in price. Those incentives are profit and to a lesser degree growth potential. The primary incentive for industry is profit, for it is the profit motive that provides the necessary stimuli for market research, product development and production capabilities. If the various levels of government can, either individually or collectively, assure industry of a market or even a sound market estimate for a given product or service, the costs of market research can be minimized for the suppliers. Those savings can logically be expected to be passed on to the buyer. The findings of the market research effort could also result in the costs of product development being spread over a larger base and also provide the necessary incentives for increased efficiency and resultantly lower costs in production and distribution. The timely dissemination of the information gained through market research by government agencies could also lead to an expansion of the competitive marketplace.

In the present economic environment, the number of organizations with capital available for product development and testing has been drastically reduced. Independent engineering toward the development of components and systems frequently represents an unnecessary duplication of effort that could be more gainfully expended on applying previously developed components to commercial applications and refining manufacturing processes. Many types of equipment and a variety of components have been developed and manufactured in limited quantities under government contracts with NASA, DOD, and a number of other agencies.

The Federal Government through the various space exploration programs and the Department of Defense has been instrumental in the development of many miniaturized components with high reliability. Many of these components have commercial applications and their expanded use will conserve both space and energy. The development costs, including engineering drawings, as well as the tooling required for production were borne by the government, therefore, ownership rests with the procuring activity and are not for the most part available to private industry. In the interest of conserving the financial resources of the industrial community, it would appear appropriate to make much of the technical information available to private industry through recognized channels. 
In reviewing the procurement techniques that can be utilized to motivate industry to respond in an affirmative manner to the needs of government, we will touch on areas that are being discussed in other workshops in this symposium. However, in this workshop, special emphasis should be placed on specific areas, as noted below.

\section{VALUE INCENTIVES:}

The first area to be considered is that of the Value Incentive. A possible Value Incentive Clause, see Attachment, could be thus applicable. Value incentive provisions are useful to spur innovation. They are not a one shot answer to all problems. When in the appropriate framework, these incentive provisions should reduce overall costs to the government and increase profit to contractors. Funding, administrative problems, and laws may be roadblocks to use incentive clauses in some purchasing areas like states or other local government bodies.

Prior to initiating the acquisition cycle, the alert and astute procurement activity should perform some type of value analysis for each requirement. The extent and depth of value analysis conducted will in a great measure be determined by cost and usage factors. The need for value analysis may be precipitated by the appearance in the marketplace of a new product or an item with improved performance characteristics, increased life or reduced cost resulting from changes in materials. A more exhaustive value analysis program effort should include representatives from the using agency having complete knowledge of the intended use of the item, the operational environment and all other pertinent factors. Tradeoffs can thus be explored on the basis of cost as compared to suitability for intended use, simplicity of operation, frequency of repair or replacement that is to be expected or any other relevant factors. In all procurements, the exploration of alternatives can be rewarding in the ultimate results achieved. The value analysis program is normally initiated by the procurement activity or using agency and there is little participation by potential suppliers. Thus, it can be classed primarily as an "In House" activity. It is a tool that should be more widely used in the development of specifications and purchase descriptions prior to the issuance of bid documents. In many manufacturing organizations, the value analysis program has had a significant impact on makebuy decisions.

Value Engineering as a concept is related to the value analysis program by the scope of its activity. As a management tool, the application of value engineering studies have resulted in 
substantial reductions in the total costs of manufactured items that have been made possible by modifications to relatively inexpensive components. Cost reductions have also resulted from the application of value engineering concepts to manufacturing methods, packaging and distribution of the finished product. In many organizations, the principles of value engineering and value analysis have been successfully welded into a value control concept through the application of these combined principles and they have improved the value of their products in terms of life expectancy and performance. By applying the same techniques in the design stages of a product, maximum value can be obtained in the initial design. This overall effort is frequently referred to as a value assurance program. Others hold that the words Value Analysis, Value Engineering, Value Assurance, etc. are synonymous, therefore similar programs may have different names.

The Value Incentive Clause is but one of many incentive clauses that can be incorporated into a contract in order to increase the contractors interest in a given program. The Value Incentive Clause places the onus on the supplier or manufacturer to utilize value engineering and/or value analysis techniques and principles in system or equipment design and/or production in order to maximize his return on investment in the submission of Value Incentive proposals under the Value Incentive provisions of his contract. The technological advances in many fields have accelerated to such a degree that adequate documentation becomes difficult and in some areas a practical impossibility. Technological advances may be achieved in an effort to meet a specific need or requirement. More frequently, however, they are the results of the manufacturer's efforts to become more competitive. There is a definite need for a working relationship between industry and the procurement activities that will promote the use "of the most efficient and effective technology available, as well as encourage the development of innovations. The obvious incentive to industry is increased profits, while the incentive to the procurement activity is a better product at the same cost or less.

A well-written Value Incentive Clause will provide for sharing the costs of implementing innovations in design and/or improved manufacturing processes as well as increasing the contractor's profits by sharing any savings that might be realized. Today's economic environment is not conducive to expenditures for extensive design effort or improvements in manufacturing methods by the manufacturers without adequate compensation in one form or another. If the savings thus realized are to be suitably shared by the customer, the percentage apportionment of any savings that may be realized are important considerations in determining the effectiveness of a Value Incentive clause. 
The Value Incentive Clause is appropriate for use in complex, sophisticated systems or equipments with stringent performance requirements and a high degree of reliability as well as in the procurement of run-of-the-mill consumer products where specification, purchase descriptions, etc., are used. It may also be considered appropriate for use in those cases where anticipated usage is relatively high. A value Incentive Clause should be mandatory in all contracts, for other than proprietary items, if there is any likelihood of its successful application. There is no useful purpose served by cluttering up a contract document with clauses that will not be operative.

Procurement personnel should bear in mind that there are no limitations on the number of types of contracts or the types of incentives that can be applied to any given contract. For example, a contract containing the generally recognized Value Engineering clauses with a mutually agreeable sharing arrangement can be established on a firm-fixed-price basis. The delivery schedule as stated in the contract documents represents the recognized best efforts of the contractor. However, the addition of a contractor's performance incentive clause may be the inducement required to accelerate delivery without degradation of equipment performance and/or quality.

Some type of Value Incentive Clause can be applied to virtually all major dollar procurements. Its application, however, should not be confined to those items having only a high dollar unit price. Significant savings can be achieved on items with a unit cost of pennies if the volume is great enough. In order to maximize the efforts of the supplier and overcome the normal resistance of the contractor to provide more than is required, the sharing arrangements must be weighed in favor of the supplier. In some cases, it may be in the best interest of the procuring activity to waive any participation in any savings resulting from the innovations of the contractor. In such cases, the creativeness of the contractor will be evidenced by a reduced bid price for succeeding procurements.

Another, but little used, method of providing the desired incentives to industry is the application of a multiple award technique for an item requiring a substantial amount of design and development to meet specific performance, reliability or maintainability criteria or any combination of these. This technique can produce surprising results in that although the end items may have been designed for a specific purpose there are frequently innovations achieved during the design stages that have other applications.

In brief, industry is generally receptive to bidding on contracts which include provisions for increasing profits. The 
procurement activity must be acutely aware of the fact that such contracts require more time in both contractor surveillance and the normal contract administration activity. Value engineering proposals must be evaluated from an objective viewpoint and must be subjected to scrutiny from every angle. The costs of implementing the change may exceed the amount saved on the current contract but may result in substantial savings on follow-on procurements.

\section{LIFE CYCLE COSTING:}

In evaluating life cycle cost, the procurement officer must give consideration to factors beyond the initial cost of acquisition. Consideration must also be given to the cost of operation, maintenance and continued suitability of the equipment for the purpose intended. The obvious objective is to insure the acquisition of equipment with the lowest possible cost of ownership. The procurement officer, therefore, must think in terms of the lowest total cost of ownership, or Life Cycle Cost (LCC). LCC can serve as an excellent incentive for product innovations (the purpose of the ETIP program). However, its application may be limited unless appropriate training is used as required prior to its implementation. Such training is also in order if we are to simplify, expand the flexibility and secure the variety of applications of the concept.

*The LCC procurement technique is presently difficult to apply to multiple award contracts except those placed as a negotiated procurement. To apply the LCC approach in a strict competitive situation, is inappropriate, due to the variables that could conceivably be evidenced in the bid proposals on a line item basis. In order for the LCC technique to become a viable means of obtaining material, it is currently necessary for the procuring activity to specify, in detail, the designed shelf and useful life, in addition to performance parameters, MTBF, and maximum acceptable level of maintenance. This effort, on the part of the procuring activity could, for the most part, ibe eliminated if manufacturers would take the initiative and incorporate as part of the public literature, such pertinent information as would enable the purchaser to evaluate in a uniform manner, the competitive proposals received with full assurance that the items selected will meet the requirement of the user and that the price bid represents the lowest possible cost of ownership. In any one instance, this should be encompassed by the use of a specific formula on a measuring gauge that would represent the total cost of possession.

\footnotetext{
ॠAll members of Workshop IA did not agree with parts of this paragraph.
} 
*Prior use of LCC as a procurement technique has been in the acquisition of complex equipments, and in the construction industry, where there is a measurable service life, mean time between failure (MTBF), or mean time to repair (MTTR) could be calculated with a reasonable degree of accuracy; however, LCC is now being applied in the procurement of commercial products also.

In soliciting proposals on the basis of life cycle costs, the buyer must first assure himself of the accuracy, adequacy and reasonableness of the specifications. The specifications must define, within reasonable limits, the expected useful life of the item, the length of time the equipment should operate without failure, and the basis to be used for establishing the time required for repair or to make the equipment operable after failure. The specifications should, therefore, be functional in character and permit the bidder sufficient latitude in the design stage to include the latest technological advances while assuring that the item to be supplied will satisfy the requirements of the user. The specifications should, therefore, clearly define all known requirements of the using agency. The level of competence of operations and maintenance personnel are also important factors that must be considered by the bidder in this type of procurement.

The buyer is not necessarily interested in "front-end costs" or the costs of equipment or component design and test. The buyer is primarily interested in the cost of the hardware, the cost of labor and energy for its efficient operation and routine maintenance and the "back-end" cost or cost of labor for maintenance and repair personnel and spare parts during the anticipated useful life of the equipment. If bids are evaluated on total ICC rather than initial cost alone, this should provide incentives for manufacturers to develop products with a longer life, and lower operating and maintenance costs. The buyer must give consideration to significant factors in evaluating the cost or price proposals received. Recognition must be given to the possibility of increasing deterioration of the equipment over the term of useful life and the accelerated need for replacement parts required to support the equipment. The rate of deterioration and attendant degradation of equipment performance are normally directly related to the quality of workmanship and materials used. While these factors can be discounted to the extent they are covered by the warranty or guarantee offered by the seller, the inconvenience and aggravation to the using agency can be minimized by adequate testing including accelerated life tests.

\footnotetext{
*All members of Workshop lA did not agree with parts of this paragraph.
} 
The use of life cycle costing as a procurement technique has been limited due to the lack of uniform standards of testing and evaluating tests results. The lack of such industry-wide standards frequently leads to the item being over specified by the buyer as a protective mechanism to insure that the performance and useful life of the equipment will meet all requirements. It would, therefore, appear to be in the best interest of both buyer and seller to establish mutually acceptable uniform standards for testing which would provide the much needed measures of performance. The efforts toward the establishment of industry-wide test and performance standards should also be expanded or extended to encompass the area of performance warranties on the basis of the data accumulated. The use of a performance warranty and the administration of it is difficult, especially with a life cycle of 5 - 10 years.

The various government agencies could make significant contributions by making available to industry performance data on sophisticated, technologically improved systems, equipments and/or components that have been in service for substantial periods of time under diverse atmospheric and environmental conditions. Industry has, in many areas, rendered the warranty provisions of their sales contract unenforceable by limiting returns to internal components that are difficult to remove and reinstall or by imposing on the customer the costs of transportation. It would appear to be in the best interest of industry to simplify their policies and procedures relating to warranty repairs and returns. We believe that a simplified approach would increase customer confidence in the products offered.

There was general agreement on the appropriateness of the concept. There exists some disagreement when getting down to specifics on when and how to apply it. Some positive steps which will be needed for implementation are:

(1) Better industry - accepted testing procedures. More work is needed (led by the Government) in developing controlled or accelerated tests for items under LCC consideration.

(2) Better education. There is much confusion on definitions and meanings. Also on the application and complexity (or noncomplexity) of evaluation techniques and procedures.

(3) More specific Government information. State and local groups would really appreciate, and probably need, specific information on successful contract clauses, evaluation criteria, formulas, etc. Unless this is available, many doubt that LCC would be broadly applied at the local level. 
(4) There seems to be a general need for good data collection and dissemination services.

(5) One argument was made that longer term contracts be provided as an incentive to increase $R \& D$ efforts.

As a relatively new governmental procurement technique, LCC has great potential. It broadens the concept of lowest acquisition cost to include all conceivable costs over the expected useful life of a product or piece of equipment.

There are naturally problems involved with this - and any other new way of doing things. Not the least of these problems is one dealing with semantics involving definition of terms as well as defining the parameters of maintenance and operating guidelines to be used in LCC. There must be common understanding by all procurement officials and potential suppliers of the exact criteria to be cranked into the LCC formula.

Another problem, one that faces procurement officers in state and local government is that of legal authority to use the LCC concept in addition to, or in conjunction with, lowest acquisition price. LCC does not obviate the lowest bid concept. LCC really is an update of specs to include, if not already done so, elements of maintenance, operations, and replacement cost, that are practical to develop and evaluate. Local and state officials must work in concert to get antiquated state laws changed to permit use of LCC and other innovative purchasing techniques. As an incentive to industry, LCC can serve a useful purpose if it is properly marketed.

\section{UNSOLICITED PROPOSALS :}

There is not a purchasing department or procuring activity in any manufacturing facility or in the public service that is not visited by representatives of producers of raw materials or supplies of components or services on a daily basis. These same representatives frequently visit with engineers and/or others that may be instrumental in the awarding of contracts. Each of these representatives brings with him, in one form or another, an unsolicited proposal. An unsolicited proposal is any proposal for supplies, services, research, development, etc., submitted to a purchasing activity. Unsolicited proposals represent what amounts to a "Supplier Suggestion System." Many of those who visit have nothing to offer but conversation. However, there is that rare exception that cannot or should not be ignored. The new and innovative component developments may be just what the design engineer has been looking for to save both time and money. Unsolicited proposals have definite potential. To give each 
visitor to the procuring activity audience is time-consuming and, therefore, the time available must be allotted judiciously. There is no question but that the unsolicited proposal system is difficult to manage. Many of the unsolicited proposals received are in the form of brochures and advertising literature, which unfortunately usually falls into the category of "junk mail."

The true Unsolicited Proposal is generally submitted by an organization recognizing a specific need and responding to that need by preparing documentary evidence that they are qualified to provide the required services or equipment. The organization may be cognizant of their relatively unknown position and have chosen the unsolicited proposal route to make themselves known. The unsolicited proposal may also represent innovations in the use of components that have resulted in improvements to a given product that may have been supplied previously in the areas of performance, reliability, maintainability, price or delivery. The submission of an unsolicited proposal by any organization cannot, however, be accepted as prima facie evidence of their ability to render exemplary service or a technically acceptable product. All suppliers of goods and services should be encouraged to submit, possibly on a standard form or otherwise, unsolicited proposals to either the purchasing activity or the ultimate user, preferably both. It is by reading and evaluating the variety of proposals received that the buyer is able to keep abreast of the technological advances in the industry. The costs of making engineering assessment of new product capabilities, feasibility studies and finding practical applications of newly developed products are usually borne by the developers. However, the costs associated with validating the claims of the offerers and finding solutions to any problems that may develop from applying new products or techniques to current requirements are normally borne by the user. In any event, such a program needs organized management with proper funding. It is noted that certain difficulties exist. A proper point of receipt and docket record should be established. Appropriate legal protections must be accorded the receiver. The suggester should receive acknowledgement of the receipt. An applicable process and follow-up to completion control must be designed.

Many of these problems and much of the attendant costs could be obviated by the offerer's use of independent testing laboratories that are capable of conducting exhaustive tests, including, where deemed necessary, accelerated life tests. The test results could then be used with full confidence by potential users in evaluating the proposals received. There are more new products, new services, new manufacturing and production methods, tools and techniques available today than 
ever before. Their scope is so diverse that each industry will be required to develop its own methodology for evaluating and screening solicited or unsolicited proposals that is most suited to its own individual situation. There is no practical solution to problems of this nature that would be universally acceptable. It is recommended that the various engineering, purchasing and trade associations with specific interests consider the development of test standards, methods of evaluation and any other criteria deemed essential to their particular type of operation for dissemination to their suppliers and potential suppliers. Insofar as the user is concerned, he also must develop a proper method of validating unsolicited proposals.

\section{POSSIBLE OTHER PROCUREMENT INCENTIVES:}

(1) Maximum use, where practical, of Firm Fixed Price contracts. This places all the risk of effective and efficient performance on the contractor. It also permits the contractor to maximize his profit position by using innovative and more efficient production and distribution methods.

(2) The use of Two-Phase procurement techniques, with possibility of pay for first phase. If properly provided for in the contract documents, this permits the procurement activity to transfuse from one technical proposal to another prior to soliciting price proposals on a competitive basis. Potential bidders would be more receptive to the Two-Phase procurement technique if the cost of preparing technical proposals was, as a minimum, shared by the buyer.

(3) The use of competitive negotiations.

(4) Research and Development type contracts should provide for reprocurement on a competitive basis.

(5) Consideration should be given to making multiple awards of $R \& D$ contracts and possibly production. Balance quantity versus quality versus suitability.

(6) Sole source procurements of many components could be eliminated by funding duplicate tooling. This will possibly increase the initial cost of acquisition from the second or third source, but will also expand the competitive base thereby ultimately reducing costs.

(7) Contractors should be permitted more latitude in the selection of components and materials to be used consistent with form-fit and function and environmental requirements. 
(8) The costs of evaluating bid samples that deviate from bid specifications could be shared by both buyer and seller. This would provide an inducement for the seller to submit bid samples and give the buyer a greater exposure to newly developed items that may meet all requirements of the user.

(9) Value analyze specifications with supplier help. Encourage Standardization.

(10) Publish LCC formula book.

(11) Value analyze and/or simplify procurement, including payment cycle process.

(12) Hold supplier symposium/conferences. Establish friendly adversary/partner arrangement.

(13) Market Value Analysis provided by the buyer.

(14) Results of Government research made available to industry.

(15) Use longer time contracts.

(16) Use of "Design to Cost" or "Should Cost" concept in parallel with $R \& D$ and production contracts development and/or multiple award contracts.

(17) Encourage the use of the lowest total cost of possession as the lowest life cycle cost $\left(\mathrm{I}^{2} \mathrm{C}^{2}\right)$.

\section{CONCLUSIONS :}

The following general reactions appear to be reasonably commonly held by the participants of this workshop:

(1) There is broad agreement on the potential usefulness of the concepts as discussed and enumerated in these proceedings.

(2) Industry can be specifically motivated to use procurement incentives when appropriately applied to the particular procurement involved.

(3) To be properly successful in the use of incentives, there must be a working relationship between buyer and seller for depth of understanding of two adversaries. 
(4) There exists an apparent need for in-depth training of all users of these procurement incentives to remove the fog of semantic differences and achieve a clarity of understanding of specific application in any one instance. Procurement incentives will only be as effective or resultful as the proficiency of the user. That proficiency can only be achieved by means of such thorough training.

(5) Funding for these corollary and possibly additive activities should be more than realizable through the savings secured by the program. 
6.3 The determination of the reasonableness, allocability and allowability of collateral costs contained in the Contractor's estimates shall be made by the Contracting Officer. In the event that agreement cannot be reached on the amount of the estimated collateral costs the Contracting Officer shall determine the amount. In either case, the Contracting Ofticer's decision will be final and not subject to the provisions of the "Disputes" clause of this contract.

7. COMPUTATIONS FOR FUTURE ACQUISITIONS-If a VCP is accepted under this clause and used in future solicitations the Contractor will be paid a royalty share of savings realized by the General Services Administration on future purchases, if any, of items utilizing the VCP or on modifications made to other existing contracts to utilize the VCP within the royalty sharing period.

7.1 To qualify for royalty sharing, the VCP must result in a unit price reduction for an item under this contract. The Contractor will be paid for the actual number of items purchased during, and limited to, the periods of time as follows; for indefinite quantity and requirements contracts, the next 12 month contract period following the expiration of this contract: or for definite quantity contracts, any solicitation issued that utilizes the VCP during the next 12 month period commencing with the date of moditication of this contract accepting the VCP.

7.2 For purposes of determining the Contractor's royalty share, the "unit price reduction" under this contract is the Contracting Officer's estimate of the effect which the VCP would have had on the Contractor's cost of performance if the change had been included in the original specifications under this contract (this estimate shall not take into account any costs of developing or implementing the change).

8. SHARING ARRANGEMENTS-If a VCP is accepted by the Government, the Contractor is entitled to share in instant and/or future contract savings, or collateral savings to the full extent provided for in this clause. For the purposes of sharing under this clause, the term "instant contract" shall not include any changes to or other modifications of this contract, executed subsequent to acceptance of the particular VCP, by which the Government increases the quantity of any item of work or adds any item of work. It shall not include any extension of the instant contract through exercise of an option (if any) provided under this contract after acceptance of the VCP. Such actions shall be eligible for future acquisition savings.

If a VCP accepted by the Government results in a net reduction in contract price, the Contractor is entitled to share in instant and future acquisition savings but not in collateral savings. If a VCP, accepted by the Government, results in a net increase in contract price, the Contractor shall share in collateral savings, but not in future acquisition savings. In case of accepted price increases, the current contract will be modified to allow for the increae in price plus the amount allowed for collateral savings for the remainder of the current (instant) contract period. The amount of sharing shall be at the rates provided below.

If the Contractor submits under this clause a proposal which is identical, or substantially similar, to one previously received by the Contracting Officer under a different contract with the Contractor for substantially the same terms and both proposals are accepted by the Government, the Contractor shall share instant contract savings realized under this contract, pursuant to paragraph 8.1 of this clause, but he shall not share future acquisition savings.

8.1 If the prime Contractor is solely responsible for the VCP, he shall receive $50 \%$ and the Government $50 \%$ of the net reduction in the cost of performance of this contract.

8.2 If a Subcontractor is responsible for the VCP, the prime Contractor agrees that the Subcontractor shall receive a minimum of $25 \%$, the prime Contractor a maximum of $25 \%$, and the Government a fixed $50 \%$, of the net reduction in the cost of performance of this contract. Other Subcontractors shall receive a portion of the first-tier
Subcontractor savings in accordance with the terms of their contract with first-tier Subcontractor.

8.3 When collateral savings occur the Contractor shall receive $20 \%$ of the average one years net collateral savings.

8.4 When future acquisition savings occur, the Contractor shall receive a royalty share equal to $30 \%$ of the unit cost reduction realized under the instant contract.

\section{ADUSTMENT TO CONTRACT PRICE-}

9.1 The method for payment of instant savings shares shall be accomplished by reducing the contract unit price by an amount equal to the Government's share of the savings.

9.2 Payments for accepted VCP's involving price increases and collateral sharing will be accomplished by adjusting the current contract unit price by the amount of the increase plus the increase as provided for in paragrah 8.3. All orders placed after acceptance of the VCP will be paid for at the increased unit price until expiration of the current (Instant) contract.

9.3 Payments for accepted VCP's involving price decreases and royalty sharing will be accomplished by adjusting the current contract unit price by the price decreases and, if the current Contractor submitting the accepted VCP, receives the "future" contract, that unit price will be increased, as provided for in paragraph 8.4, at the time of award for the new contract period.

If a different Contractor receives the future contract, the Contractor submitting the accepted VCP shall be paid, as provided for in paragraph 8.4 . by multiplying the savings by the number of units actually purchased by the Government. In this case, royalty shares will be permitted to accumulate and paid quarterly.

10. DATA RESTRICTION RIGHTS-The Contractor may restrict the Government's right to use any sheet of a VCP or of the supporting data, submitted pursuant to this clause, in accordance with the terms of the following legend if it is marked on each such sheet:

The data furnished pursuant to the Value Incentive Clause of contract * shall not be disclosed outside the Government, or duplicated, used, or disclosed in whole or in part, for any purpose other than to evaluate a VCP submitted under said clause. This restriction does not limit the Government's right to use information contained in this data if it is or has been obtained or is otherwise available, from the Contractor or from another source. without limitations, nor, shall this restriction apply in any respect after a period of two years from the date the VCP is submitted. If such a proposal is accepted by the Government under said contract after the use of this data in such an evaluation the Government shall have the right to duplicate, use, and disclose any data reasonably necessary to the full utilization of such proposal as accepted, in any manner and for any purpose whatsoever, and have others so do.

In the event of acceptance of a VCP the Contractor hereby grants to the Government all rights to use, duplicate or disclose, in whole or in part. in any manner and for any purpose whatsoever, and to have or to permit others to do so. data reasonably necessary to fully utilize such proposal on this and any other Government contract.

In lieu of repeating the above legend, Contractors may use a reference as follows on the appropriate sheet. "This sheet is restricted as provided in paragraph 10 of the Value Incentive Clause of Contract number * "

*Contractor will insert the applicable contract number. 
PROCUREMENT INCENTIVES

WORKSHOP NO. IB 
Mr. John Short

Director, state Bureau of

Co-Chairman

Purchases and Services

State of Wisconsin, Rm. 211

1. W. Wilson Street

Madison, Wisconsin 53702

(608) 262-1558

Mr. H. D. Voegtlen

Asst. to the Vice President

Co-Chairman

Product Effectiveness

Hughes Aircraft Company

P. O. Box 90515

Bldg. 100, Mail stop \#45

Los Angeles, California 90009

(213) 670-1515 x6495

Mr. Allan W. Beres

Federal Supply Service, GSA

FCV

Crystal Mall Bldg. 4, Rm. 724

Washington, D. C. 20406

(703) 557-1583

Mr. James M. Cloney

Vice President, Government Relations

GAF Corporation

4601 Lydell Road

Cheverly, Maryland 20781

(301) 322-3130

Mr. S. J. Hanna, Chief

Purchasing Bureau

Dept. General Services

State of Maryland

301 W. Preston street

Baltimore, Maryland 21201

(301) 383-3644

Mr. J. Hueniken

Design Consultant

Office of Design

Dept. of Industry, Trade \& Commerce

Ottawa, Canada KlA OH5

992-4494 
Mr. Frank Leach

V. A. Central office

Supply Service (135)

810 Vermont Avenue, N. W.

Washington, D. C. 20420

(202) 389-3306

Mr. D. McCurrach

Executive Vice President

National School Supply \& Equip. Assn.

1500 Wilson Boulevard

Arlington, Virginia 22209

(703) 524-8819

Mr. George B. O'Gorman, C.P.P.O.

Assistant Director

Bureau of Purchases

Commonwealth of Pennsylvania

P. O. Box 1365

Harrisburg, Pennsylvania 17125

(717) 787-2841

Mr. George O. Pringle

Chrysler Corporation, Airtemp Air

P. O. Box 66

Dayton, Ohio 45401

(513) $461-5100$

Mr. J. P. Simpson

Procurement Analysis

Dept. of the Treasury

Office of Administrative Programs

1625 Eye Street, N.W., Rm. 309

c/o Main Treasury Mail Room

l3th \& Pennsylvania Avenue, N. W.

Washington, D. C. 20220

(202) 634-5021

Mr. Donald E. Stiling

Management System Division

Procter and Gamble

Box 599

Cincinnati, Ohio 45201

(513) 562-4152

Mr. Joseph R. Wilk

Sr. Research Associate

Logistics Management Institute

4701 Sangamore Road

Washington, D. C. 20016

(301) 229-1000 X42 
Mr. J. H. Wilson

Specifications Development Coordinator NASPO

The Council of state Governments

Iron Works Pike

Lexington, Kentucky 40511

(606) 252-2291

Mr. Frank Varasano

Booz Allen \& Hamilton

4733 Bethesda Avenue

Bethesda, Maryland 20014

(301) 656-2200

\author{
RECORDER \\ Ms. Louise Nyland \\ Federal Supply Service \\ General Services Administration \\ Crystal Mall Building \#4 \\ Washington, D.C. 20406
}




\section{PROCUREMENT INCENTIVES}

WORKSHOP NO. IB

\section{INTRODUCTION}

The Procurement Incentives Workshop was divided into three subgroups which considered the following specific topics:

I. Life Cycle Costs

II. Value Engineering Incentives

III. Unsolicited Proposals

Each subgroup stated an overall objective, identified key problem areas that stand in the way of achieving the objective, and made a series of recommendations designed to remove or reduce the effect of the roadblocks. Subgroup 3 also gave brief consideration to some procurement incentives not included in the three principal topics listed above. The reports of the subgroups follow.

I. Life Cycle Costs

Allan W. Beres, Leader

Objective

Apply Iife Cycle Cost techniques to insure that the item acquired will result in the lowest total ownership cost during the time the item's function is required.

Problems

1. The technical and contractual aspects of LCC are not well understood by a very broad spectrum of buying agencies and their suppliers.

2. The tradition of awarding to low-price bidder on the part of procurement officers and legislative bodies prevent application of LCC methods in most cases.

3. Some procuring activities do not have command over specifications and testing resources. The interdisciplinary approach is essential to successful LCC applications.

4. LCC requires additional resources if lab testing or extensive user data is needed.

5. To date LCC has been applied to only a few products. The methods need to be developed and expanded to permit application to a much larger variety of product. 
1. Promote and sell LCC concept to state and federal agency heads of purchasing. Develop informational brochure and a standard presentation to be made available to Regional Governors' Conferences, meetings of NIGP, NASPO, NASBO and similar organizations. This effort should be coordinated through ETIP, using the efforts of FSS, NIGP and NASPO.

2. The LCC workshop training conducted by FSS should be made available to state and local procurement and specifications personnel. FSS should conduct the training with NIGP and NASPO responsible for publicizing and stimulating attendance.

3. Adopt a systematic way of identifying commodity groups that are good candidates based on the following: (a) LCC criteria, (b) cost of procuring, (c) pay-off in reduced total cost.

4. Provide orientation to manufacturers on the use of LCC techniques in government procurements. ETIP and the Federal Supply Service should provide statements to be used in trade journals and trade association newsletters. Brochures and presentations to trade associations and other vendor groups should be made available. Manufacturers should inform their dealers of the implications of LCC when they bid on local contracts.

5. ETIP should explore means of minimizing the costs of testing product performance in the award of LCC contracts; eliminating duplication of test requirements when several jurisdictions are procuring the same item. Greater use should be made of university facilities to design and conduct performance tests. The NBS should accelerate their laboratory certification program, so that more use can be made of test results submitted by the bidders.

6. ETIP should explore ways to have the LCC concept included in university curriculum in Engineering and Sciences.

7. There is a need for a publication devoted to the technical interchange of LCC applications and techniques.

8. Establish experiment between FSS and large user of household appliances. Administer contracts on LCC buys. Is performance there? What other functions should be evaluated? 
9. Use LCC criteria in multiple award schedules by:

(a) developing performance criteria, (b) indicating cost/ performance of items offered, (c) providing information

for users to make intelligent decisions.

II. Value Engineering Incentives H. Dean Voegtlen, Leader

Objective

Use contract value engineering incentives to encourage contractors to develop and propose contract changes that will reduce the price (cost) of procurements. The incentives may apply to the current contract, to future purchases and to user collateral costs.

\section{$\underline{\text { Problems }}$}

1. Many procurements are limited to a year or less by law. There is little opportunity to develop and implement a change, therefore little or no economic incentive.

2. The government market, where $V E$ incentives have been used in the past, represents only a small portion of the total market for many suppliers. A supplier is reluctant to make changes in a product for one customer where limited quantities may not result in overall cost effective operations.

3. The paperwork justification, negotiation, administrative delay, and technical/legal apparatus required all add cost. Many relatively small concerns do not have the expertise or the business base to make it pay.

4. Application of VE incentive clauses may not be appropriate for many off-the-shelf items where requirements are controlled by outside forces (i.e., the competitive pressure of the commercial market place).

5. The unilateral decision of the procurement officer to reject a recommended change has an inhibiting effect on contractor submissions.

6. Many changes, increase the cost of the current or instant contract, even though they may be cost effective in later procurements of the same item and also reduce collateral costs to the user. But funds are seldom available to purchase this type of change however beneficial or innovative it may be in the future. 
7. Overly restrictive standards for safety, environmental effects, and other well intentioned restrictions applied across the board tend to reduce the opportunities for cost effective changes.

8. The unlimited use of data in connection with VECP's submitted on government contracts discourages contractor submission of changes where protection of proprietary data is required.

\section{$\underline{\text { Recommendations }}$}

1. ETIP should recommend policy change to permit the use of multi-year procurements where this method provides a more cost-effective way to insure that innovative technology will be developed.

2. The use of a program clause (as opposed to an incentive clause) requiring a specific level of effort should be used where cost reduction is needed but where other business factors may counteract the benefit available from an incentive provision.

3. Multiple procurements of the same item at the federal, state and local levels is inefficient. Methods to consolidate such purchases would provide a profitable base for reducing the cost through the VE clause and other procurement practices.

4. Guidelines should be developed for selective application of the incentive clause. What types of procurements are best suited for this and what types offer little possibility for constructive application. The purchasing agent needs clear direction on how to proceed. (This task will be referred to the Electronic Industries Association Value Engineering Management Committee for action.)

5. Educational and promotional material is needed at lower levels of procurement, i.e., state and local government and subcontract, second and third tier levels. (The Society of American Value Engineers will be asked to undertake this task.)

6. The administrative process of change approval must be streamlined.

7. Methods of motivating creative change are needed. It is not always possible to employ the economic or profit motive to encourage such change even though the need may be well recognized. 
8. Use of out-dated specifications is still rampant throughout the business and government community. The VE incentive clause is an ideal vehicle to help clean up the specs and should have wider application by procurement agencies.

9. Protection of proprietary data is necessary if innovative change is to be encouraged.

III. Unsolicited Proposals

John Short, Leader

Objective

Promote establishment of an environment of policy and procedure at all levels of government hospitable to the submission of innovative, unsolicited proposals. A climate incentive, i.e., positive encouragement, of experimental technology is essential. Technical transference will generally be produced by careful planning and management. We cannot, however, overlook the opportunities of inadvertent circumstance, coincidence or dumb luck in providing the initial exchange of ideas which would result in improved technology. To maximize these opportunities, open doors and open minds are essential.

\section{Problems}

1. The term "unsolicited proposal" has gained considerable currency in the purchasing community. Nevertheless, the term is inherently negative. The term begs the legitimacy of the proposal and the opportunity of the unit of government to seize upon it profitably.

2. The response to unsolicited proposals at the several levels of government has varied greatly within agencies at each level. The responses cover the spectrum from a firm policy of encouragement to a rigidity that nearly always dismisses them out of hand. Uniform policy and initiative is needed.

3. The mere initiation of an innovative unsolicited proposal program is not sufficient to establish the climate of incentive. This program must be fully developed to carry through the entire cycle of possible utilization of an innovative unsolicited proposal.

4. Part of the concern over the semantics of "unsolicited proposal" lies with the situation where a proposal is not fully unsolicited, i.e., a response to an IFB which presents an innovative answer to the request for bids but 
which is frequently categorized as "not meeting (design) specifications." The opportunity for innovation should not be stifled by a rigidly structured bid procedure.

5. The success of an unsolicited proposal program rests in part upon the successful impetus which can be given to these proposals by the procurement officer. Frequently and particularly in smaller federal agencies and in local units of government, the status of the procurement officer precludes his ability to fully serve as the advocate for an unsolicited proposal.

Recommendations (listed in response to numbered problems above)

1. Use of the term Innovative Unsolicited Proposal (IUP) is recommended. The modifying adjective suggests the expectation of merit in these proposals which indeed is what is sought.

2. Federal Government: Policies and procedures must be established by the Office of Federal Procurement Policy. (Federal agencies with present capability are encouraged to proceed immediately.)

State and Local Governments: Policies and procedures must be established at the direction of the chief executive and supported by the centralized purchasing facility and/or budget facility.

3. Clear line responsibility for the program must be established. In smaller agencies it is entirely probable that the IUP officer will serve in this function in addition to other duties, but his position has to be a focus for the reception of all innovative unsolicited proposals.

Having established the focal point for reception of proposals, it is necessary for the agency to widely publicize the fact that they are in business. This report has earlier dealt with the many avenues for broadcasting this kind of information.

Procedures must be set up for accepting, assigning and assessing innovative unsolicited proposals. The person or firm submitting the proposal must be kept fully advised as to its progress and final disposition.

Implementation of an IUP may call for unconventional procurement procedures. Inherent in the establishment of policy and procedure of an IUP program within an agency, 
must be policy for the acceptance of the concept of noncompetitive award.

4. Use two step formal procurement to provide an opportunity for determination of the "state of the art" before a formal request for bids is finalized.

Use performance specifications in IFB's to promote a climate of wider response rather than a request circumscribed by tightly drawn design specifications.

IFB's should carry a statement of "innovative proposal acceptance" to assure that the thrust of the IUP program is unimpeded.

5. Procurement officers should be at the same organizational level as the program officers of a given agency.

The procurement officer should be at the "second" echelon of agency organization and certainly no lower than "third" echelon of top management.

\section{OTHER PROCUREMENT INCENTIVE CONSIDERATIONS}

Overview

This workshop was given the charter to focus on special incentives to promote innovations in products purchased at all levels of government with emphasis on life cycle costing, value incentive clauses, and unsolicited proposals. The foregoing represents the product of in-depth discussion on the three principal areas of consideration. The workshop, however, also addressed themselves to other findings and recommendations.

The first Symposium on Procurement Practices was a dialogue between the federal establishment and major manufacturers and suppliers to the Federal Government. The second symposium included the voices of state and local government as well as some representation from the industries that serve state and local government. The broadening of the base of participation also made us aware of a broadening of the problem areas incident to state and local government. The objective, therefore, is to address those problems as they become identified as constraints to the use of the procurement strategies previously discussed. 
The workshop established the need for change in statute and ordinance law where present statutory law precludes the use of sophisticated procurement techniques. To the best knowledge of the workshop, no state or local government purchasing law permits the use of negotiation as it is understood at the federal level. Further, there is some question as to the legality of multiple award contracts for states and local units of government under their present laws. The workshop also identified that many of the procurement strategies were dulled if not made completely ineffective by the very short allowable time for a contract to run as prescribed by state and local unit law. Most frequently this period is a $12-$ month contract.

\section{Recommendation}

A model purchasing law for state government should be introduced through the Committee on Model Legislation of the Council of State Governments; similar model legislation for counties and cities should be introduced through their several associations.

\section{Further study Required}

Time did not permit the workshop to discuss in depth a number of other problems which were identified as standing in the way of innovative procurement, particularly by state and local government. The workshop, however, feels that it is of some value to include in this report a laundry list of these problems and some possible areas to be explored in their solution.

1. Procurement officers are not brought into program inception at an early enough point to permit them to lend their expertise in innovative solutions to program requirements. Likewise, many units of government fail to provide sufficient lead time in response to their IFB's to permit a creative answer to the problems described.

2. No level of government seems to be giving realistic treatment to the question of patent or licensing rights. There is a need to define the concept of competition in this regard.

3. The workshop noted that the government sales program personnel of most major corporations consists almost completely of marketing people, with little attention paid to the potential for $R \& D$ staff to creatively solve problems for their government customers. 
4. At the same time, most procurement offices at the state and local level do not have the budget or the capability of playing an R\&D role vis-a-vis their program constituency.

5. Finally, the workshop recognized that there are a number of procurment strategies which were to be discussed by other workshops. Nevertheless, it is important to identify several of these as impacting on procurement incentives. The use of performance specifications, the systems approach to procurement, the R\&D contract and the use of consultants in procurement policy and procedure implementation are all valuable tools in encouraging procurement incentives. 

INTERACTION AND INFORMATION INTERCHANGE WORKSHOP NO. $2 \mathrm{~A}$ 
Dr. Robert W. Shaw, Jr. Co-Chairman

Research Director

Booz-Allen \& Hamilton Inc.

Booz-Allen Research Division

4733 Bethesda Avenue

Bethesda, Maryland 20014

$301 / 656-2200$

Mr. William B. Whitson, C.P.P.O.

Co-Chairman

Purchasing Agent

Division of Purchasing

Metropolitan Government of Nashville and Davidson County

207 Court House

Nashville, Tennessee 37201

615/747-4201

Mr. Sol Berger

Director of Purchase

N.Y.C. Board of Education

Bureau of Supplies

44-36 Vernon Blvd.

Long Island City, New York 11101

$212 / 786-8800$

Mr. John Burt

Consultant - Committee for Economic Development

3573 Ft. Meade Road, Apt. 209

Laurel, Maryland 20810

$301 / 725-5249$

Mr. Donald W. Corrigan

NBS

18907 Mills Choice Road

Gaithersburg, Maryland 20760

301/921-3694

Mr. John T. Cronin

Procurement Services Coordinator

State and Local Government

Eastman Kodak Co.

343 State Street

Rochester, New York 14650

$716 / 724-4501$

Mr. Walter V. Cropper

Director, Developmental Operations

American Society for Testing \& Materials

1916 Race Street

Philadelphia, Pennsylvania 19103

$215 / 569-4200$ 
Mr. William F. Drake

Director Gov't. Operations

Ford Industries, Inc.

5034 Wisconsin Avenue, N.W.

Washington, D.C. 20016

202/966-8931

Mr. Wilbur F. Jensen

Market Manager

Audio-Visual Products

Mincom Division

3M Company, 3M Center

St. Paul, Minnesota 55101

612/733-4363

Mr. William J. Slattery

for

Dr. Lawrence Eicher

Chief, Standards Information and Analysis Section

National Bureau of Standards

Tech. Bll5

Washington, D.C. 20234

$301 / 921-3235$

Mr. John F. Wynn, Jr.

General Services Admin./FSS

Crystal Mall \#4

Washington, D.C. 20406

703/557-7882

RECORDER

Ms. Ann Deatherage

National Institute of Governmental

Purchasing, Incorporated

1001 Connecticut Avenue

Washington, D.C. 20036 
INTERACTION AND INFORMATION INTERCHANGE

WORKSHOP NO. 2A

INTRODUCTION :

The objective of this workshop was to explore three basic issues:

- The need for improved information exchange between procurers at the Federal and state/local levels and manufacturers

- The types of information which could most usefully be interchanged and how this information would be used by the recipient in carrying out his function

- The effectiveness of alternative systems for accomplishing the required information dissemination.

In the discussion of these issues, a number of significant observations were made by workshop participants and a series of recommendations were developed. This report presents these observations and recommendations in summary form.

\section{PRINCIPAL OBSERVATIONS}

1. The Current Interchange of Information Between All Participants in the Procurement Process is Inadequate

In discussing the information flow process, the workshop found it useful to consider several principal users of information coupled by exchange pathways as shown in Figure 1 .

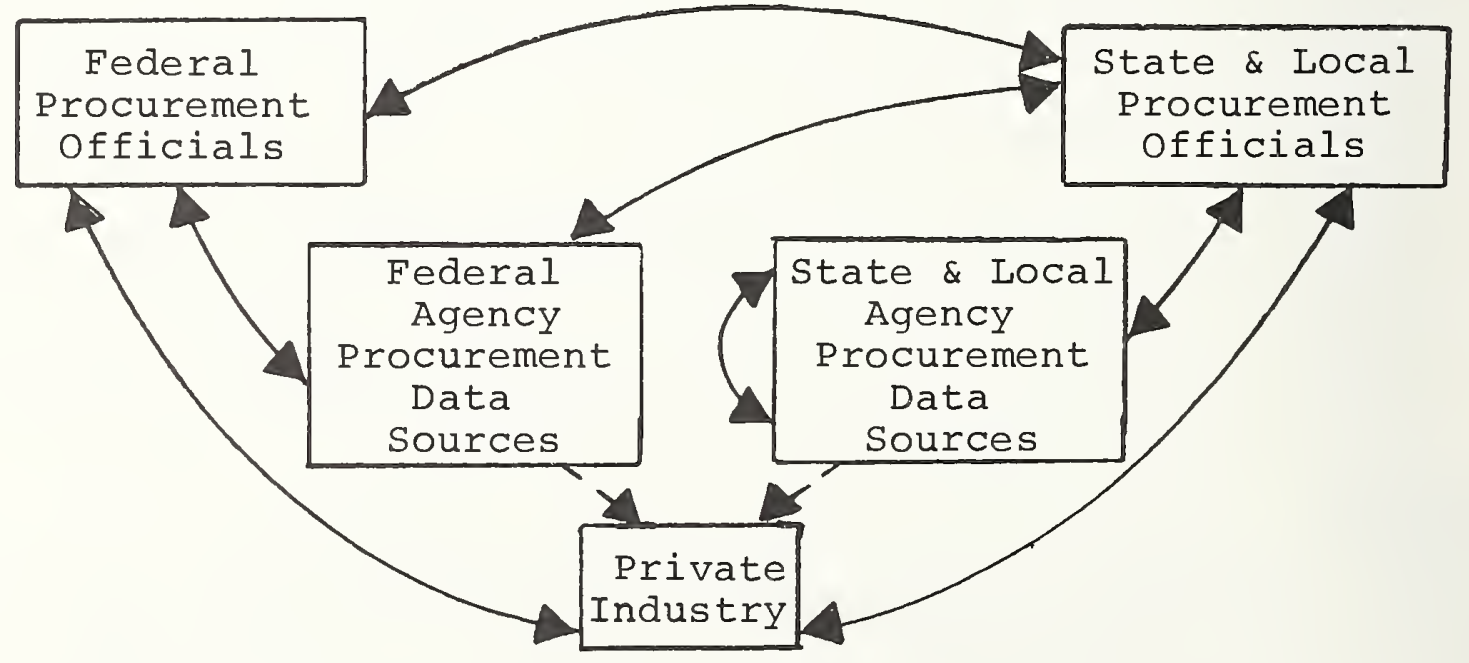

Figure 1

Information Users and Flow 
The type of information flowing and its application is different for each of these pathways and users.

Private industry has traditionally accepted the burden of making its product information available to users. There may occasionally be a mismatch between what industry is offering and what government needs, since at present there is no systematic procedure for transmitting government needs to industry. Furthermore, the market is often highly disaggregated, with different procurers having different needs. This places a heavy burden on industry, and often industry does not respond effectively unless the prospective market is large. Sales representatives are not very skilled at defining user needs and most industries use market research techniques to do that. The bulk of their effort is aimed at the commercial marketplace, however, and there is some reluctance to become involved in the procurement process because of the complexity of procedural factors which must be dealt with. Industry recognizes that it may not always be addressing its product data to specific government needs and is willing to be more responsive in this regard. The information flow problem from the industry perspective is relatively simple. Suppliers are focusing on their own narrow product areas and are attempting to identify specific user needs. Their interaction with government agencies is primarily to obtain specifications and standards data.

The problem faced by the procurement official at the Federal or state/local level is far more complex, and almost certainly these officials lack the kind of information they need, in the view of the workshop participants. The problem may not be lack of information so much as its availability in a convenient, accessible form (see later discussion). In an important sense, government isolates its users from the mainstream of commerce. The procurement official must endeavor to do two things to overcome this problem.

- Maintain active contact with the widest possible spectrum of suppliers and stay abreast of industry developments.

- Be sensitive to the needs of the organization he serves, aggregate the product needs of the users he represents, and transmit these needs to industry.

The procurement official must take on the role of a "Manager of Materials and Services" (a term used by industry), rather than serve only as a buying conduit. He must work aggressively to improve the response time of government and to eliminate unnecessary procedures. 
Procurement officials also have a need to interact with each other (the types of data which should be exchanged in this interaction are discussed later) and at the present time this interaction is almost nonexistent. In particular, the workshop participants felt that state and local procurement officials are now operating almost in an information vacuum. NIGP and NASPO are making efforts to reduce the information gap but are hampered in their programs by lack of adequate resources. In many cases procurement officials recognize the need for information on products and procurement practices but do not know where to obtain it.

State and local procurement officials would benefit from interaction amongst each other but there appears to be no mechanism in place for achieving the kind of interchange which is necessary to make these officials more responsive to the needs of the users they represent. And frequently these officials obtain information from industry and other sources which does not match their needs and which they do not have sufficient resources to interpret or utilize.

2. There is a Need to Develop an Information Exchange

Process Which Matches User Needs With Supplier Capabilities. To Meet This Objective Several Types of Information Should Be Exchanged.

Users of products and services have specific needs and requirements which must be identified by the procurement official and presented to industry in aggregated form. Industry in turn must make available to procurers information which defines the capabilities of its product and the full range of its applications. The processes of matching needs and capabilities is illustrated schematically in Figure 2 .

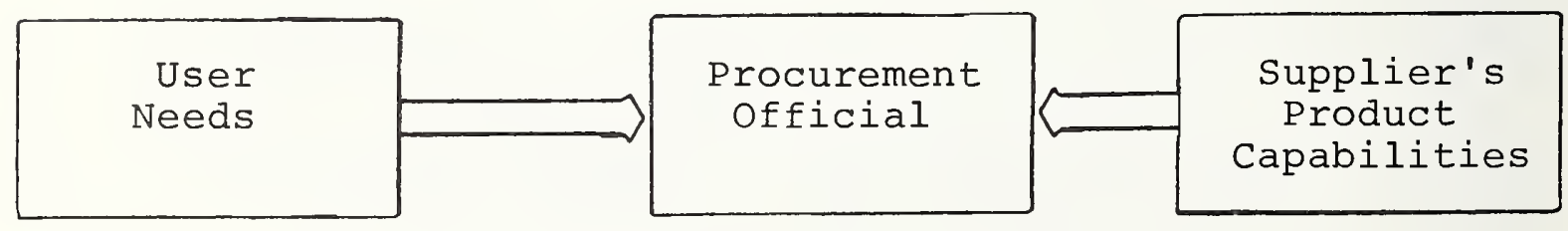

Figure 2

The Procurement Official Has The Responsibility

To Match User Need With Available Products 
If needs are not adequately met by available products, the procurement official should indicate to industry the innovations required and encourage the development of more responsible products. Several creative examples of

- Procurement officials stimulating product innovation,

- Industry representatives identifying novel applications for their products to meet government needs,

were discussed in the workshop.

In order to be fully responsive to the needs of his organization, the procurement official requires more than product information from industry. He needs to know:

- What procurement techniques can be used to obtain products meeting defined needs in a way which minimizes the complexity of the procurement process and encourages industry responsiveness.

- How have officials in other states and cities, and in Federal agencies, handled procurement problems similar to those he faces.

- Are there data available from laboratories or other users which will define product reliability and life-cycle cost. The relationship of these results to manufacturer's quality data and "targets" would also be desirable.

- What kinds of specifications and standards for selected products have been set by other states and by the Federal government.

In more general terms it is desirable for the procurement official to be familiar with procurement mechanisms, policies and guidelines used in other jurisdictions, even though he may have no flexibility to adopt innovative concepts given the rigidity of most state and local procurement regulations.

Although there is a definite need for information, particularly on what other states and localities are doing to improve the procurement process, there is a danger that officials will be inundated with information which they cannot use. If too much information is received, it is likely that none of it will be used effectively because the job of sorting out what is relevant will be too burdensome. Any information system will therefore have to be designed to incorporate what users need (and these needs will have to be defined with some precision) and to make available to users just that 
information which is desired, on request. One possible classification scheme to use at the top level would be

- Procurement Information: data on processes and procedures, how specific procurement problems have been dealt with, application of life-cycle cost analysis, qualified product listings, multiple award schedules and so on.

- Technical Data: data on specifications and requirements established for specific products by various jurisdictions. Much of this data is similar to that now provided on FSS schedules.

- Performance Data: data on the way in which specific products have performed as reported by testing laboratories or other users. This data would be useful both to procurement officials and to industry.

Industry has a need for information on user needs and requirements at an aggregated level. If it were possible to develop uniform requirements over a broad spectrum of purchasing jurisdictions, that would assist industry by multiple specifications and standards. The approach used by the FSS Committee on Procurement Practices in endorsing the purchase of standard commercial products was viewed by the workshop as desirable.

3. Existing Sources of Information Are Not Being Utilized Adequately, Primarily Because They Are Not Widely known

There are a number of sources of data which could be tapped by procurement officials to obtain much of the information they need, but these sources are not now being adequately exploited. The principal reasons are that they are not widely known and there is no simple way to access the information.

Several sources of information were identified by workshop participants, including:

- The "Directory of U.S. Standardization Activities" published by the NBS Standards Information and Analysis Section

- The data bank on specifications test methods, and other procurement information maintained by the NBS

- Specifications and Standards published by ANSI, ASTM, ASME, ASHRAE and other professional and standards setting organizations

- The DOD Index of Specifications and Standards 
- NIGP, NASPO and NAPM information data banks and dissemination capabilities

- Trade associations

Although NIGP and NASPO have made great strides in endeavoring to fill the need for improved information, there is clearly still room for substantial improvement, in the view of workshop participants. In addition to the lack of a central data source, there are no well defined channels of communication and dissemination. Furthermore, the information which is available is often out of date and there are not sufficient resources available to keep the data bank current. Finding the information desired, given the current system, is difficult and time consuming; consequently few make the effort.

4. A Properly Conceived and Executed Information Development and Dissemination Program Would Significantly Improve Current Procurement Practice

The workshop participants recognized that there is a need to improve the currently deficient information exchange process among procurement officials and industry representatives. There are however, certain criteria which any new system must meet to be optimally useful:

- It must be easy to use and provide precisely the information requested by the user

- It should contain data which is thoroughly cross-referenced so that entry and access to the desired information is easy (for example classification of product data by general name, brand name and SIC)

- It must safeguard any proprietary data but at the same time be accessible to industry as well as procurement officials

- It must be current, providing up-to-date product data, standards, and references to procurement situations and personnel

- It should serve both as a source of information and as a mechanism for aggregating data on user needs

- It should avoid any legislative or involved mechanisms in order to make user application as straight forward as possible 
If an information system were set up, either under government or independent sponsorship, the procurement process would be improved in several ways:

- The time spent by the purchaser in obtaining the information needed to serve his organization would be reduced and hence the cost and manpower requirements of the purchasing function could be reduced

- It would improve the effectiveness of procurement officials by giving them increased knowledge of how problems similar to theirs have been solved by others

- It would permit user needs to be satisfied more fully by enabling the procurement official to identify the most responsive product or service

- It would assist industry by aggregating user needs.

As alternative information systems are considered, it will be essential to establish whether the cost of the proposed system exceeds the benefits which can be achieved. It will be important to focus attention on insuring that the system provides information that users need and can use, and that a mechanism is set up to provide direct and immediate access to the information which users request.

RECOMMENDATIONS

Several recommendations for actions which could be taken to improve the current process of information development and dissemination were made by the workshop. These recommendations are presented below and followed by an overview of the various issues which were raised during the discussion of the recommendations.

1. An Independent Organization Should Be Established, Having as Its Primary Responsibility The Development of Information Concerning Products and Procurement and the Dissemination of That Information

A number of alternative approaches were considered for establishing this organization. Among them were:

A National Institute of Materials and Standards (NIMS) having the same type of independent stature as NIH, for example 
- A vastly expanded version of NIGP, receiving funding from the Federal government, possibly on a matching basis

- An office within FSS having responsibility exclusively for information exchange

- An office within NBS, possibly an extension of ETIP in combination with the Standards Information and Analysis Section

- An annual procurement methods conference modeled along the lines of the National Conference of Weights and Measures, and organized by NBS or GSA.

The workshop concluded that it was not feasible to develop structures in any meaningful way given the scope of its activities, and instead chose to recommend that:

"The proposed organization perform the following functions to assist and complement existing organizations, working closely and cooperatively with them in:

- Promoting professionalism in procurement through

- establishing educational programs and standards for certifying the professional credentials of procurement officials

- supporting traineeships and internships

- Disseminating procurement policy information

- Maintaining a data bank for use by procurement officials and industry. "This data bank would be structured using a "National product Identification system," and would be designed to be easily used, readily accessible and widely publicized

- Serving as a focal point for positive interchange between government and industry to achieve the matching of user needs with industry capabilities

- Sponsoring national conferences

- bringing together procurement professionals to discuss common problems

- making product information available and providing procurement officials with a way to stay abreast of industry developments." 
During the discussion of this recommendation, a number of issues were considered and several of these deserve comment in this summary. The view of the workshop was that a strong, central organization with adequate funding was needed to carry out the functions prescribed. The operation of a computerized data bank, with remote access by telephone, was contemplated. It was recognized that the operation of such a system would require significant funding, and a permanent central staff to maintain the bank and develop data to enter into it.

Views of workshop participants differed on whether it was more desirable to have the proposed organization a part of the Federal government, either as a separate agency or as part of an existing one, or to have it remain autonomous, receiving its support from Federal, state and local governments and industry users, perhaps through memberships or users fees.

It was envisioned that the proposed organization could

- Conduct "short courses" around the country to provide periodic training to procurement officials

- Give "grants-in-aid" to allow state and local officials to work for a period of time at FSS or in the central organization (e.g., NIMS)

- Establish vigorous certification procedures for procurement officials and help establish procurement as a profession

- Provide a central focus for study of legal issues surrounding procurement

- Sponsor industry-government exchanges among top procurement officials and managers

- Coordinate the activities of professional societies influencing procurement practices, standards setting, and so forth

- Develop a National Product Identification System.

It was recognized that an effective Federal organization would have to be established through passage of enabling legislation such as a "National Purchasing and Procurement Act" similar to NDEA. A case in support of the proposed institution would have to be made before the Congress on the grounds of its costeffectiveness and the opportunity it would provide to upgrade the quality of the procurement function. 
If the goals and objectives of NIGP are studied carefully, it becomes clear that the workshop has, in effect, recommended an extension of activities now undertaken by NIGP--with the exception of the computerized data bank. It was the consensus of the workshop that NIGP should play an integral role in establishing the proposed organization, if it was not itself designated to assume the responsibility. Some members of the workshop felt that NIGP could complement a NIMS, for example, by serving as an independent voice and advisor and that it would thus be advantageous for NIGP to remain autonomous.

Based on the discussion of the principal recommendation the workshop proposed two corollary recommendations as follows

2. An Industry-Government Task Force Should Be Established to Explore the Feasibility of the Proposed Organization and Recommend Specific Implementation Steps

There are a number of important issues to be considered in assessing the feasibility of the proposed organization. The relationship of the function to prospective users should be considered, along with alternative organizational structures, administrative procedures, funding mechanisms and so forth. The possibility of establishing regional offices should also be considered.

3. Efforts Should Be Initiated to Professionalize the Procurement Process and To Establish Procurement as Part of the Mainstream of Commerce and the Economy

NIGP has sponsored a number of programs to achieve this objective and the workshop participants felt that these should be supported and given greater recognition by the Federal and state governments until such time as a procurement institute is established and assumes responsibility in this area. The workshop noted that in government procurement there is nothing equivalent to the profit motive which operates in industry to provide incentive to procurement officials to serve the users they represent in an optimally effective way and to insure that the procurement function is conducted in a competitive environment where quality performance is rewarded and lack of responsiveness to user needs or market inputs is considered unacceptable. An effort to establish standards of professionalism in procurement could help to introduce a positive change in this area. It was suggested by the workshop participants that in focusing too heavily on the need for procurement information flow the symptom of the problem may be addressed rather than the problem itself--the establishment of a competitive environment to improve the quality of procurement actions by rewarding professionalism and service in procurement activity. 

INTERACTION AND INFORMATION INTERCHANGE WORKSHOP NO . 2B 
Mr. Troy C. Martin

State Board of Control

111 East 17 th street

P. O. Box 13047

Capital Station

Austin, Texas 78711

(512) 475-2232

Mr. Harry M. Tayloe

Co-Chairman

Vice President

Logistics Management Institute

4701 Sangamore Road

Washington, D. C. 20016

(202) 229-1000

Mr. George Dyevoieh

FSS/GSA

26 Federal Plaza, Room 2800

New York, New York 10007

Mr. John D. Ketch

Executive Vice President

Golden Oak, Inc.

2392 East 48 th street

Los Angeles, CA 90058

(213) 589-9181

Mr. Donald A. Loren

Standards Engineer

Purchasing Division

Prince Georges County

Court House Annex

Upper Marlboro, MD 20780

(301) 627-3000 Ext. 507

Mr. Paul Rezachek

State of Minnesota

Procurement Division

Standards \& Engineering Section

50 Sherburne - 112 Admin. Bldg.

St. Paul, Minnesota 55155

Mr. Bob J. Tomlinson

Vice President, Government Sales

Airway Industries

1550 Patuxent Manor Court

Davidsonville, MD 21035

(301) 261-4369 
Mr. Charles Travis

Consultant

4617 Randolph Drive

Annandale, Virginia 22003

(703) $354-8898$

Ms. Martha Weems

Martha Weems, Ltd.

8238 Taunton Place

Springfield, Virginia 22152

(703) 451-9571

\section{RECORDER}

Ms. Barbara Beorlin

National Institute of Governmental

Purchasing, Incorporated

1001 Connecticut Avenue

Washington, D.C. 20036 
In the first paragraph of the guidelines provided by ETIP, which established the areas of concern for this workshop, emphasis was placed upon a "systems approach to interaction and information exchange." We were also charged with developing an overall plan to incorporate recommendations made by the other workshops. When viewed in the context of ETIP's fundamental objective of using procurement practices to stimulate technological invention and innovation in private industry, we were able to identify the two major components of our task. The first relates to the term "information" and its implications, while the second relates to identifying the most appropriate methods, procedures or systems which could be utilized to facilitate the interchange of information among and between those individuals and agencies having a need for such information.

Having reached this point, we found it necessary to "...become generally familiar with the types of information susceptible to development by various agencies and susceptible to multiple use."I By interpreting the term "information" to include written data, knowledge, techniques, procedures, etc., we were able to develop the following list of questions which we felt were pertinent to our assigned task:

a. What information needs to be disseminated?

b. Should the stream of information flow in one or several directions?

c. Have the needs for the information been established?

d. If so, who has the need? --who has the information?

e. Who determines the value and nature of the information to be interchanged?

f. What incentives, if any, exist to achieve appropriate interchange of useful information? If none, what incentives, if any, should be developed?

$\overline{1_{\text {Workshop Guidance }}}$ 
In response to the first question, the members concluded that information would generally fall into two major categories;

(1) technical, e.g., specifications, test reports, and (2) procurement or business methodology, e.g ., procurement techniques, purchasing methods. The answer to the second question is also straight-forward. We were required to look at means of "information exchange," which strongly implies a multidirectional flow of data. The remaining questions were much less amenable to solution. We finally concluded that we did not possess sufficient knowledge to provide adequate answers to those questions, nor were we capable of acquiring such knowledge in the limited time available. Further, it appeared that no single response could properly answer the questions, since circumstances unique to each supplier and user of information could affect the nature of the answer.

Although it was not possible for us to provide definitive answers to the questions we had raised, there was a strong feeling that they were critical to the development of an effective system, and that answers would be required whenever information was being considered for dissemination. It was decided, therefore, that criteria should be developed and adopted which could be applied by any individual or agency wishing to disseminate information to others. The following criteria are recommended for such guidance:

potential for dollar savings improved energy conservation improved productivity

enhancement of the environment advancement in the state-of-the-art increased awareness of test data improved procurement processes increased safety potentially useful performance standards new application of existing technology

The group believes that the criteria should have two primary users: (1) the individual or agency initiating the information exchange and (2) the clearinghouse reviewing the information.

In considering the method or system by which appropriate information could be interchanged, we adopted the concept of a conveyor belt moving in a circle. This "circular" function is important inasmuch as information should be susceptible of generation and use at any level of federal, state or local government or industry. The members conceived of all participants being contributors of information as well as users of information. Therefore, any system for acquiring and disseminating information must accommodate all interested participants 
and should be designed to facilitate ready input and retrieval. The system should be designed to take full advantage of existing methods of communications.

The group recommends that ETIP establish a clearinghouse, the primary functions of which should be to:

- determine the most appropriate system for information interchange

- select and develop media appropriate for incorporation within the system

- determine, on a continuous basis, that the information submitted meets the criteria for dissemination.

It is suggested that the clearinghouse exert every effort to utilize existing information systems and media to as great an extent as possible. In this connection, we believe the Agriculture Extension Service, which has been largely responsible for dissemination of technology in agriculture and for creating the world's leading agriculture system, should be examined. The Agriculture Extension Service might represent an excellent analogue for a system useful to ETIP.

We further concluded that in addition to establishing a clearinghouse, ETIP should launch an educational program aimed at the highest levels of government and industry users. The education program should emphasize the potential of the ETIP program and the information interchange system for:

- total cost savings by

- reducing procurement cost

- reducing operating costs

- reducing procurement time

- improved product performance measured by reliability and maintainability

- increased efficiency

It is also recommended that maximum use be made of the resources of organizations slich as the National Association of Purchasing Management, the National Association of State Purchasing Officials, the National Institute of Governmental Purchasing, the National Association of Counties and the International City Management Association, as well as various industry and state associations. These organizations publish an extensive variety of literature which is widely distributed among key governmental and industry personnel. Furthermore, we believe that 
personal contacts and communications made directly by ETIP, as well as through those organizations identified above, would be of great value in furthering the ETIP objectives. Finally, but by no means the least important element of the education program, we strongly encourage ETIP to sponsor additional regional and national conferences of the same general nature as this symposium in the interest of emphasizing the ETIP program and achieving cooperation of all levels of government agencies and industrial organizations. 


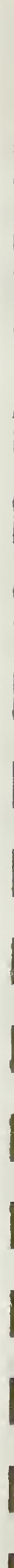


MARKETING, R\&D AND GOVERNMENT PROCUREMENT CYCLES WORKSHOP NO. 3 
Mr. Robert M. Belmonte

Co-Chairman

Director of Purchasing

County of Bergen

County Administrative Bldg. Annex

355 Main street

Hackensack, New Jersey 07601

201/646-3245

Dr. William H. Goldwater

Assistant to Associate Director

Co-Chairman

Office of Collaborative Research

National Institutes of Health

Bethesda, Maryland 20014

301/496-2241

Mr. Keith A. Angier

Director

Washington state Dept. of

General Administration

218 General Administration Bldg.

Olympia, Washington 98502

206/753-5435

Mr. Frank P. Corso

Government Sales

Colgate Palmolive Research Labs.

909 River Road

Piscataway, New Jersey 08854

Mr. Louis E. Desmond

Washington Manager

Defense Products

Caterpillar Tractor Co.

Suite 720, Executive Bldg.

1030 15th street, N.W.

Washington, D.C. 20034

202/296-6704

Mr.W. L. Eckbreth

Director

Office and Photographic Equipment Div.

Federal. Supply Service

General Services Administration

Crystal Mall Building \#4, Rm 808

Washington, D.C. 20406

703/557-8377 
Mr. Glenn K. Ellis

Technical Util. Analyst

Energy Research and Development Admin.

Room B-127

Washington, D.C. 20545

301/973-5156

Ms. Linda Goldstein

Para-Legal

Baker, Nostetler, Frost \& Towers

500 Southern Building

Washington, D.C. 2005

202/393-5360

Mr. Ross E. Hofmann

Ross Hofmann Associates

2908 Salzedo Avenue

Coral Gables, Florida 33134

Mr. John F. Hogan, Jr.

Washington, Rep. - Govt. Marketing

The Goodyear Tire \& Rubber Co.

Suite 902

Ring Building

Washington, D.C. 20036

202/331-9500

Dr. Otto B. Martinson

Project Director

Logistics Management Institute

4701 Sangamore Road

Washington, D.C. 20016

202/229-1000

Mr. Robert G. Meisner

Assistant Director. $\mathrm{S} / \mathrm{T}$

Procurement and Systems Acquisition

Division

U.S. General Accounting office

441 "G" Street, N.W. (Rm 6079)

Washington, D.C. 20548

Ms. Karen Merrill

Research Associate/Govt. Affairs

Westinghouse Air Brake Co.

1200 "12th" Street, N.W.

Suite 916

Washington, D.C. 20036

202/293-1289 
Mr. Kenneth H. Russell

Executive Director of Marketing and Sales

Plastic Reel Corp. of America

650 S. Commercial Avenue

Carlstat, New Jersey

201/933-9125

Mr. Laird Smith

Customer Market Research \#1023

Federal Supply Service

General Services Administration

Washington, D.C. 20406

$703 / 557-8640$

Mr. Louis D. Sorrentino

Vice President

Corporate Marketing Services

Johns-Manville

2009 N. 14th Street

Arlington, Virginia 22201

$703 / 524-9250$

Ms. Celene Strong

Booz, Allen \& Hamilton

4733 Bethesda Avenue

Bethesda, Maryland 20014

301/656-2200, Ext. 357

Dr. William E. Tucker

Technology Utilization Coordinator

office of Industry and State

and Local Government Relations

Energy Research and Development

Administration

Washington, D.C. 20545

301/973-5156

Mr. Edmond G. Young

Manager, Business Development

El Dupont DeNemoors \& Co.

1007 Market Street

Wilmington, Delaware 19898

302/774-5844

RECORDER

Ms. Karen E. Shuhy

Federal Supply Service

General Services Administration

Crystal Mall Building \#4

Washington, D.C. 20406 


\section{MARKETING, R\&D AND GOVERNMENT PROCUREMENT CYCLES WORKSHOP NO. 3}

PURPOSE I. ESTABLISH THE INTERRELATIONSHIP BETWEEN R\&D, MARKETING, AND GOVERNMENT PROCUREMENT CYCLES

As a starting point for discussion, we worked with the notion that there are essentially three steps in the new product development process, as well as in the procurement process. Both processes may not in fact always proceed in the same way, but common to both of them is an interdisciplinary exercise in the identification of Customer Need.

It is therefore recommended that government procurement and using personnel determine the needs of public agencies with the participation of industrial marketing and technical personnel. The concurrent participation of an independent thirdparty, as represented by non-profit professional engineering organizations such as ASTM, would also seem appropriate as well as desirable.

PURPOSE II. DEVELOP APPROACHES THROUGH WHICH THE PROCUREMENT PROCESS CAN MORE EFFECTIVELY INTERFACE WITH INDUSTRY CYCLES TO ACQUIRE THE LATEST TECHNOLOGY IN COMMERCIAL ITEMS

Workable approaches for this purpose could include:

- Industry advisory panels established on a product-group basis ;

- Annual marketing conferences, also organized on a productgroup basis, which bring together the Manufacturer, Buyer, and User, as represented by market research and selling people, as well as by product design, development, and test engineering personnel, from both the public and private sectors.

- The explanation and promotion of the "ETIP idea" at annual meetings of trade associations, the American Manufacturers Association (AMA), National Association of Counties (NACO), International City Managers Association (ICMA), and the like. 
PURPOSE III. DEVELOP APPROACHES TO ENCOURAGING THE TRANSFER OF NEW TECHNOLOGICAL INNOVATIONS TO COMMERCIAL PRODUCTS .

The workshop endorses:

1. The expanded use of Performance Specifications, Life Cycle Costing Techniques, Value Incentive Clauses, Value Compensation Systems, and the interdisciplinary Product Group Manager approach to organizing large public procurement agencies.

2. The greater acceptance of certified test data generated by industrial product testing laboratories.

3. Giving Contracting officers evaluation tools and decisionmaking powers for the acceptance, review and disposition of unsolicited proposals for new and improved items.

4. Exploring the feasibility of purchasing R\&D prototype items by resort to a modified Two-step procurement process based on multi-year funding and the multiple award of cost-plus contracts.

5. The dissemination to 50 state government procurement offices, 3,050 counties, and 58,000 municipal governments and public school districts*, of basic performance specifications, standard value incentive clauses, and life-cycle costing procurement procedures, developed or inspired by ETIP, for their review, consideration, and voluntary application to state and local government purchases exceeding \$120-billion in the aggregate.

a. The greater emergence of state and county-sponsored voluntary intergovernmental cooperative purchasing programs which, by their very nature, are in position to capitalize on such information, thereby creating a total governmental market for new products far exceeding federal needs alone.

b. The utilization of both NASPO and NIGP for the dissemination of such information, and the promotion of new state and local government ventures in cooperative purchasing.

*Not included in these statistics are the more than 21,000 state and local government special-purpose authorities. 
PRODUCT TESTING AND EVALUATION WORKSHOP NO. 4 
Mr. Roger J. Amorosi Co-Chairman

President

Electrical Testing Laboratories, Inc.

2 East End Avenue

New York, N. Y. 10021

(212) 288-2605

Mr. James P. Arnold

Co-Chairman

Purchasing Agent

City of Chicago

Purchasing Department

Room 400, City Hall

Chicago, Illinois 60602

(312) 744-4900

Mr. Francis Annis

Standards Exec.

State of Michigan

Purchasing Division

Lansing, Michigan 48910

(517) 373-0322

Mr. William A. Bickerstaff

Specifications Analyst

Va. Dept. of Highways \& Transportation

$1221 \mathrm{E}$. Broad Street

Richmond, Virginia 23219

(804) 770-5179

Mr. Thomas A. Camp

Sears Laboratories, Dept. 817

Sears, Roebuck \& Co.

925 S. Homan Avenue

Chicago, Illinois 60607

(312) 265-4074

Dr. Alexander R. Craw

Technical Analysis Div.

National Bureau of Standards

Washington, D. C. 20234

(301) 921-3583

Mr. James W. Goff

Director

School of Packaging

Michigan State University

E. Lansing, Michigan 48824

(517) 353-6462 
Mr. H. D. Harback

Chief Elect., Mach. \& Inst. Br/FSS

General Services Administration

Washington, D. C. 22406

Mr. Charles A. Knapp

Property Management Specialist

office of the secretary

Dept. of HEW

Rm. G322 - So. Bldg.

330 Independence Avenue

Washington, D. C. 20201

(202) 245-0601

Mr. Ted W. Lashof

Laboratory Evaluation Technology Section

National Bureau of Standards

Washington, D. C. 20234

(301) 921-2983

Mr. Reuben T. Morgan

Quality Control Division

FSS/GSA

Rm. 524, Bldg. 4

Arlington, Virginia 20406

(703) 557-7570

Mr. Jan N. Ostborg

Mgr. Furniture Engr.

Harvard Interiors Mfg. Co.

4321 Semple Avenue

St. Louis, Missouri 63120

(214) 382-5590

Mr. Chappell D. Pierce

Assistant Director of Technical Services

Gas Appliance Manufacturers Assn.

1901 N. Fort Myer Drive

Arlington, Virginia 22209

(703) 525-9565

Mr. Gene A. Rowland

Acting Chief

Engr. \& Product stds. Div.

National Bureau of Standards

Washington, D. C. 20234

(301) 921-3731 
Mr. Donald B. Sheeley

Director Central Services

Baltimore County

Towson, Maryland 21204

(301) 494-2230

Mr. C. L. Walleigh

Deputy Director

Defense Supply Service - Washington

Department of the Army

Pentagon, Rm. 1D245

Washington, D. C. 20310

(703) OX 5-2007

Mr. Philip Williams

Manager - Product Testing

GF Business Equipment

Youngstown, Ohio 44501

(216) 746-7271

RECORDER

MS. Bobbi French

National Institute of Governmental

Purchasing, Incorporated

1001 Connecticut Avenue

Washington, D.C. 20036 


\section{PRODUCT TESTING AND EVALUATION}

WORKSHOP NO. 4

\section{WORKSHOP MEMBERSHIP:}

This Workshop was composed of twelve Government representatives and seven industry representatives.

\section{PREFACE :}

The recommendations set forth below are presented without the discussion and editorial comment that took place during the workshop sessions. This was done in the interest of readability, clarity and brevity. We hope that our efforts will be helpful to the ETIP Program and will result in more efficient and cost effective procurement methods for all government agencies. We also hope that these findings will aid industry in that they will provide for more flexible procurement methods resulting in specifications that will, because of this latitude, provide part of the incentive necessary for the development of new technology.

Recommendation \#1:

Develop an agency to coordinate tests, evaluation, and inspection activities to improve product evaluation and reduce duplication of effort. This agency should be a repository for test information and act as a vehicle or clearing house for the dissemination of this information to Federal, State, and local government agencies as well as private industry.

At present there is no central source for information and very little communication between the hundreds of governmental and industry testing laboratories, and this results in tremendous expenditures of funds in many cases for duplicate test procedures.

Consideration should be given to systems of accumulating, storing, and analyzing test data from large banks of information such as certification programs and the many laboratories of the Federal Government. This agency might also be responsible for the accreditation of laboratories or play an active role in the coordination of accreditation programs. The accreditation programs will be helpful in improving the reliability and credibility of test results.

ETIP should encourage certification programs and accreditation programs to move forward quickly. 
Performance specifications should be used wherever possible. A good performance specification can allow for the impact and frequency of technological change and can build in a level of quality. They are best suited for ETIP's objectives. Care must be taken, however, during the development of tests and evaluation parameters, to insure practical and comprehensive test methods. Consideration should be given to the greater use of panels of experts and user panels. The reports from user panels should be validated by quality control personnel or their equivalent. These panels can be used effectively for routine procurement as well as new product evaluation.

Recommendation \#3:

Testing and evaluation personnel should be involved in the early planning stages of specification development to insure comprehensive, equitable, and practical test methods. These personnel would be in a better position to know whether new test methods should be developed, or whether there exists established test procedures that can be adapted to the particular need.

During the developmental stages of a specification more emphasis should be placed on the investigation of existing consensus (industry) standards, and existing certification programs, to be determined if they can be utilized in the ETIP program.

Recommendation \#4:

Consider the use of a warranty program in lieu of formal acceptance tests where the costs and the time of development for these tests are prohibitive.

Recommendation \#5:

We recommend that these symposiums be continued. It is felt that there are tremendous benefits accrued to both the ETIP Program and the participants in the Workshop Sessions. 
QUALIFIED PRODUCTS LISTS AND BID SAMPLES WORKSHOP NO. 5 
Mr. Hugh M. Carleton, C.P.P.O. Co-Chairman, CPM (NASPO)

Deputy Secretary, Procurement

Commonwealth of Pennsylvania

Room 414, North Office Bldg.

Harrisburg, Pennsylvania 17125

$717 / 787-5995$

Mr. Larry Merhaut

Co-Chairman,

Government Sales Manager

Rockwell International

131 Park street, N.E.

Vienna, Virginia 22170

$703 / 281-4388$

Mr. John T. Bland

Director, Materials Evaluation

and Development Laboratory (FML)

Federal Supply Service

General Services Administration

Washington, D.C. 20405

202/282-7051

Mr. Dennis Ciboch

Administrative Operations Manager

Builder and Contract Sales

Whirlpool Corporation

Ad Center

Benton Harbor, Michigan 49022

616/926-3591

Mr. Stan Durkee

Environment Protection specialist

Office of Noise Abatement \& Control

U.S. Environmental Protection Agency

Crystal City

Arlington, Virginia 20460

$703 / 557-7760$

Mr. Edward W. Erne

Chief, Standards \& Specifications Division

Bureau of Standards

Commonwealth of Pennsylvania

P.O. Box 3361

Harrisburg, Pennsylvania 17125

$717 / 787-3860$ 
Mr. Donald Gross

Contracts Administrator Hewlett-Packard Company

2 Choke Cherry Road

Rockville, Maryland 20850

$301 / 948-6370$

Mr. Elton Hailey

Director, General Products Division (FPG)

Federal Supply Service

General Services Administration

Washington, D.C. 20406

703/557-7901

Mr. R. E. Hasselman

Caterpillar Tractor Company

Washington Marketing Representative

1030 15th street, N.W.

Suite 720

Washington, D.C. 20005

202/296-6704

Mr. Jonas K. R. Jefferies

Buyer, Bureau of Purchases

Commonwealth of Pennsylvania

P.O. Box 1365

Harrisburg, Pennsylvania 17125

$717 / 787-4352$

Mr. W. C. Petrie

Director, Furniture Packaging and Fibres Division

Federal Supply Service

General Services Administration

Crystal City

Washington, D.C. 20406

703/557-7834

Mr. Charles "Sid" Saunders

Marketing Representative

GAF Corporation

4601 Lydell Road

Cheverly, Maryland 20787

$301 / 322-3130$

Mr. E. T. Watterud

Director, Standards Branch

Canadian Government Specifications Board

88 Metcalfe Street

Ottawa, Canada KlA OS5

613/996-1013 


\section{RECORDER}

Ms. Barbara Blickenstaff ETIP

National Bureau of Standards Washington, D.C. 20234 


\section{QUALIFIED PRODUCTS LISTS AND BID SAMPLES WORKSHOP NO. 5}

This report of the workshop on Qualified Products Lists and Bid Samples is the result of lively discussions and has been unanimously agreed to by all members of the group. The group was well balanced with equal representation from both industry and government. - Everyone agreed that this was an area that needed change. We are happy to present these recommendations in the hope that the government procurement process can be improved.

RECOMMENDATION NO. I - QPLS and Bid Samples in themselves as they exist today do not provide incentive for product innovations. However, we recognize that QPLs and Bid samples serve useful purposes. We feel that incentives for product innovations can be achieved by augmenting QPLs and Bid Samples with other purchasing techniques such as LCC, modified two step, quality rating technique, etc.

DISCUSSION - The group agreed that there were advantages and disadvantages of QPLs. Many of the industry participants present had products on QPLs and could relate problems that had occurred. Some of the disadvantages mentioned were: (a) Obsolescence, (b) Lack of Opportunity for Innovation, (c) High Cost of Testing. It was the consensus of the group that the advantages outweighed the disadvantages and that QPLs and Bid Samples serve a useful purpose. However, we also agreed that dramatic modifications must be introduced to allow product innovation.

RECOMMENDATION NO. 2 - Specifications having indefinite period of inclusion on $a$ QPL should be reviewed at some specified interval not to exceed 5 years and where necessary the QPL purged and requalification accomplished.

DISCUSSION - The group agreed that many QPLS have obsolete specifications and that a time limit was imperative with periodic reviews. Several products now on QPLs were named during the discussion, that had been discontinued by the manufacturer in favor of improved products.

RECOMMENDATION NO. 3 - When a vendor offers a new innovation, the following two situations can occur: 
(a) When this vendor already has a contract then value incentive clauses should be used.

(b) When the vendor does not have a contract, consideration should be given to rewriting specs with a new level of quality that reflects the innovations. This would result in requalification.

DISCUSSION - One of the basic problems noted by the group was the lack of flexibility in QPLs to allow product innovation. We feel that procedures must be set up as recommended to encourage the introduction of product innovation.

RECOMMENDATION NO. 4 - To alleviate the high cost of QPL testing, consideration should be given to acceptance of test results from contractors having test facilities, test procedures and methods acceptable to the qualification agency.

DISCUSSION - It was pointed out by industry that in many cases their testing facilities were superior to those utilized by the government and that present procedures would not allow the use of these facilities.

RECOMMENDATION NO. 5 - The high cost of testing when borne by the vendor has acted as a deterrent to industry participation in QPLs and may inhibit innovation by vendors currently on QPLs. Studies should, therefore, be made to determine ways to reduce this cost to the vendor.

DISCUSSION - Discussion within the group indicated that there was a distinct lack of uniformity within government as to who pays for the high cost of testing. 
QUALIFIED MANUFACTURERS

WORKSHOP NO. 6 
Mr. William H. Rockwell Co-Chairman

Director, Certification

American National Standards Institute

1430 Broadway

New York, N.Y. 10018

$212 / 868-1220$

Mr. Warren K. Wright, Jr.

Co-Chairman

Deputy Director

Office of Central Services

Court House Annex

Upper Marlboro, Maryland

301/627-3000 (ext. 452)

Mr. John Anesi

Mgr, Government Sales

GF Business Equipment, Inc. 2241 Wisconsin Avenue, N.W.

Washington, D.C. 20007

202/337-1400

Mr. T. J. Bundy

Eastern Regional Manager

Lexitron Corporation

1500 Wilson Blva.

Rosselyn, Virginia 22209

703/527-0654

Mr. Roger F. Carroll, Jr.

Deputy Asst. Commissioner

Office of Standards and Quality Control

General Services Administration, FSS

Washington, D.C. 20406

$703 / 557-8660$

Mr. Frank J. Casey

Asst. P.A.

Metropolitan Sanitary District

of Greater Chicago

100 E. Erie Street

Chicago, Illinois 60611

312/751-5763

Dr. Orville L. Pierson

Codes and Standards

Rohm and Haas Company

Independence Mall West

Philadelphia, Pennsylvania 19105

215/592-2583 
Mr. Louis Sorett

Office of Federal Management Policy

General Services Administration

Washington, D.C. 20405

202/343-7528

Mr. Ivan L. Weinstock

Publisher

Government Product News Magazine

614 Superior Avenue $W$.

Cleveland, Ohio 44113

$216 / 696-0300$

Mr. Leigh W. Willoughby

Director, Furniture and Furnishings Division

Federal Supply Service

Office of Procurement

General Services Administration

Washington, D.C. 20406

$703 / 557-8336$

\section{RECORDER}

Ms. Margaret Lucas

Federal Supply Service

General Services Administration

Crystal Mall Building \#4

Washington, D.C. 20406 


\section{QUALIFIED MANUFACTURERS \\ WORKSHOP NO. 6}

Introductory statement

As set.forth in the assignment of this workshop, the objective was to review possible techniques and mechanisms available at the federal, state and local levels to provide assurance that the products supplied meet the technical requirements of procurement agencies. In the course of the review by the workshop of the use of the qualified manufacturers mechanism, the conclusion was reached that new and innovative techniques were needed to make this mechanism available to the broad spectrum of government procurement agencies. The initial step in our objective of improving the quality of products for the public is to promote an incentive for manufacturers to produce and continue to produce quality products. The conclusions reached are set forth below.

Proposed Policy

In order for government to provide incentives to industry to improve the quality of commercial products which are purchased by government, there should be established a Qualified Manufacturers Procedure.

Premise

Government procurement shall normally be made only from those manufacturers who have been qualified. A master list will be developed for qualified manufacturers on commercial products. A mechanism should be developed for dissemination of qualified manufacturers information to the public. This policy should be implemented on a product by plant basis establishing a priority listing by commodity.

1. Criteria for qualification of manufacturer.

The group determined that there are significant criteria for qualification of manufacturers. The committee has developed initially the following eight specific elements for qualification:

a. Capability to produce products to specific technical requirements, i.e., facilities, expertise, equipment, etc.

b. Acceptable Quality Control system. Sufficient to meet a uniform criteria to be established.

c. Maintenance of Inspection and Test Records.

d. Financial status. 
e. Delivery Performance, i.e., proven and sustained record of reliable deliveries, customer satisfaction, etc.

f. Organizational structure outlining responsibility of each element particularly of the quality control operation.

g. Distribution and Customer Service Capability.

h. Compliance with applicable legal requirements.

2. Initial Qualification.

Manufacturer who wishes to qualify should submit his application with the established fee to the designated agency identifying his plant and product to be qualified. No manufacturer may resubmit a request for requalification until he submits evidence of completing all actions to correct the deficiencies found in the rejection of his prior application.

Surveillance should be made as often as necessary to insure that no changes in qualification criteria affecting quality of products have occurred since the initial qualification. Qualification and surveillance processes will be conducted by product and by plant.

Removal from qualified manufacturers list. Manufacturer shall be removed from the list of qualified manufacturers when he defaults in his compliance with the criteria after full investigation and the manufacturer fails to correct the deficiencies. In those instances where the deficiencies are corrected, the manufacturer shall be retained on the list.

3. Qualification Responsibility.

An appropriate agency should be assigned responsibility to evaluate and approve individual manufacturers. Other certification programs should be evaluated and approved if they meet all the criteria of this program. The agency should be one nationally recognized by all interested parties as an appropriate group to operate the qualified manufacturers program. Recommend that a panel comprised of procurement officials of federal, state and local governments review the proposed policy established in this report to develop appropriate implementation procedures and make appropriate recommendations. The proposed procedures should be coordinated with industry. 
4. Information Dissemination.

In the event these policies are adopted by the Federal Government, it will be promulgated by means of a Federal Management Circular which will be published in the Federal Register. Appropriate notice shall also be furnished to state and local government.

Qualified manufacturers listing should be published by the assigned agency and supplemented monthly.

5. Other Considerations.

a. Changes to appropriate regulations and laws.

b. Acquisition of necessary resources.

c. Training.

d. Development of appropriate seal or label for the qualified product $(s)$.

e. Marketing of the program to state and local government, industry and the public.

6. Potential Benefits.

The development of acceptable and qualified manufacturers lists will:

a. Provide savings to the government and the public sector.

b. Reduce waste and inefficient use of resources.

c. Improve consumer awareness and confidence in product integrity and service.

d. Reduce duplication of effort by many private, public and governmental entities.

7. Recommendation.

Recommend qualified manufacturers program be established within the framework contained in this report and that a pilot program on a designated product be initiated as a prototype. 
METHODS AND TECHNIQUES OF CONTRACTING WORKSHOP NO. 7 
Mr. Herman Crystal

Co-Chairman

Deputy Director

Division of Purchase

\& Property

State of New Jersey

State House

Trenton, New Jersey 08625

$609 / 292-4724$

Mr. William W. Thybony

Co-Chairman

Director for Procurement

Management

Office of Federal Management

Policy

General Services Administration

Washington, D.C. 20405

202/343-6201

Mr. David R. Baird

GSA Contracts Manager

3M Company

1750 Pennsylvania Avenue, N.W.

Washington, D.C. 20006

202/298-9200

Mr. Ernest C. Baynard

Computer \& Business Equipment

Manufacturing Association

1828 L Street, N.W.

Washington, D.C. 20036

202/466-2288

Mr. James A. Hawkins

Manager, Government \& Education

Markets Services

Eastman Kodak Company

500 12th street, S.W.

Washington, D.C. 20024

202/554-9300

Mr. Robert G. Hendrickson

Technical Analysis Division

National Bureau of Standards

Washington, D.C. 20234

301/921-3694 
Mr. Thomas E. Lewis

Manager, Government Technical Services

Armstrong Cork Company

1666 K Street, N.W., Suite 205

Washington, D.C. 20006

202/296-2830

Mr. David Littleton

Ass't. Director, Procurement

U.S. General Accounting Office

Washington, D.C.

202/386-5430

Mr. Ralph S. McCrea

Government Contracting Manager

IBM Corporation

4301 Connecticut Avenue, N.W.

Washington, D.C. 20008

202/686-3790

Mr. William R. McQuiston

Contract Administration Manager

Tektronix, Inc.

P.O. Box 500

Beaverton, Oregon 97077

503/644-0161

Mr. W. B. MacDonald

General Motors Corporation

Government \& Defense Sales

1660 L Street, N.W.

Washington, D.C. 20036

202/659-5060

Mr. Willard F. Martin

Manager, National Government Marketing

Itek Corp., Graphic Products Div.

Suite 900

200 North Glebe Road

Arlington, Virginia 22203

$703 / 524-5820$

Mr. William H. Metzger

Manager, Government Services

GAF Corporation

140 W. 5lst Street

New York, New York 10020

212/582-7600 
Mr. Robert A. Miller

Buyer, Commonwealth

of Pennsylvania

Bureau of Purchases

P.O. Box 1365

Harrisburg, Pennsylvania 17125

$717 / 783-1282$

Mr. Karl G. Newell, Jr.

Acting Chief, Standards Development

Services Section

Engineering \& Product Standards

Division

National Bureau of Standards

Tech B-166

Washington, D.C. 20234

301/921-2356

Mr. Russell W. Piazza

Director of Purchasing

County of Montgomery

Pennsylvania

Courthouse

Norristown, Pennsylvania 19404

215/275-5000

Mr. George W. Saunders

Acting Deputy Commissioner

Federal Supply Service

GSA

Washington, D.C. 20406

$703 / 557-8688$

Mr. David Thompson

Government Sales Manager

Turf Products Division

Outdoor Power Equipment Group

The Toro Company

8111 Lyndale Avenue S.

Bloomington, Minnesota 55420

612/888-8801

Mr. Einar Windingland

Director, Policy \& Procedures Div.

Office of Procurement

FSS (CM Bldg. 4)

General Services Administration

Washington, D.C. 20406

703/557-8231 


\section{RECORDER}

Ms. Darlene Mattern

ETIP

National Bureau of Standards

Washington, D.C. 20234 


\section{METHODS AND TECHNIQUES OF CONTRACTING WORKSHOP NO. 7}

A. Relationship of ETIP to the Office of Federal Procurement Policy.

The Congress has established the Office of Federal Procurement Policy (OFPP) in the Office of Management and Budget (OMB) to develop, coordinate and direct high level procurement policy for the Federal Government. It is headed by an Administrator for Federal Procurement Policy. In this legislation Congress has also set forth a basic framework that will allow the executive branch of government greater opportunity to structure procurement methods and techniques to meet the needs of the government and the public as a whole.

Optimum transfer of technology requires that the goals and objectives of the Experimental Technology Incentives Program be reflected in the policies and procedures that this new office may implement. We recommend, therefore, that the goals and objectives of ETIP be adopted as a matter of policy by the office of Federal Procurement Policy.

At the state and local levels we urge adoption of the concept of more central policy direction upon which more sophisticated procurement systems can evolve at all levels of government, patterned after the new Public Law 93-400, which created the Office of Federal Procurement Policy. From a basic policy perspective, we call particular attention to the restatement and significant revision of congressional policy in Section 2 of P.L. 93-400 which calls for establishing policies, procedures and practices requiring the government to acquire property and services of the requisite quality and within the time needed at the lowest reasonable cost, utilizing competitive procurement methods to the maximum extent practicable. The significance of this congressional statement may lead to the desirable result of allowing the Federal Government to require products of a better rather than minimum quality, which would reflect a higher level of technology.

B. Consistency in Procurement Statutes.

Workshop No. 7 recognizes that there are substantive differences in the legal basis on which state and local governments conduct their procurement operations. Some laws are antiquated and outdated. To assist in achieving ETIP objectives, it is recommended that efforts be made to 
eliminate undesirable and unnecessary inconsistencies in state and local government laws along similar lines or under-development by the Federal Government. One method to achieve this objective would be to develop a model procurement statute which could be utilized as an authoritative guideline by the various state and local governments.

C. Subject: Economic Price Adjustment Clauses.

Any effective program to encourage technical transfer between industry and government requires recognition by governments at this time of the serious inflationary forces that hamper industry in determining reasonable price levels for products and services sold to governments.

We urge appropriate procurement officials at all levels of government to take whatever action necessary after consulting with industry to make appropriate provisions in contract procedures that allow reasonable releases from these inflationary forces.

In this regard we urge prompt adoption of recommendations to the office of Federal Procurement Policy and to officials at the state and local government level fostering industry and business participation in the development of procurement policy.

D. New Item Introductory Schedule - Expand Concept to Encourage Innovative Technology.

The "Federal Supply Service (FSS) New Item Introductory Schedule" provides for acceptance of unsolicited proposals for new products or services and negotiation of proprietary contracts when mutually advantageous. This schedule is published on a national basis in Washington and is distributed to all federal agencies.

Expansion of this concept is recommended to encourage industry to bring new and innovative products to the attention of the government, particularly items which will conserve energy and scarce natural resources, reduce pollution and increase productivity. To bring about this expansion, it is recommended that the General Services Administration (GSA) publicize this program to industry to increase their participation. Also, GSA should give special publicity to new and innovative items which identifiably contribute to energy conservation and other technological innovation. 
Other federal agencies, and state and local government purchasing activities, should be encouraged to adopt similar concepts.

E. Specifications.

There is a paramount requirement that any procurement system contain the means to protect the taxpayers. The public justly deserves the most meaningful level of competition that the nature of the products allow and the need to use competitive bidding whenever appropriate. But, this need should not obscure the benefit that will come from greater reliance on commercial specifications when products needed by the government are comparable to those offered the public in commercial sales.

We endorse early implementation of the Commission on Government Procurement Recommendations $\mathrm{D}-3$ and $\mathrm{D}-4$ relating to the use of commercial specifications by the new OFPP.

In addition, we urge review of government requirements and fees relating to the qualification of products in establishing eligibility for procurement. The underlying policy should be to encourage qualification of new items and to expedite qualifications for procurement. This objective is of particular importance in allowing small and minority business enterprises fair opportunity to compete.

The workshop further recommends use of the most effective methods of allowing full industry participation and competition in fulfilling the government's needs and at the same time giving government users the widest latitude in selecting the products that best meet their unique requirements.

F. Multi-year Contracts.

We support legislation to enable federal, state and local governments to enter into contracts that extend beyond one year.

The advantages to government and industry include lower costs and administrative savings, and the ability of contractors to amortize startup and other non-recurring costs over a longer period of time. Both government and industry should, therefore, benefit from longer business commitments. 
G. Life Cycle Costing and Total Economic Costs.

While not having been able to make a complete analysis of the concepts of total economic costs and life cycle costing, we support these concepts as having contributory potential for technological advances.

H. Information Exchange.

At all levels of government there is a growing need for better information concerning procurement - particularly in the technological area. If technological breakthroughs are to be exploited to an optimum degree, then information regarding these advancements must be disseminated as broadly as possible to all levels of government federal, state, county, and local.

The complexity of procurement, the number of people involved, and the vast expanse of products and services subject to procurement makes advancements in the dissemination of data an extremely difficult task. The National Bureau of Standards programs, the GSA Business Service Center program and other programs are of significant assistance. But, an increase in the effectiveness of these and other programs must be realized before a satisfactory level of technological transfer can be achieved.

I. Conclusion.

In conclusion, the workshop recognizes the importance to society of fostering increased technological transfer between public sectors of the economy. To optimize this result, the goal must be reflected in the methods and techniques public bodies use in contracting for goods and services. That the systems of procurement governments use must be as fair, expeditious and as economical as possible is basic. In this connection, recognition of the need for a reasonable profit by contractors is essential.

Government must recognize the economic conditions in which the industry must operate and make provisions in procurement procedures that afford contractors reasonable protection from inflationary trends, energy dislocations, shortages and other factors beyond contractors' control.

The Federal Government should evaluate present procurement procedures to enhance the opportunity of industry to offer products of more advanced technology. 

ACCOMPLISHMENTS 


\section{FEDERAL SUPPLY SERVICE}

Report on Accomplishments

Based on Recommendations of the First ETIP Symposium on Procurement Practices

The following is a summary of the actions taken and actions underway which relate to the comments and recommendations of the first ETIP Symposium on Procurement Practices held in May 1974 .

The recommendations have been summarized into four categories:

1. Procurement

2. Specifications, Standards, and Quality Control

3. Communication

4. Organization

I. PROCUREMENT

1. Life Cycle Costing

Solicitations containing Life Cycle Costing provisions have been issued for lawn mowers, window air conditioners, water heaters, refrigerators, and gas ranges. No acceptable offers were received on lawn mowers. However, awards were made to the General Electric Company $(\$ 2,533,000)$ and the Fedders Corporation $(\$ 3,980,000)$ for air conditioners. A 21 percent savings in energy and $\$ 400,000$ in costs are expected as a result of these awards. Awards are pending on water heaters, refrigerators, and gas ranges. We expect to issue solicitations for other commodities in the near future which will utilize Life Cycle Costing techniques.

\section{Value Incentives}

A value incentive clause has been approved and is in printing. Implementation will follow shortly.

3. Increased Use of Negotiation

Small purchase procedures have been implemented to make maximum use of the new authority to negotiate procurements up to $\$ 10,000$ under 302 (c)(3). Further broadening of negotiation authority cannot be done in the absence of additional legislation. 


\section{Increased Use of Multiple Awards}

We are continuing to expand the multiple award Federal Supply Schedule program as opportunities arise. During the period $7 / 1 / 74$ and $12 / 31 / 74$, five new multiple award schedules were authorized and assigned. They cover such commodities as Storage Cabinets; Water Purification Equipment; Food Service, Handling, Refrigeration, Storage, and Cleaning Equipment; Clothing and Footwear; and Fertilizers.

\section{Upgrade the Training Qualifications of Procurement Personnel}

A program of supplemental on-the-job training sessions for procurement personnel has been initiated by the Office of Procurement (Policy and Procedures Division, FPP). The primary purpose of this training program is to discuss recent regulatory and policy changes, including background explanations and their application. The training sessions are taped and sent to the regions to be viewed by our regional procurement counterparts. These training sessions are held each month.

\section{Procurement Officers Should be Encouraged to be Innovative in Procurement Techniques}

Procurement innovations, methods and techniques found to be successful, news flashes, and proposals for the future will be provided to procurement personnel in the form of a new "Procurement Information Bulletin." This bulletin will be used as an idea swapping media to encourage innovations on the part of procurement personnel.

\section{The Purchase, Testing, and Evaluation of Prototypes by GSA}

Broad outlines of procedures have been developed for the purchase, testing, and evaluation of prototypes by GSA to definitize specifications prior to procurement of production requirements. A trial procurement project will be in the furniture commodity area.

\section{Utilization of a "Guaranteed Percent of Business" Concept}

The guaranteeing of a percentage of Government business to a given contractor, even if tied directly to Life Cycle Costing and Value Management concepts, has potential problems without specific statutory changes. Such statutory changes appear unlikely in view of the basic policy of competition for the Government's requirements. 


\section{Use of "Reverse Two-Step" Procurements}

The use of "reverse two-step" procurements, in which a price which the Government will pay is established together with desired performance of the item and then proposals are evaluated for the most innovative offer which comes closest to or exceeds the established objectives, is an interesting concept. However, there are so many real or potential problems involved in the concept such as identifying suitable items for procurement, establishing a price the Government would pay, establishing the desired performance characteristics, the subjective nature of the evaluation, etc., that it is questionable whether the concept would prove practicable in our procurements of common commercial type items. However, it is the type of concept which might have potential as an ETIP sponsored project.

10. Initiate an Incentive Program to Motivate Government Procurement Personnel to Recognize and Keep Abreast of New Technology

We are presently considering several alternatives identified as incentives to motivate buyers to recognize and keep abreast of new technology.

\section{Develop a Modified Method of Two-Step Procurements} for Furniture

The Furniture and Furnishings Division has developed a modified two-step procurement method along the lines suggested by the ETIP Workshop involving the use of technical proposals to establish a qualified products/suppliers list and resulting in a form of multiple awards in the second step. Consideration is being given to establishing a trial procurement project.

12. Develop Some Type of Incentive System Whereby a Supplier Receives Compensation for Contribution of Technological or Design Innovations

The Value Management concept, which is in the process of being implemented, will provide an incentive system whereby a supplier receives compensation for contribution of technological or design innovations.

13. Encourage Unsolicited Proposals for New and Improved Items and Provide Means for Evaluating Such Proposals

This recommendation is closely related to Recommendation B-7 of the Commission on Government Procurement which reads "Eliminate restraints which discourage the generation and acceptance of innovative ideas through unsolicited proposals." 
The Executive Branch adopted Recommendation B-7 and it is being implemented through the Armed Services Procurement Regulations Committee and the Federal Procurement Regulations Committee.

14. Contract on a Multiple Award Basis by Regions to Enable New Products to be Introduced on a Regional Rather Than National Basis

The basic concept of the Schedule program is to provide national coverage for products which are sold nationally on a commercial basis. Contracting for these items across-the-board on a regional basis would greatly increase the procurement workload and it could not be accomplished with present resources. However, we do in fact occasionally contract for items on a limited geographical basis which are otherwise national in scope, as for example, when a contractor is test marketing an item in a limited area. Contracting on a limited geographical basis is within the discretionary powers of the Contracting officers and no further implementation is required.

15. Give Contracting Officers Decision Authority Commensurate with Responsibility and Sharply Reduce Reviews

This recommendation is closely related to Recommendations A-13, A-14, and G-1 of the Commission on Government Procurement. GSA fully concurred in these recommendations and is taking steps to implement them.

16. Request Multiple Award Contractors to Summarize in Their Price Lists Information on Improved Performance, New Technology, New Items, etc.

Since most FSS multiple award contractors use their commercial literature, either in whole or in part, for the Government price list, the above information is usually presented. As a matter of fact, information as recommended has been a problem for the GSA Contracting officers. Since the price list that the contractor is required to distribute to Government activities is an official "authorized" price list, the implication is that all descriptions and claims therein are verified by the GSA Contracting Officer and statements may be substantiated. GSA does not have the ability in most cases to ascertain the validity of the statements made. We have therefore discouraged, or prohibited, the contractors from making some claims or statements about their products simply because they may mislead potential buyers and there is no way to readily verify them. 


\section{Provide Long Range (Up to Five Years) Requirements Forecasts}

The constant change in agency demands, the addition and deletion of items from the system, uncertain budgets, and changing market conditions all combine to make it difficult, if not impossible, to provide meaningful long range requirements forecasts. Indeed, our experience with one year forecasts indicates that it is problematical whether longer range forecasts would be sufficiently valid to provide a base for advance industry planning. This is particularly true since there is no assurance that a given firm would be a successful bidder in the future.

\section{Reduce Small Quantity Ordering on Multiple Award Schedules}

For a number of years the minimum order under most Schedules was set at $\$ 50$. Consistent with this recommendation, Procurement Letter No. 109-4 was issued on December 5, 1974, to allow Contracting Officers to tailor the small requirements clause to the commodity being procured. This will undoubtedly raise the minimum order under many schedules.

\section{Limit Percentage of Total Government Requirements to a Single Contractor}

In the absence of statutory changes, we are without authority to arbitrarily limit the percentage of total Government requirements on which a firm may bid and receive awards, except in certain situations involving capacity, credit, or responsibility. Such statutory changes appear unlikely in view of the basic policy of competition for the Government's requirements.

\section{Consolidate and Simplify Procurement Regulations}

To provide a more simplified and uniform regulatory structure, we are in the final process of eliminating one layer of procurement regulations in their entirety--GSPR 5 . The ASPR and FPR are now on a direct course to make these respective regulations consistent with each other. We are continuously striving to simplify and reduce written regulatory material.

21. All Items on Multiple Award Schedules Should Conform to Safety Standards

GSPR 5A-2.201-70 provides guidance when the items being procured involve fire, casualty, safety, or health hazards and the Contracting officer believes they should 
conform to the standards of nationally recognized technical societies, associations, or laboratories, or other GSA-approved testing laboratories. Two appropriate clauses are in the current clause manual. However, there are thousands of safety standards, laws, and regulations which may apply to various items among the hundreds of thousands of items made available through multiple award schedules. The sheer volume of the items involved, plus our practice of contracting on the basis of the offerors' commercial catalogs, and the inherent policing problems, make it difficult, if not impossible, to achieve this worthy goal.

\section{Extend Contract Periods for Products with New Tech- $\underline{\text { nology }}$}

Except in most unusual circumstances, we lack the statutory authority to extend contracts which were awarded on a competitive basis. Statutory change in this area would appear unlikely in view of the basic policy of competition for the Government's requirements, and since extension of contracts could foster an element of favoritism on the part of the Government toward a specific contractor. We do, of course, have authority to extend multiple award and new item introductory Federal supply Schedule contracts within certain limits, and do so as a matter of practice.

\section{Encourage Product Innovation by Small Business}

The Workshop was not specific as to how this recommendation might be accomplished. Many of the ideas developed at the ETIP Symposium will, of course, encourage product innovation by small business as they are implemented. Further, small business interests will be protected and encouraged by the Government's policy of fostering small business and seeing that a fair proportion of Government purchases of goods and services, including research and development, are placed with small business. However, this recommendation is so broad that it might well serve as the topic for a future ETIP Workshop.

24. Select from the Range of Possible Procurement and Specification Techniques the Combination That Gives Government the Strongest Position in Attracting Products and Technological Innovation

This recommendation is worthy of further detailed study. Accordingly, a Workshop to consider this entire area has been scheduled for this second Symposium. This Workshop is entitled "Methods and Techniques of Contracting." 


\section{SPECIFICATIONS, STANDARDS, AND QUALITY CONTROL}

\section{Improve and Expand Laboratory Facilities}

We have recently completed a comprehensive study of our laboratory resources and workload (present and potential). We have centralized some of our laboratory capability in order to get optimum utilization of sophisticated and expensive laboratory equipment. For example, we are doing our hand tool testing in our regional laboratory in Kansas City and our paint testing in our regional laboratories in New York, Fort Worth, and Auburn. In addition, we are progressively updating our laboratory equipment and facilities in areas where needs are most acute. One example is packaging laboratory and test equipment which was added to our Washington facility during the past year. We have increased the staffing in one laboratory by 12 positions to conduct more extensive tests on the products we buy. We now have in being a system of effective feedback for the results of our field laboratory testing. This testing is responsive both to product acceptance from contractors and to customer complaints.

2. Increase Acceptance of Industry Test Results from Qualified Laboratories for Product Performance

It has long been our policy to accept the results of qualified laboratory tests. In addition, and less costly and time consuming, is the acceptance of effective quality control systems and tests by the manufacturer. We are encouraging this arrangement under our Quality Approved Manufacturer Program. Currently, we have agreements with manufacturers under this program with attendant benefits both to the manufacturer and the Government.

\section{Use Panels of Experts for Subjective Evaluation}

We are expanding the use of this technique. We have used it successfully in the purchase of dictionaries and kitchen ranges and feel that it has potential in many product areas where it is not economically feasible to develop performance specifications and where design specifications are not practicable.

\section{Pre-qualify Products and Suppliers}

Currently, we have about 100 specifications which require product testing for qualification prior to the award of contracts. We feel that this technique has good potential for expansion with benefits both to prospective suppliers and government. We have no experience with qualified manufacturers although we understand this technique has been applied by 
some other Federal agencies. We are anxious to utilize these techniques to their optimum potential and have included them in workshop agendas in order to get the best guidance available for development and application.

\section{Institute Long Range Froduct Development Programs}

This is an area which requires careful planning and close collaboration with users. We have initiated a project to explore possibilities within statutory limitations in a single area of furniture. Conceptually, we are thinking along the lines of design competition leading to the development of a statement of technical requirements which can be used in two-step procurement. However, it is much too early to make any predictions in this area.

\section{Minimize the Number of Types of Items Available to Customer Agencies}

We are now actively engaged in reducing the range of sizes and varieties of items offered to customer agencies. An example of item reduction is reflected in the furniture category. We recently completed a study of our contemporary line of furniture, and plan to reduce the number of line items from 2744 to 331 , all of which will then be in stock.

7. Establish GSA/Industry Groups on a Commodity Basis to Develop Minimum Standards for Product Acceptance

We have established such a group in the furniture area as a pilot test.

\section{Increase Participation in Industry and Trade Associa- tion Activity}

We have long recognized the benefits of such participation although resource limitations somewhat curtail our participation. However, we think our batting average is pretty good. We now have 58 representatives on 96 national committees and will continue our policy of participation where it can be justified.

\section{COMMUNICATIONS}

1. Develop a Procedure for Inviting Counsel From Both Marketing and R\&D People

In our specifications development conferences, we attempt to get representation from both areas, and we have noted that more often two company representatives are attending 
these and bidders conferences. However, we recognize that there is more to do in this area.

2. Use Wall Street Journal and Trade Journals for More Significant Communications

We have recruited a specialist to develop a program through which information of significance can be screened and channeled to appropriate publications on a timely basis. This will fill a real need. Of course, this symposium deals with the broad subject of information interchange, so we hope to get some significant recommendations that will vastly improve overall effectiveness in this important area.

\section{User Feedback to Industry}

An ETIP project providing for user feedback to industry in the procurement of oscilloscopes is in the planning stage. The techniques used in this pilot procurement, if successful, could be extended to other commodities.

4. Free Flow of Information Between the Federal Establishment and state and Local Governments

Greater emphasis is being placed on our relationship with state and local procurement officials, particularly through the Joint Federal, State and Local Government Advisory Panel on Procurement and Supply. For example, a two-day GSA sponsored procurement conference is scheduled for the week of March 24, 1975, in Denver, Colorado. It is envisioned that this conference will provide an interface of information between the procurement personnel in attendance, representing various levels of Federal, state and local government procurement offices. The conference theme is tentatively scheduled to be "Satisfying Customer Requirements in Today's Market Environment."

\section{Office Machine Contractors Should Include a User Feedback Form in Their Instructional Manuals}

While some manufacturers do include a "feedback form" for the convenience of customers, the practice is not widespread. In order to maintain the commerciality of products we attempt to stay as close to commercial practices as possible. Deviation from commercial practices tends to raise prices. Moreover, a pilot ETIP project involving "user feedback" for oscilloscopes is in the planning stage, and if the proposed procurement techniques proves successful, it could be expanded to the procurement of other items such as office machines. Pending results of the ETIP project, we believe it is advisable to encourage "user feedback" in the office machine area rather than to require it. 
IV. ORGANIZATION

1. Reorganize FSS to Accommodate Product Group Managers with Responsibility for Product Development

We are establishing as a pilot project a furniture center which will bring all elements of the procurement process together. These include specification development and maintenance, procurement, and inventory and commodity management. In addition, a study is nearing completion which will serve as a basis for a comprehensive marketing effort within Federal Supply. Of equal or greater importance is the recent establishment of a top level policy and planning organization which will continuously re-assess programs and policies and redesign as necessary for us to maintain the most cost effective material management organization in the Federal Government.

2. Establish a Market Research Group Within FSS to Identify User Needs and Provide Forecasts

Such a group has been established. The Market Research Branch is currently working with civil agencies of the Executive Branch to obtain detailed data on open market procurements for the primary purpose of determining if GSA/FSS can provide a more economical source of supply for repetitively procured items, and also, to determine customer satisfaction or dissatisfaction with items currently available in GSA/FSS supply system. 

PARTICIPANTS/ATTENDEES 


\section{ATTENDEES/PARTICIPANTS}

Dr. Ernest Ambler

Deputy Director

National Bureau of Standards (NBS)

ADMIN All31

Washington, D.C. 20234

301/921-2451

Mr. Roger J. Amorosi

President

Electrical Testing Laboratories, Inc.

2 East End Avenue

New York, New York 10021

$212 / 288-2605$

Mr. John Anesi

Mgr. Government Sales

GF Business Equipment, Inc.

2241 Wisconsin Avenue, N.W.

Washington, D.C. 20007

202/337-1400

Mr. Keith A. Angier

Director

Washington State Dept. of

General Administration

218 General Administration Bldg.

Olympia, Washington 98502

206/753-5434

Mr. Francis Annis

Standards Exec.

State of Michigan

Purchasing Division

Lansing, Michigan 48910

517/373-0322

Mr. D. L. Anthony

Purchasing Agent

Townghip of Cherry Hill

820 Mercer Street

Cherry Hill, New Jersey 08002 $609 / 665-6500$ 
Mr. James P. Arnold

Purchasing Agent

City of Chicago

Purchasing Department

Room 400, City Hall

Chicago, Illinois 60602

312/744-4900

Mr. Dāvid R. Baird

GSA Contracts Manager

3M Company

1750 Pennsylvania Avenue, N.W. Washington, D.C. 20006

202/298-9200

Mr. Raymond L. Bancroft

Managing Editor

Nation's Cities

National League of Cities

1620 Eye Street, N.W.

Washington, D.C. 20006

202/293-6799

Mr. Ernest C. Baynard

Computer \& Business Equipment

Manufacturing Association

1828 L Street, N.W.

Washington, D.C. 20036

$202 / 466-2288$

Mr. Robert M. Belmonte

Director of Purchasing

County of Bergen

County Administrative Building

Annex

355 Main Street

Hackensack, New Jersey 07601

201/646-3245

Mr. Allan W. Beres

Federal Supply Service, GSA

FCV

CMBg 4, Room 724

Washington, D.C. 20406

$703 / 557-1583$ 
Mr. Sol Berger

Director of Purchase

N.Y.C. Board of Education

Bureau of Supplies

44-36 Vernon Blvd.

Long Island City, N.Y. 11101

212/786-8800

Mr. Joseph G. Berke

Deputy Chief

Procurement Policy Area, ETIP

ADMIN A735

Washington, D.C. 20234

$301 / 921-3171$

Mr. William A. Bickerstaff

Specifications Analyst

Va. Dept. of Highways \& Transportation

$1221 \mathrm{E}$. Broad Street

Richmond, Virginia 23219

804/770-5179

Mr. John T. Bland

Director, Materials Evaluation

and Development Laboratory (FML)

Federal Supply Service

General Services Administration

Washington, D.C. 20405

202/282-7051

Mr. Arnold H. Brogan

Director, Value Management

Office of Management Planning and Program Analysis

General Services Administration, FSS

Crystal Mall Building 4

Washington, D.C. 20406

$703 / 557-1583$

Mr. T. J.. Bundy

Eastern Regional Manager

Lexitron Corporation

1500 Wilson Blvd.

Rosselyn, Virginia 22209

$703 / 527-0654$

Mr. Warren Burkett

Writer for ETIP/NBS

ADMIN A735

Washington, D.C. 20234

$301 / 921-3465$ 
Dr. John C. Burt

Consultant

Committee for Economic Development

3573 Ft. Meade Road, Apt. \#209

Laurel, Maryland 20810

301/725-5249

Mr. Thomas A. Camp

Sears Laboratories, Dept. 817

Sears, Roebuck \& Co.

925 S. Homan Avenue

Chicago, Illinois 60607

312/265-4074

Mr. Hugh M. Carleton, C.P.P.O.

CPM (NASPO

Deputy Secretary, Procurement

Commonwealth of Pennsylvania

Room 414, North Office Bldg.

Harrisburg, Pennsylvania 17125

717/787-5995

Mr. Paul M. Carren

Peat, Marwick, Mitchell \& Co.

1025Connecticut Avenue

Washington, D.C. 20036

202/223-9525

Mr. Roger F. Carroll, Jr.

Deputy Asst. Commissioner

Office of Standards and Quality Control

General Services Administration, FSS

Washington, D.C. 20406

$703 / 557-8660$

Mr. Frank J. Casey

Asst. P.A.

Metropolitan Sanitary District

of Greater Chicago

$100 \mathrm{E}$. Erie Street

Chicago, Illinois 60611

312/751-5763

Mr. William T. Cavanaugh

Managing Director

American Society for Testing \& Materials 1916 Race Street

Philadelphia, Pennsylvania 19103 
Mr. Richard T. Cheslow

Project Director

Logistics Management Institute

4701 Sangamore Road

Washington, D.C. 20016

301/229-1000

Mr. Dennis Ciboch

Administrative Operations Manager

Builder and Contract Sales

Whirlpool Corporation

Ad Center

Benton Harbor, Michigan 49022

616/926-3591

Mr. James M. Cloney

Vice Pres., Government Relations

GAF Corporation

4601 Lydell Road

Cheverly, Maryland 20781

$301 / 322-3130$

Mr. Alfred A. Cooke

Senior Subcontract Specialist

Westinghouse Electric Corp, ESSD

llll Schilling Road

Hunt Valley, Maryland 21031

$301 / 667-5421$

Mr. Raymond S. Cooper

Director, Design Innovations Task Force

Department of Supply and Services

Canadian Government

Room 616, MacDonald Building

Ottawa, Canada

KIA OH5

992-9094

Mr. Robert M. Cornett (NASPO)

Director of Special Projects

The Council of State Governments

Iron Works Pike

Lexington, Kentucky 40511

$606 / 252-2291$

Mr. Donald W. Corrigan

NBS

18907 Mills Choice Road

Gaithersburg, Maryland 20760

$301 / 921-3694$ 
Mr. Frank P. Corso

Government Sales

Colgate Palmolive Research Labs.

909 River Road

Piscataway, New Jersey 08854

Dr. Alexander R. Craw

Technical Analysis Division

National Bureau of Standards

Washington, D.C. 20234

$301 / 921-3583$

Mr. John T. Cronin

Procurement Services Coordinator

State and Local Government

Eastman Kodak Co.

343 state Street

Rochester, New York 14650

716/724-4501

Mr. Walter V. Cropper

Director, Developmental operations

American Society for Testing \& Materials

1916 Race Street

Philadelphia, Pennsylvania 19103

$215 / 569-4200$

Mr. Herman Crystal

Deputy Director

Division of Purchase

\& Property

State of New Jersey

State House

Trenton, New Jersey 08625

609/292-4724

Mr. Louis E. Desmond

Washington Manager

Defense Products

Caterpillar Tractor Co.

Suite 720, Executive Bldg.

1030 15th Street, N.W.

Washington, D.C. 20034

202/296-6704 
Mr. James E. Doremus

Deputy Purchasing Agent

Central Services -

Prince George's County

Purchasing Division

Court House Annex

Upper Marlboro, Maryland

301/627-3000 Ext. 535

Mr. William F. Drake

Director Gov't. Operations

Ford Industries, Inc.

5034 Wisconsin Avenue, N.W.

Washington, D.C. 20016

202/966-8931

Mr. James H. Durfee

Senior Scientist

Braddock, Dunn and McDonald, Inc.

1920 Aline Avenue

Vienna, Virginia 22180

703/893-0750

Mr. Stan Durkee

Environment Protection Specialist

Office of Noise Abatement \& Control

U.S. Environmental Protection Agency

Crystal City

Arlington, Virginia 20460

$703 / 557-7760$

Mr. George Dyevoieh

FSS/GSA

26 Federal Plaza, Room 2800

New York, New York 10007

$212 / 264-2690$

Mr. W. L. Eckbreth

Director

Office and Photographic Equipment Div.

Federal Supply Service

General Services Administration

Crystal Mall Building \#4, Rm 808

Washington, D.C. 20406

$703 / 557-8377$

Mr. Ellis

Writer for ETIP/NBS

ADMIN A735

Washington, D.C. 20234

$301 / 921-3171$ 
Mr. Glenn K. Ellis

Technical Util. Analyst

Energy Research and Development Admin.

Room B-127

Washington, D.C. 20545

301/973-5156

Mr. Edward W. Erne

Chief, Standards \&

Specifications Division

Bureau of Standards

Commonwealth of Pennsylvania

P.O. Box 3361

Harrisburg, Pennsylvania 17125

$717 / 787-3860$

Mr. Theodore J. Fody

Chief

Procurement Plicy Area, ETIP

ADMIN A735

Washington, D.C. 20234

301/921-3171

Mr. Gerald G. Geer

Director, Division of Purchasing

The State of Washington

216 General Administration Building

Olympia, Washington 98504

206/753-6461

Mr. James W. Goff

Director

School of Packaging

Michigan State University

E. Lansing, Michigan 48824

517/353-6462

Ms. Linda Goldstein

Para-Legal

Baker, Nostetler, Frost \& Towers

500 Southern Building

Washington, D.C. 20005

202/393-5360

Dr. William H. Goldwater

Assistant to Associate Director

Office of Collaborative Research

National Institutes of Health

Bethesda, Maryland 20014

301/496-2241 
Mr. Donald Gross

Contracts Administrator

Hewlett-Packard Company

2 Choke Cherry Road

Rockville, Maryland 20850

301/948-6370

Mr. Elton Hailey

Director, General Products Division (FPG)

Federal Supply Service

General Services Administration

Washington, D.C. 20406

703/557-7901

Mr. Albert H. Hall

Executive Vice President

NIGP

1001 Connecticut Avenue, N.W.

Washington, D.C. 20036

202/331-1357

Mr. S. J. Hanna, Chief

Purchasing Bureau

Dept. General Services

State of Maryland

301 W. Preston Street

Baltimore, Maryland 21201

301/383-3644

Mr. H. D. Harback

Chief Elect., Mach. \& Inst. Br/FSS

General Services Administration

Washington, D.C. 22406

Mr. R. E. Hasselman

Caterpillar Tractor Company

Washington Marketing Representative

1030 l5th Street, N.W.

Suite 720

Washington, D.C. 20005

202/296-6704

Mr. James A. Hawkins

Manager, Government \& Education

Markets Services

Eastman Kodak Co.

500 l2th Street, S.W.

Washington, D.C. 20024

202/554-9300 
Mr. Robert G. Hendrickson

Technical Analysis Division

National Bureau of Standards

Washington, D.C. 20034

301/921-3694

Mr. Ray Hill

Acting Director, Procurement Policy

\& Procedures Division

Federal Supply Service

General Services Administration

Crystal Mall Building 4

Washington, D.C. 20406

$703 / 557-8543$

Mr. Ross E. Hofmann

Ross Hofmann Associates

2908 Salzedo Avenue

Coral Gables, Florida 33134

Mr. John F. Hogan, Jr.

Washirgton Rep. - Govt. Marketing

The Goodyear Tire \& Rubber Co.

Suite 902

Ring Building

Washington, D.C. 20036

202/331-9500

Mr. J. Hueniken

Design Consultant

Office of Design

Dept. of Industry, Trade \& Commerce

Ottawa, Canada KlA OH5

Tel. 992-4494

Mr. Jonas K. R. Jefferies

Buyer, Bureau of Purchases

Commonwealth of Pennsylvania

P.O. Box 1365

Harrisburg, Pennsylvania 17125

$717 / 787-4352$

Mr. Wilbur F. Jenson

Market Manager, Audio-Visual Products

Mincom Division

$3 \mathrm{M}$ Company - 3M Center

St. Paul, Minnesota 55101

612/733-4363 
Mr. Philip S. Johnson

Electronic Engineer

Institute of Computer Science \& Technology National Bureau of Standards

Washington, D.C. 20234

301/921-3724

Ms. Jennifer Johnston

Special Assistant to the Commissioner

Federal Supply Service, GSA

Room 1138, Crystal Mall, Bldg. \#4

Washington, D.C. 20406

703/557-1642

Mr. John D. Ketch

Executive Vice President

Golden Oak, Inc.

2392 E. 48th Street

Los Angeles, California 90058

$213 / 589-9181$

Mr. Charles A. Knapp

Property Management Specialist

Office of the Secretary

Dept. of HEW

Rm. G322 - So. Bldg.

330 Independence Avenue

Washington, D.C. 20201

202/245-0601

Mr. Ted W. Lashof

Laboratory Evaluation Technology Section

National Bureau of Standards

Washington, D.C. 20234

301/921-2983

Mr. Frank Leach

V.A. Central office

Supply Service (135)

810 Vermont Avenue, N.W.

Washington, D.C. 20420

202/389-3306

Dr. Jordan D. Lewis

Director, ETIP/NBS

ADMIN A735

Washington, D.C. 20234

301/921-3185 
Mr. Thomas E. Lewis

Manager, Government Technical

Services

Armstrong Cork Co.

1666 K street, N.W. - Suite 205

Washington, D.C. 20006

202/296-2830

Mr. David Littleton

Ass't Director, Procurement

U.S. General Accounting Office

Washington, D.C.

202/386-5430

Mr. Donald A. Loren

Standards Engineer

Purchasing Division

Prince George's county

Court House Annex

Upper Marlboro, Maryland 20780

301/627-3000 Ext. 507

Mr. W. B. MacDonald

General Motors Corp.

Government \& Defense Sales

1660 L Street, N.W.

Washington, D.C. 20036

202/659-5060

Ms. Emily A. MacFall

Economist

Public Building Service/

Special Studies

General Services Administration

18th \& F streets, N.W.

Washington, D.C. 20405

202/343-3821

Mr. Ralph S. McCrea

Government Contracting Manager

IBM Corporation

4301 Connecticut Avenue, N.W.

Washington, D.C. 20008

202/686-3790

Mr. D. McCurrach

Executive V.P.

National School Supply \&

Equip. Assn.

1500 Wilson Blvd.

Arlington, Virginia 22209

$703 / 524-8819$ 
Mr. William R. McQuiston

Contract Administration Manager

Tektronix, Inc.

P.O. Box 500

Beaverton, Oregon 97077

503/644-0161

Mr. Troy C. Martin

State Board of Control

111 East 17 th Street

P.O. Box 13047

Capitol Station

Austin, Texas 78711

$512 / 475-2232$

Mr. Willard F. Martin

Manager, National Government

Marketing

Graphic Products Division

Itek Corporation

200 North Glebe Road

Suite 900

Arlington, Virginia 22203

$703 / 524-5820$

Dr. Otto B. Martinson

Project Director

Logistics Management

4701 Sangamore Road

Washington, D.C. 20016

202/229-1000

Mr. Robert G. Meisner

Assistant Director $\mathrm{S} / \mathrm{T}$

Procurement and systems Acquisition

Division

U.S. General Accounting Office

441 G Street, N.W. (Rm 6079)

Washington, D.C. 20548

Mr. Larry Merhaut

Government Sales Manager

Rockwell International

131 Park Street, N.E.

Vienna, Virginia 22170

$703 / 281-4388$ 
Ms. Karen Merrill

Research Associate/Govt. Affairs

Westinghouse Air Brake Co.

120012 th Street, N.W.

Suite 916

Washington, D.C. 20036

202/293-1289

Mr. William H. Metzger

Manager, Government Services

GAF Corporation

140 W. 5lst Street

New York, New York 10020

212/582-7600

Mr. Robert A. Miller

Buyer, Commonwealth of Pennsylvania

Bureau of Purchases

P.O. Box 1365

Harrisburg, Pennsylvania 17125

717/783-1282

Mr. Reuben T. Morgan

Quality Control Division

FSS/GSA

Rm. 524, Bldg. 4

Arlington, Virginia 20406

$703 / 557-7570$

Mr. Karl G. Newell, Jr.

Acting Chief, Standards Development

Services Section

Engineering \& Product Standards

Division

National Bureau of Standards

Tech B-166

Washington, D.C. 20234

$301 / 921-2356$

Mr. R. C. Newton

Marketing Manager

Appliances \& Building Materials

Governmental, Dept. $733 \mathrm{G}$

Sears, Roebuck and Company

Sears Tower

Chicago, Illinois 60684

312/875-6932 
Mr. George B. O'Gorman, C.P.P.O.

Assistant Director

Bureau of Purchases

Commonwealth of Pennsylvania

P.O. Box 1365

Harrisburg, Pennsylvania 17125

$717 / 787-2841$

Mr. Myron A. Olstein

Public Technology, Inc.

1140 Connecticut Avenue, N.W.

Washington, D.C. 20036

202/223-8240

Mr. Jan N. Ostborg

Mgr. Furniture Egr.

Harvard Interiors Mfg. Co.

4321 Semple Avenue

St. Louis, Missouri 63120

$214 / 382-5590$

Mr. Richard T. Penn

Deputy Director, ETIP/NBS

ADMIN A735

Washington, D.C. 20234

301/921-3185

Mr. W. C. Petrie

Director, Furniture Packaging and Fibres Division

Federal Supply Service

General Services Administration

Crystal City

Washington, D.C. 20406

$703 / 557-7834$

Mr. Russell W. Piazza

Director of Purchasing

County of Montgomery - Pennsylvania

Courthouse

Norristown, Pennsylvania 19404

215/275-5000

Mr. Chapell D. Pierce

Assistant Director of Technical Services

Gas Appliance Manufacturers Assn.

1901 N. Fort Myer Drive

Arlington, Virginia 22209

$703 / 525-9565$ 
Dr. Orville L. Pierson

Codes and Standards

Rohm and Haas Company

Independence Mall West

Philadelphia, Pennsylvania 19105

215/592-2583

Mr. George O. Pringle

Chrysler Corporation - Airtemp Div.

1600 Webster Street, P.O. Box 66

Dayton, Ohio 45401

513/461-5100 Ext. 2369

Mr. Paul Rezachek

State of Minnesota

Procurement Division

Standards \& Engineering Section

50 Sherburne - 112 Admin. Bldg.

St. Paul, Minnesota 55155

Mr. William H. Rockwell

Director, Certification

American National Standards Institute

1430 Broadway

New York, New York 10018

$212 / 868-1220$

Mr. Gene A. Rowland

Acting Chief

Engr. \& Product Stds. Div.

National Bureau of Standards

Washington, D.C. 20234

301/921-3731

Mr. Kenneth H. Russell

Executive Director of Marketing and Sales

Plastic Reel Corp of America

$650 \mathrm{~S}$. Commercial Avenue

Carlstat, New Jersey

201/933-9125

Mr. Charles "Sid" Saunders

Marketing Representative

GAF Corporation

4601 Lydell Road

Cheverly, Maryland 20787

$301 / 322-3130$ 
Mr. George Saunders

Acting Deputy Commissioner

Federal Supply Service

General Services Administration

Washington, D.C. 20406

703/557-8688

Dr. Robert W. Shaw, Jr.

Research Director

Booz-Allen \& Hamilton Inc.

Booz-Allen Research Division

4733 Bethesda Avenue

Bethesda, Maryland 20014

$301 / 656-2200$

Mr. Donald B. Sheeley

Director Central Services

Baltimore county

Towson, Maryland 21204

$301 / 494-2230$

Mr. John Short

Director, State Bureau of

Purchases and Services

State of Wisconsin, Rm. 211

1. W. Wilson Street

Madison, Wisconsin 53702

$608 / 262-1558$

Mr. Paul Simpson

Procurement Analysis

Department of the Treasury

Office of Administrative Programs

1625 Eye Street, N.W. - Room 309

c/o Main Treasury Mail Room

13th \& Pennsylvania Avenue, N.W.

Washington, D.C. 20220

202/634-5021

Mr. William J. Slattery

for

Dr. Lawrence Eicher

Chief, Standards Information and Analysis section

National Bureau of Standards

Tech. Bll5

Washington, D.C. 20234

301/921-3235 
Mr. Laird Smith

Customer Market Research \#1023

Federal Supply Service

General Services Administration

Washington, D.C. 20406

$703 / 557-8640$

Mr. Louis Sorett

office of Federal Management Policy

General Services Administration

Washington, D.C. 20405

202/343-7528

Mr. Louis D. Sorrentino

Vice President

Corporate Marketing Services

Johns-Manville

2009 N. 14th Street

Arlington, Virginia 22201

$703 / 524-9250$

Mr. Lewis Spangler

National Institute of Governmental

Purchasing

1001 Connecticut Avenue, N.W.

Washington, D.C. 20036

202/331-1357

Mr. Donald E. Stiling

Management system Division

Procter and Gamble

Box 599

Cincinnati, Ohio

$513 / 562-4152$

Ms. Celene Strong

Booz, Allen \& Hamilton

4733 Bethesda Avenue

Bethesda, Maryland 20014

301/656-2200, Ext. 357

Mr. Harry M. Tayloe

Vice President

Logistics Management Institute

4701 Sangamore Road

Washington, D.C. 20016

202/229-1000 
Mr. John W. Taylor

John W. Taylor \& Associates

403 Aragona Drive

Oxen Hill, Maryland 20022

$301 / 567-3888$ or 3386

Mr. David Thompson

Government Sales Manager

Turf Products Division

Outdoor Power Equipment Group

The Toro Company

8111 Lyndale Avenue S.

Bloomington, Minnesota 55420

612/888-8801

Mr. William W. Thybony

Director for Procurement

Management

Office of Federal Management Policy

General Services Administration

Washington, D.C. 20405

202/343-6201

Mr. Michael J. Timbers

Commissioner

Federal Supply Service

General Services Administration

Crystal Mall, Bldg. \#4

Washington, D.C. 20406

703/557-8667

Mr. Bob J. Tomlinson

V.P. Gov't Sales

Airway Industries

1550 Patuxent Manor Court

Davidsonville, Maryland 21035

$301 / 261-4369$

Mr. Charles Travis

Consultant

4617 Randolph Drive

Annandale, Virginia 22003

$703 / 354-8898$

Dr. William E. Tucker

Technology Utilization Coordinator

Office of Industry and State

and Local Government Relations

Energy Research and Development

Administration

Washington, D.C. 20545

301/973-5156 
Mr. Frank Varasano

Booz-Allen \& Hamilton

4733 Bethesda Avenue

Bethesda, Maryland 20014

301/656-2200

Mr. H. D. Voegtlen

Asst. to the Vice President

Product Effectiveness

Hughes Aircraft Company

P.O. Box 90515

Bldg. 100, Mail stop \#45

Los Angeles, Calif. 90009

213/670-1515 Ext. 6495

Mr. C. L. Walleigh

Deputy Director

Defense Supply Service - Washington

Department of the Army

Pentagon, Rm 1D245

Washington, D.C. 20310

$703 / 0 x \quad 5-2007$

Mr. E. T. Watterud

Director, Standards Branch

Canadian Government Specifications Board

88 Metcalfe Street

Ottawa, Canada KlA Os5

613/996-1013

Ms. Martha Weems

Martha Weems, Ltd.

8238 Taunton Place

Springfield, Virginia 22152

$703 / 451-9571$

Mr. Ivan I. Weinstock

Publisher

Government Product News Magazine

614 Superior Avenue $W$.

Cleveland, Ohio 44113

216/696-0300

Mr. William B. Whitson, C.P.P.O.

Purchasing Agent

Division of Purchasing

Metropolitan Government of Nashville

and Davidson County

207 Court House

Nashville, Tennessee 37201

$615 / 747-4201$ 
Mr. Philip Williams

Manager - Product Testing

GF Business Equipment

Youngstown, Ohio 44501

216/746-7271

Mr. Leigh W. Willoughby

Director, Furniture and

Furnishings Division

Federal Supply Service

office of Procurement

General Services Administration

Washington, D.C. 20406

$703 / 557-8336$

Mr. Joseph R. Wilk

Sr. Research Associate

Logistics Management Institute

4701 Sangamore Road

Washington, D.C. 20016

301/229-1000 Ext. 42

Mr. J. H. Wilson

Specifications Development Coordinator

NASPO

The Council of state Governments

Iron Works Pike

Lexington, Kentucky 40511

$606 / 252-2291$

Mr. Einar Windingland

Director, Policy \& Procedures Div.

Office of Procurement

FSS (CM Bldg. 4)

General Services Administration

Washington, D. C.

$703 / 557-8231$

Honorable Hugh E. Witt

Administrator

Office of Federal Procurement Policy

Office of Management and Budget

Room $9001 \mathrm{NEOB}$

Washington, D.C. 20503 
Mr. Philip Wittenstein

Deputy Superintendent

Bureau of Supplies

Board of Education-City of New York

44-36 Vernon Boulevard

Long Island City, New York 11101

STillwell 6-8800

Mr. Warren K. Wright, Jr.

Deputy Director

Office of Central Services

Court House Annex

Upper Marlboro, Maryland 20870

301/627-3000 Ext. 452

Mr. John F. Wynn, Jr.

Spec. Asst. to the Asst. Commissioner

for Laboratory operations

Office of Standards \& Quality Control

General Services Administration/FSS

Crystal Mall, Bldg. \#4

Washington, D.C. 20406

703/557-7882

Mr. Edmond G. Young

Manager, Business Development

El Dupont DeNemoors \& Co.

1007 Market Street

Wilmington, Delaware 19898

$302 / 774-5844$

Mr. S. D. Zemansky

City Purchasing Agent

Bureau of Purchases

Department of Finance

City of Baltimore

IIl N. Calvert Street

Baltimore, Maryland 21202

301/396-5700 

PHOTOGRAPHS 



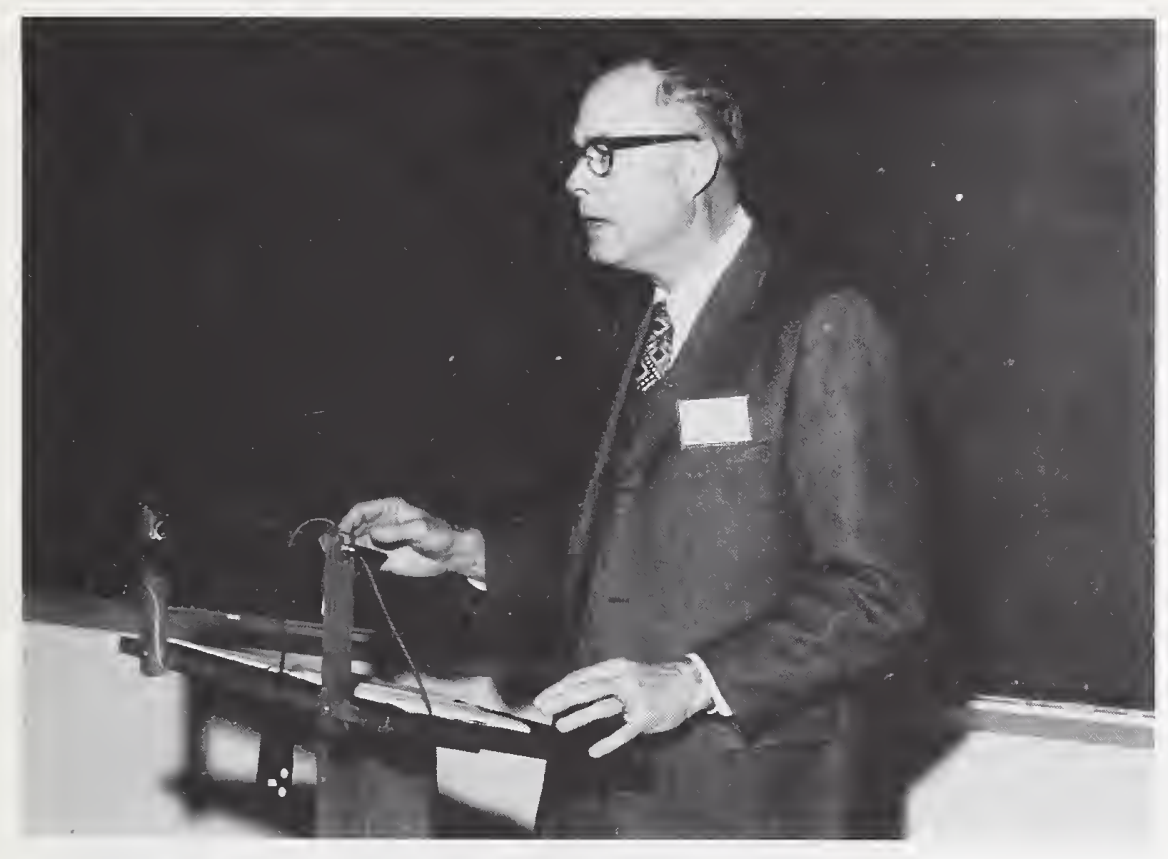

C. C. TRAVIS

Meeting of Chairpersons

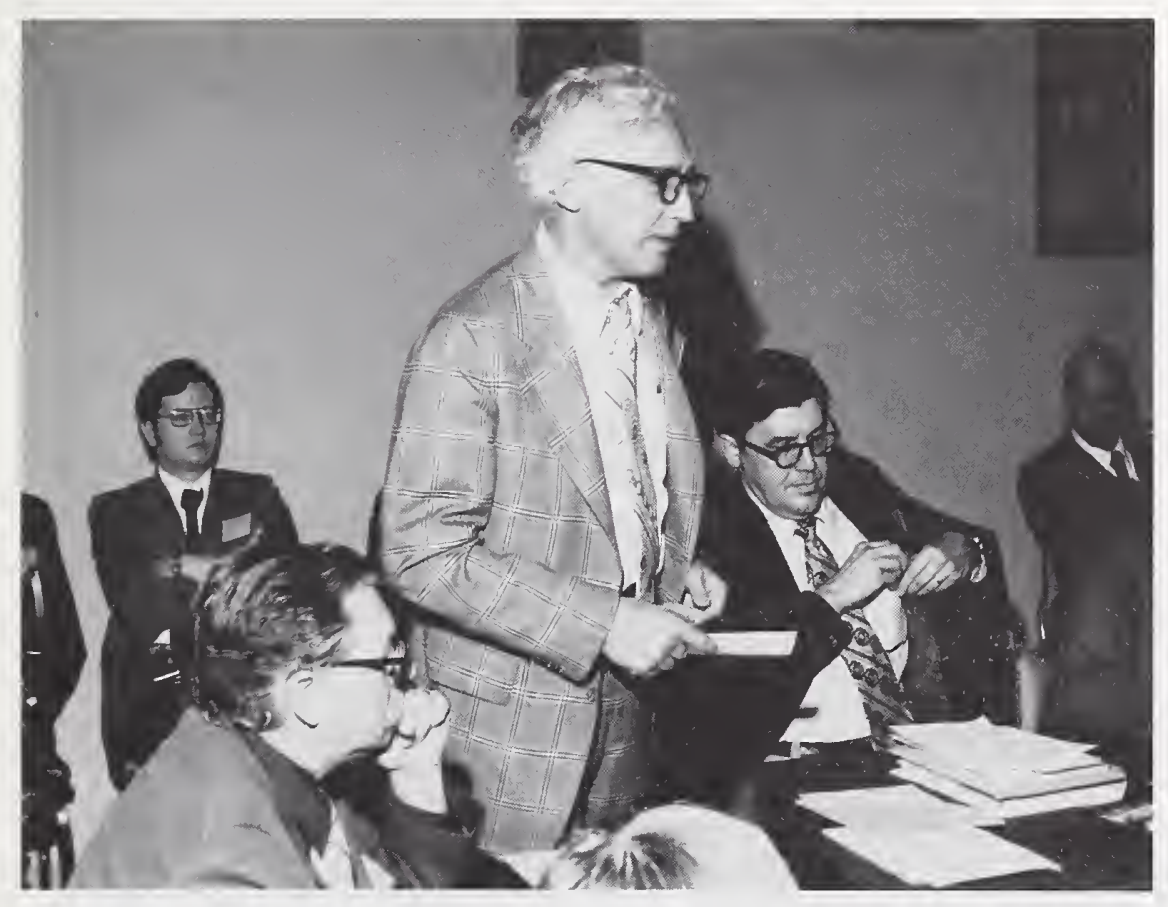

R. M. CORNETT

Secretary, NASPO

Meeting of Chairpersons 


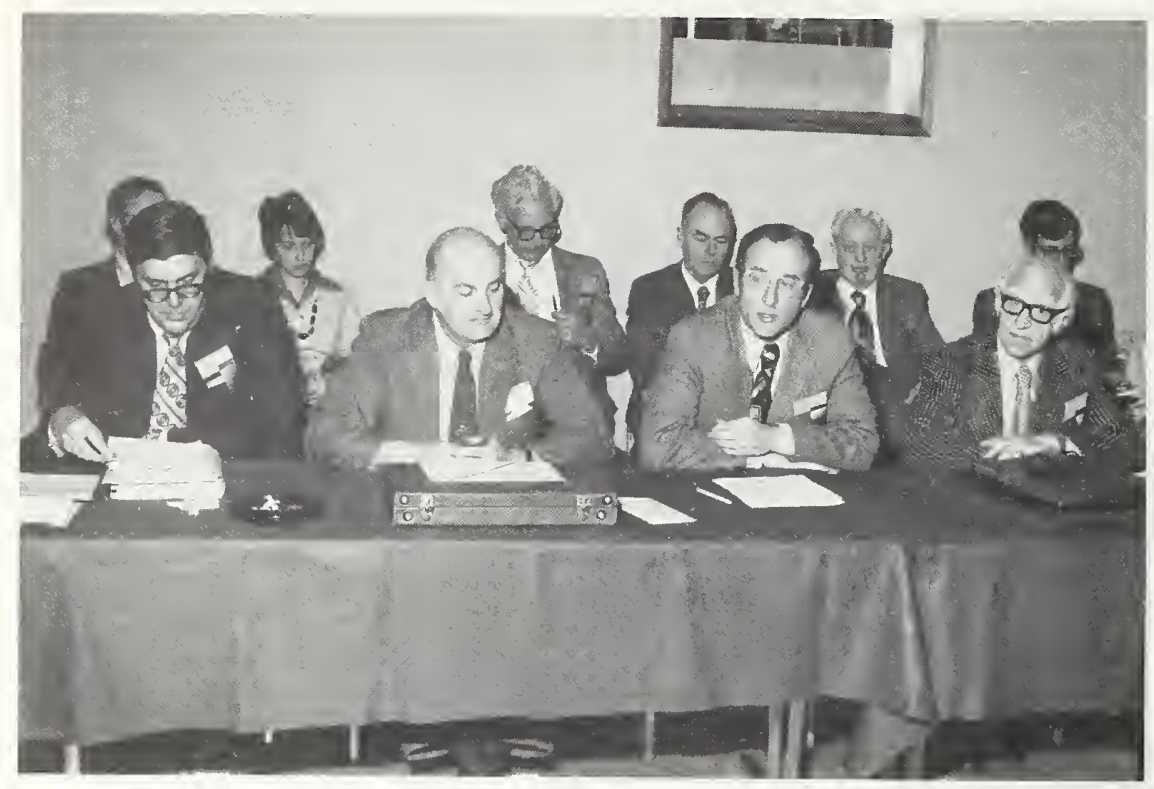

MEETING OF CHAIRPERSONS

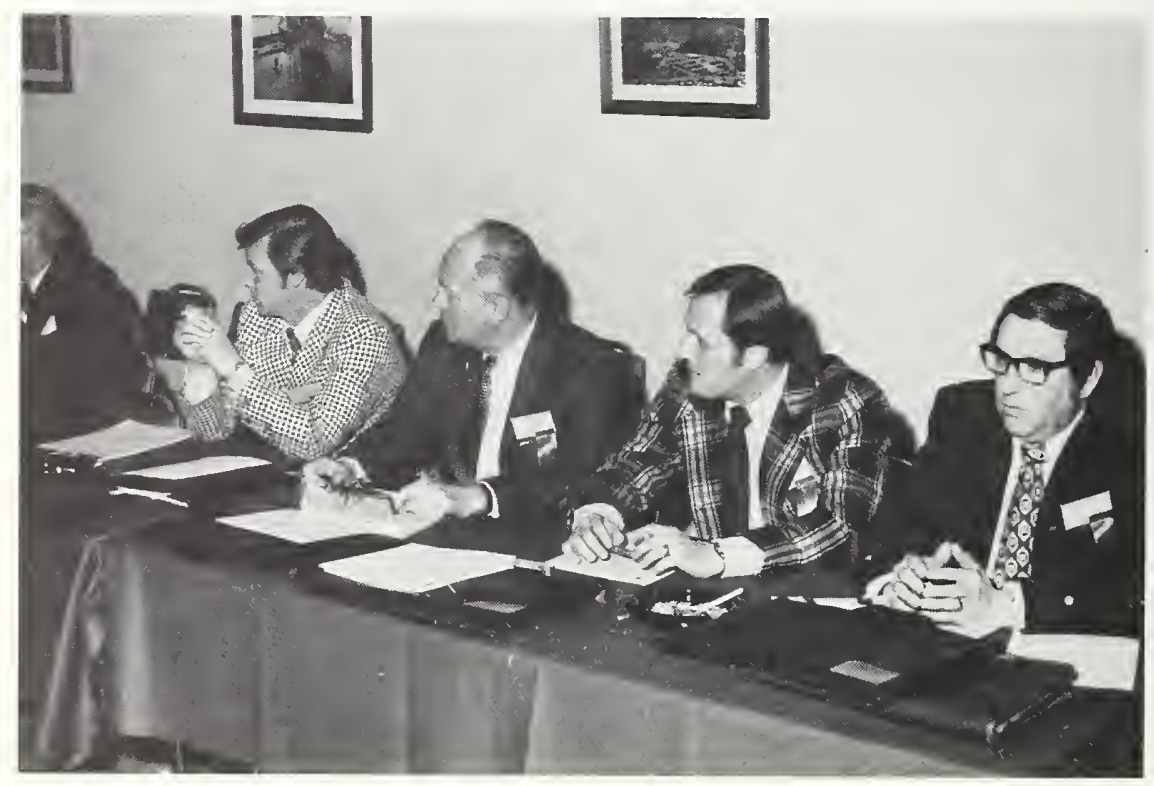

MEETING OF CHAIRPERSONS 


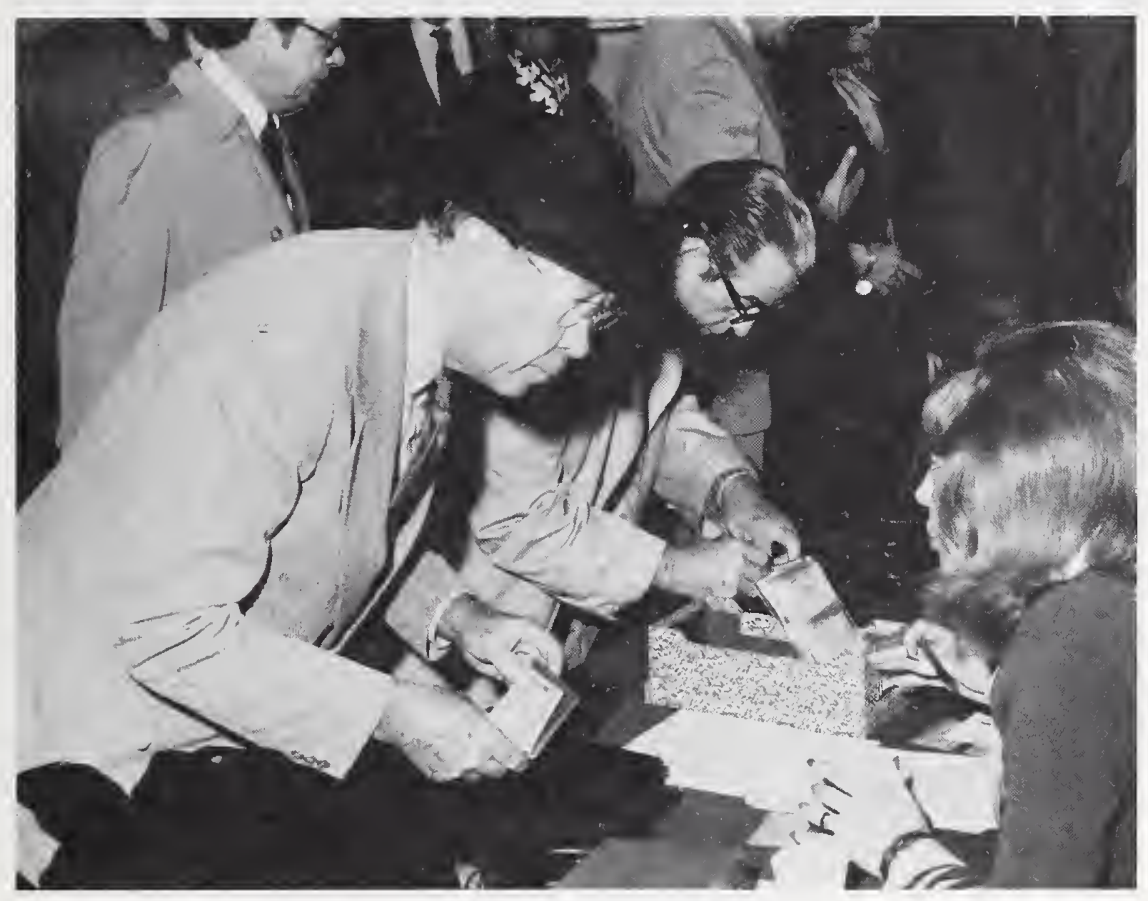

REGISTRATION

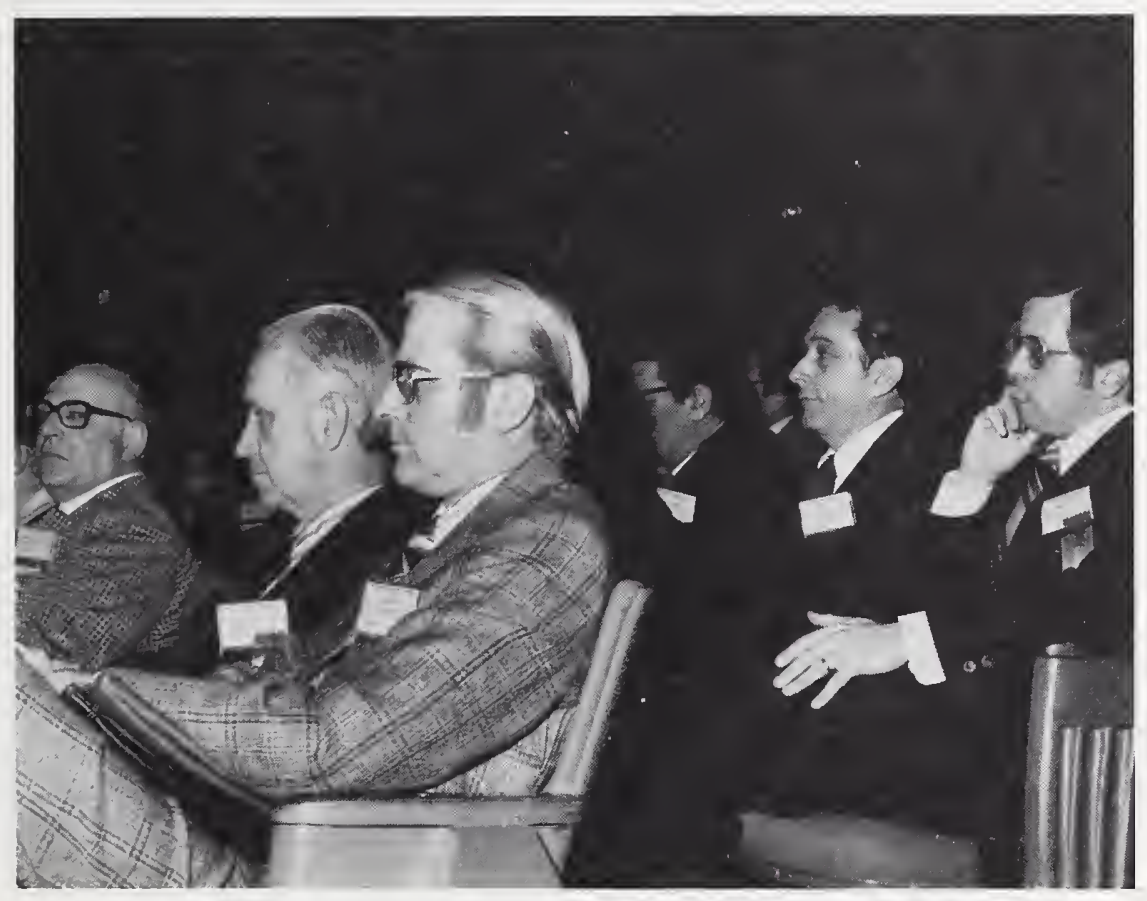

PLENARY SESSION 


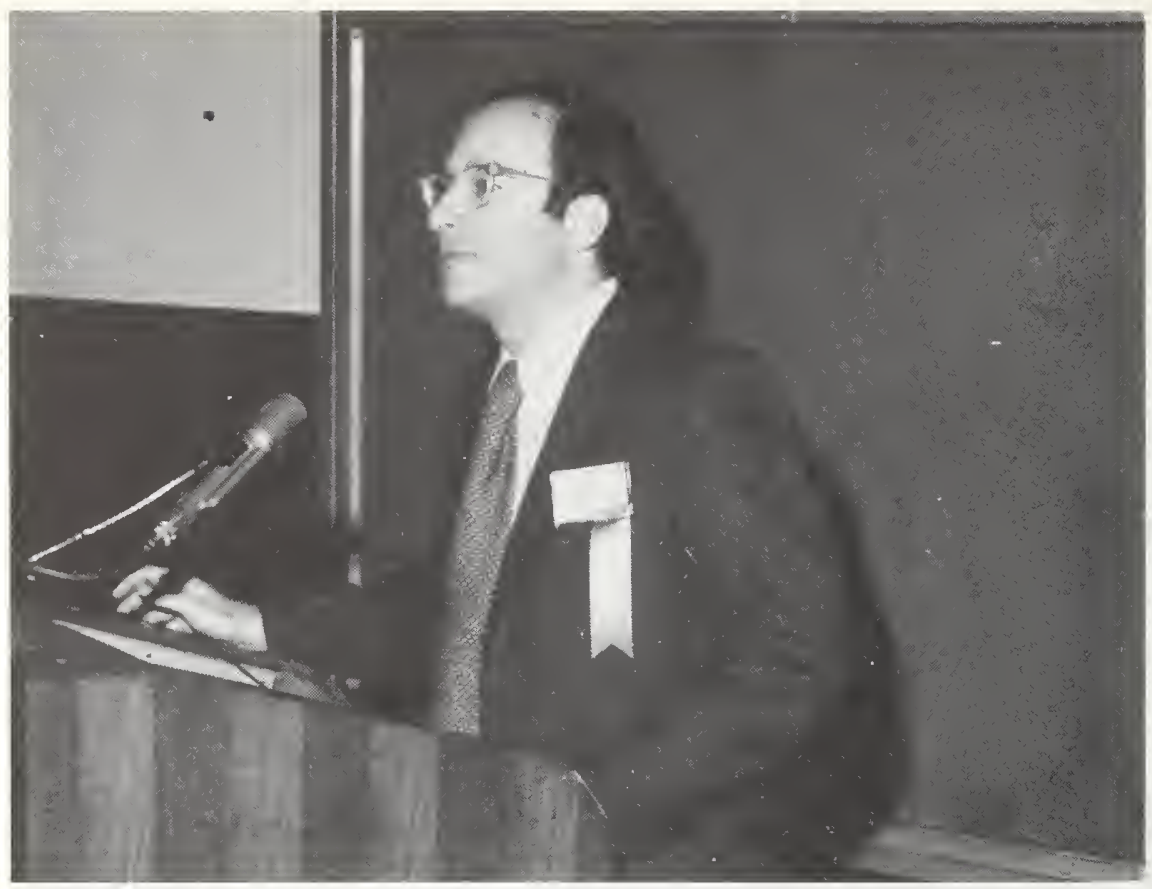

DR . JORDAN D. LEWIS

Director, Experimental Technology Incentives Program and General Conference Chairman

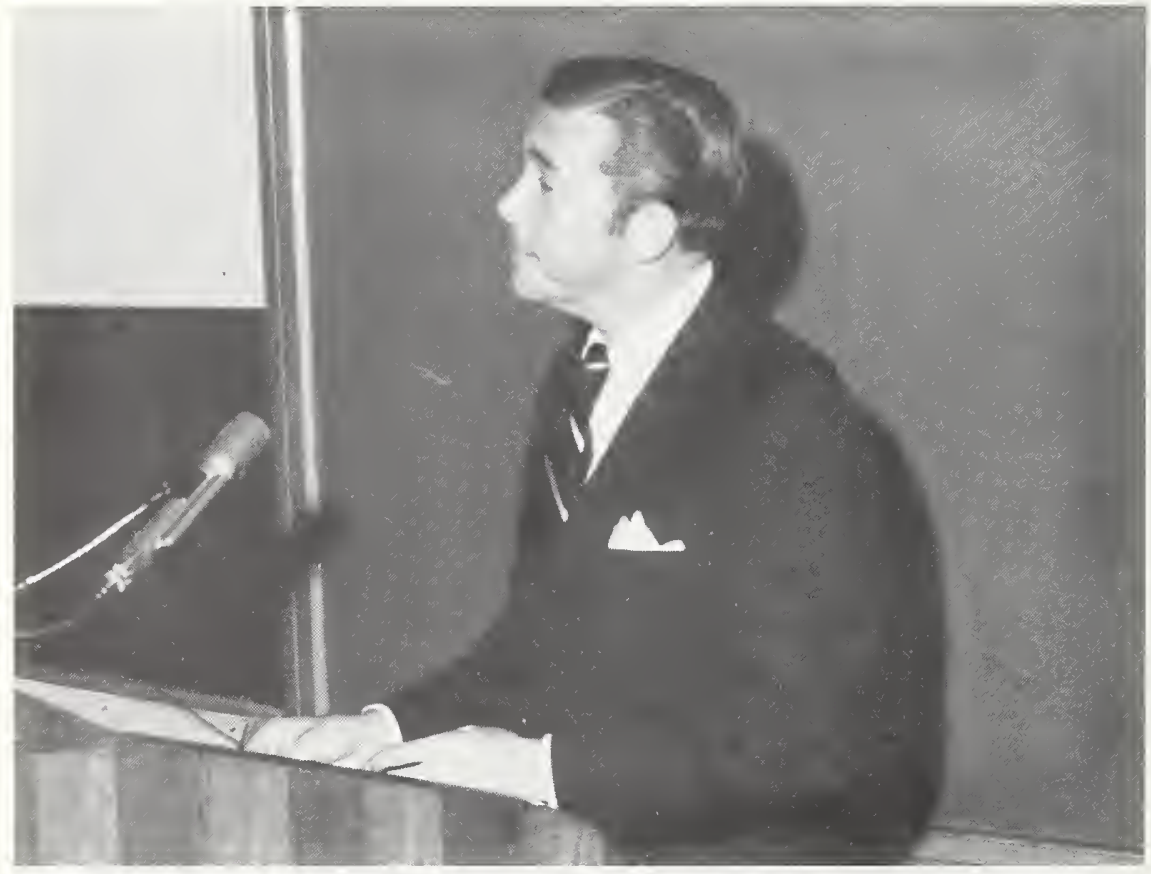

HONORABLE HUGH E. WITT Administrator, Office of Federal Procurement Policy/OMB 


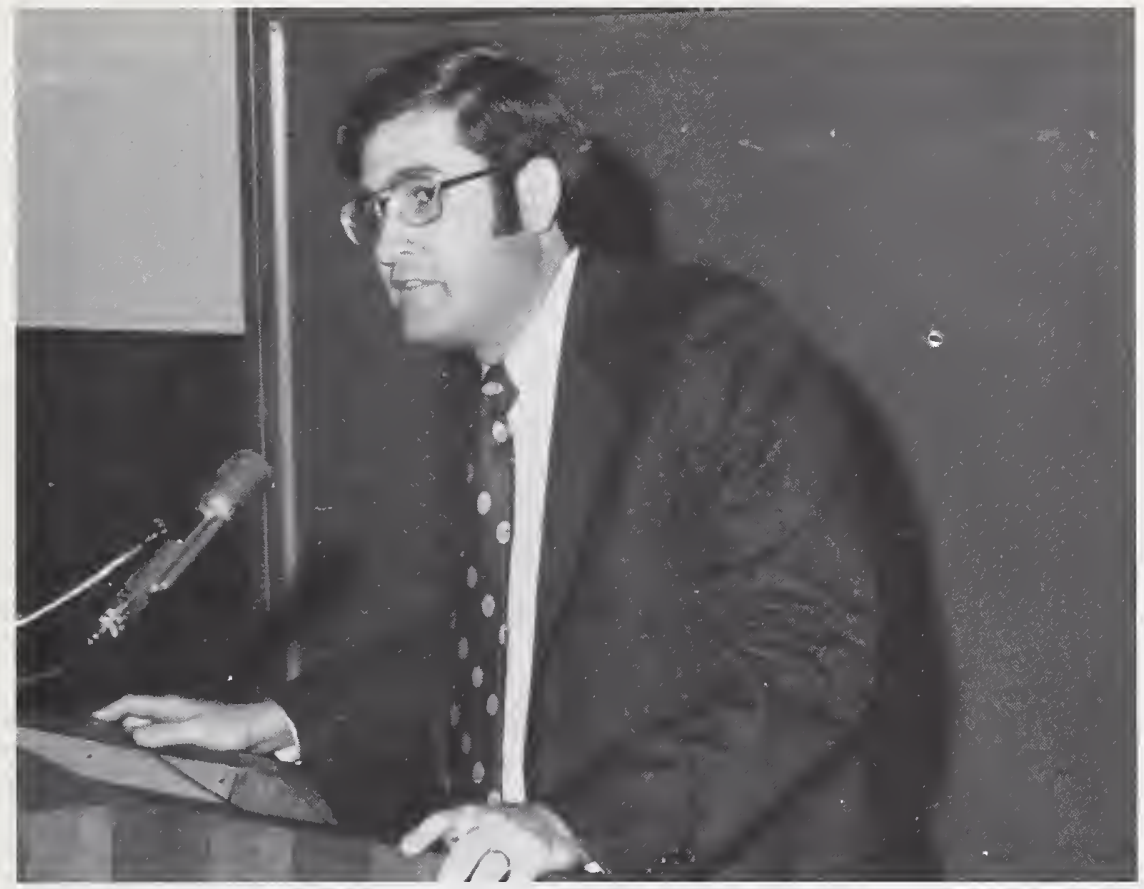

MR . MICHAEL J . TIMBERS

Commissioner, Federal Supply Service, GSA

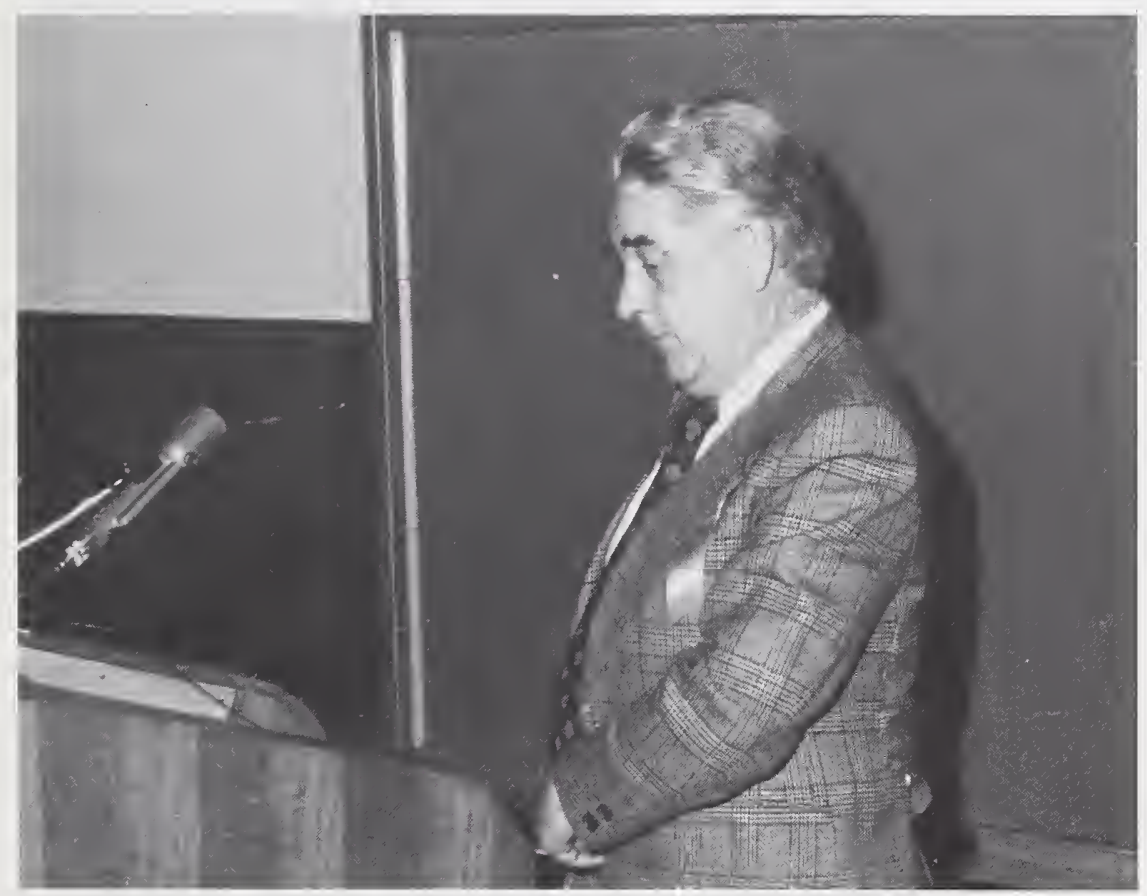

MR. WILLIAM T. CAVANAUGH Managing Director, ASTM and Keynote speaker 


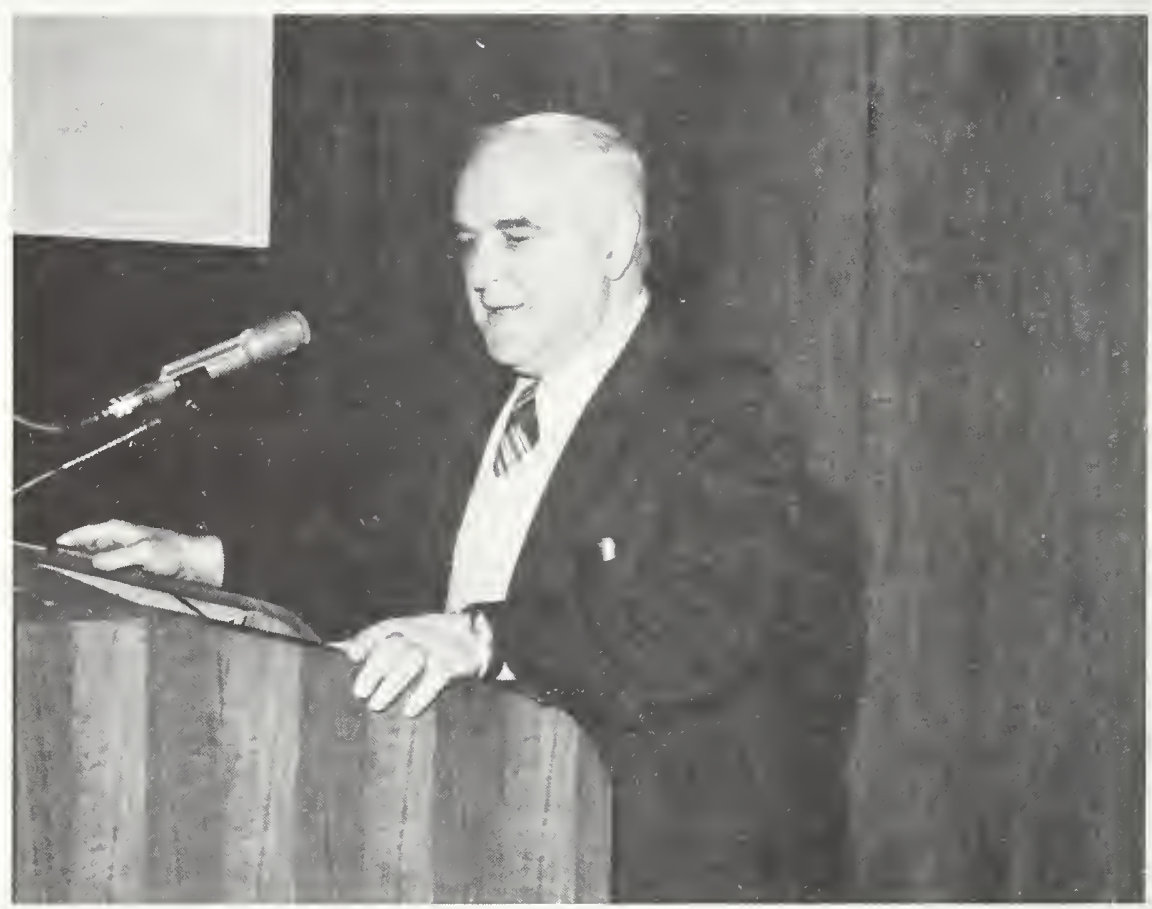

DR. ERNEST AMBLER

Deputy Director

National Bureau of Standards 


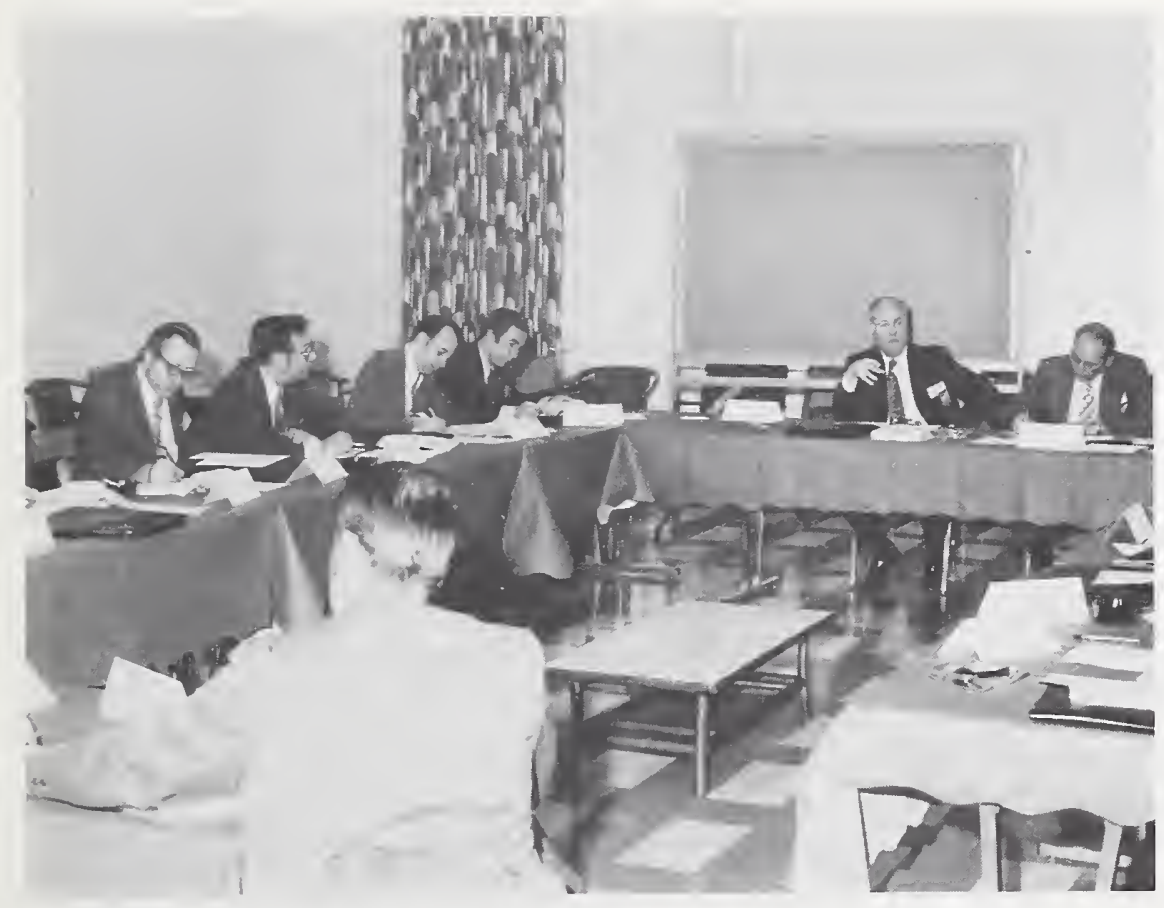

WORKSHOP $1 \mathrm{~A}$

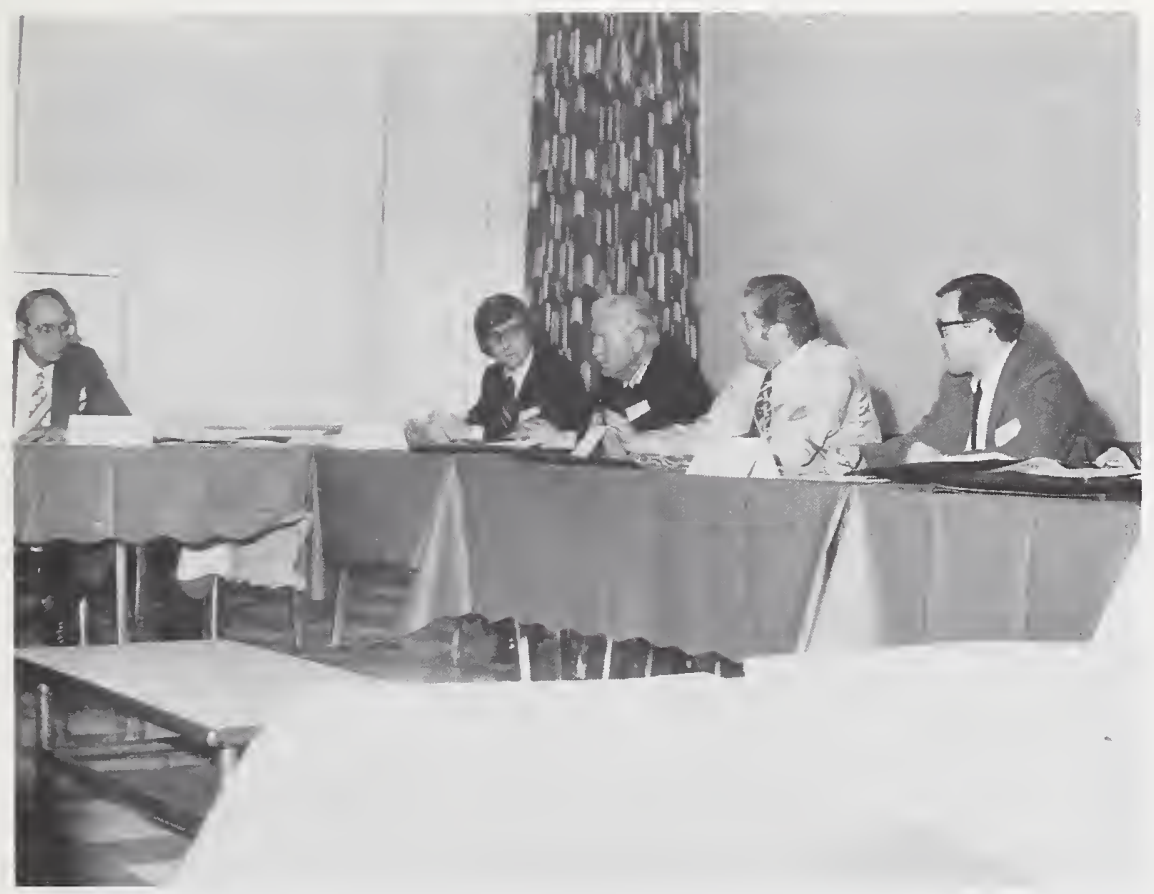

WORKSHOP IA 

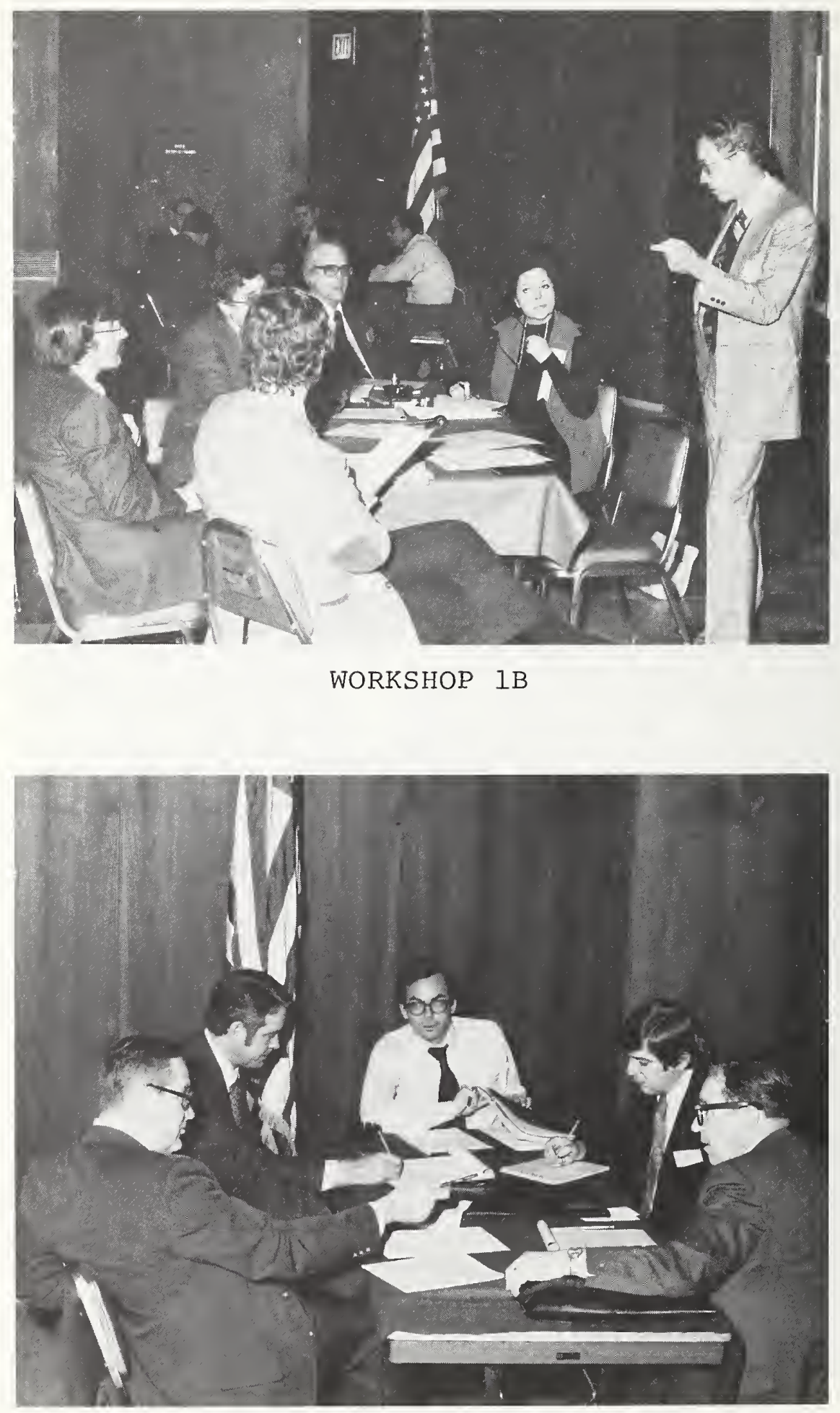

WORKSHOP IB 


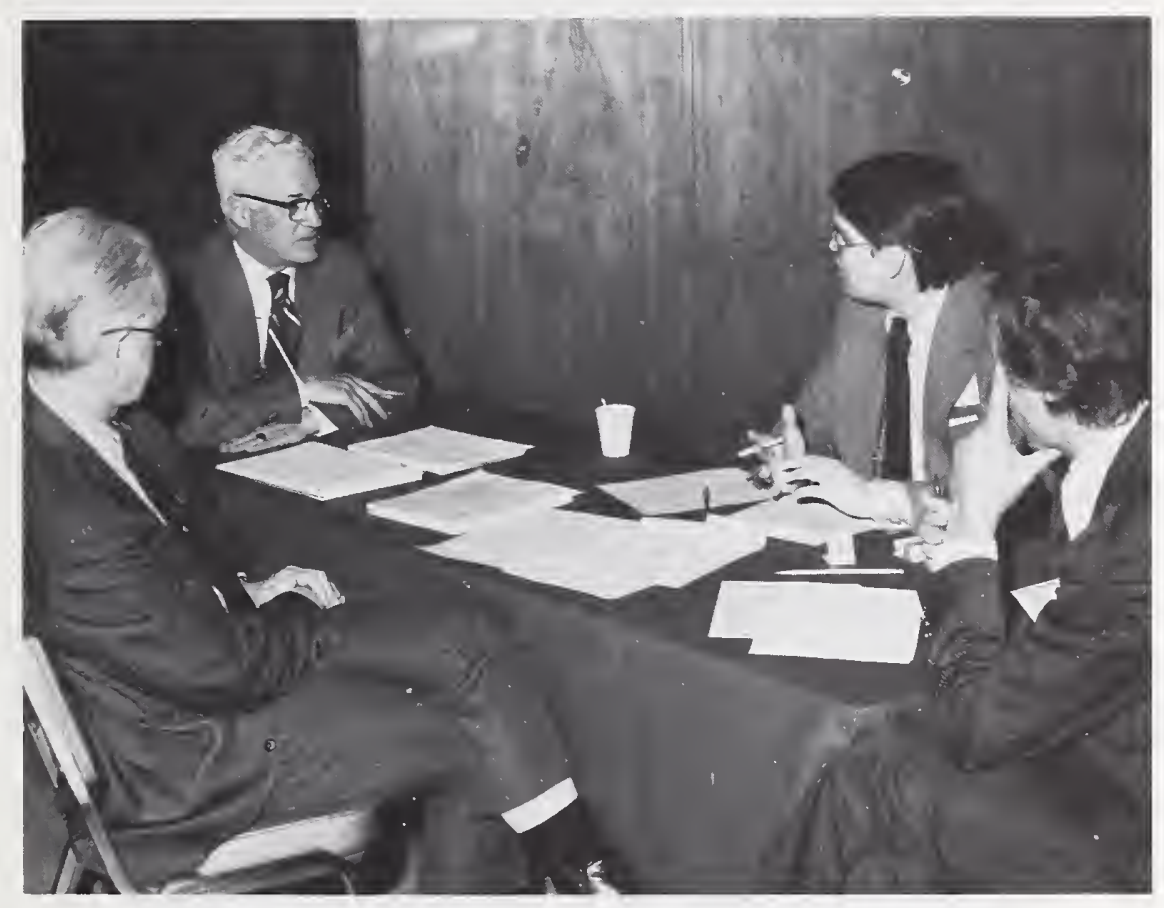

WORKSHOP IB

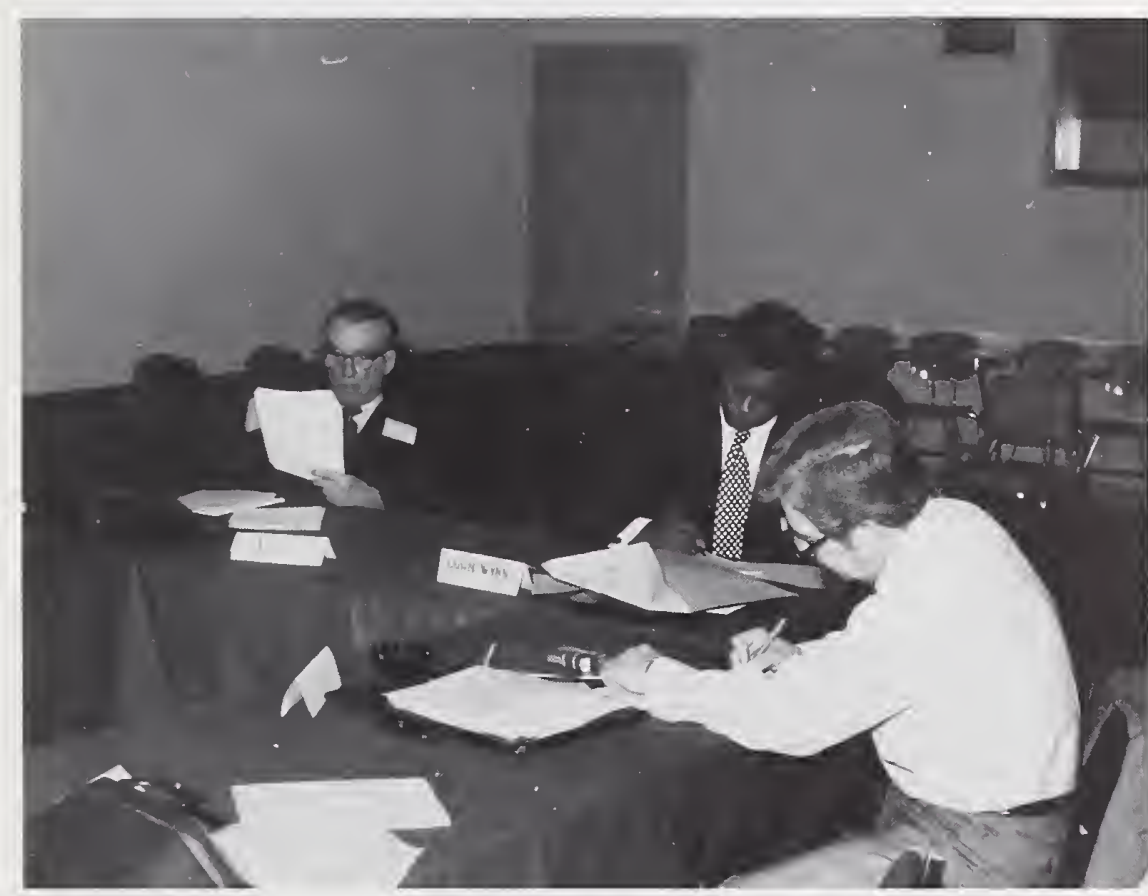

WORKSHOP $2 \mathrm{~A}$ 


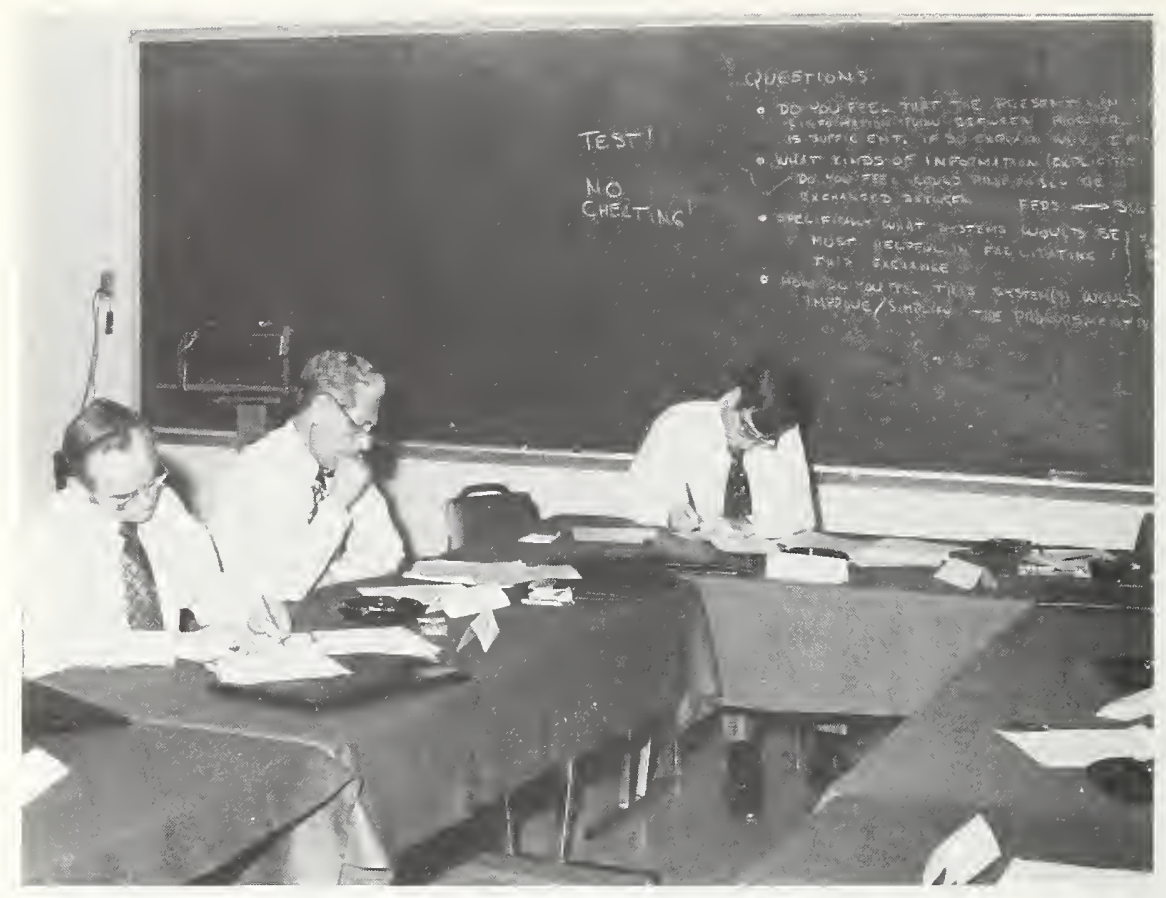

WORKSHOP $2 \mathrm{~A}$

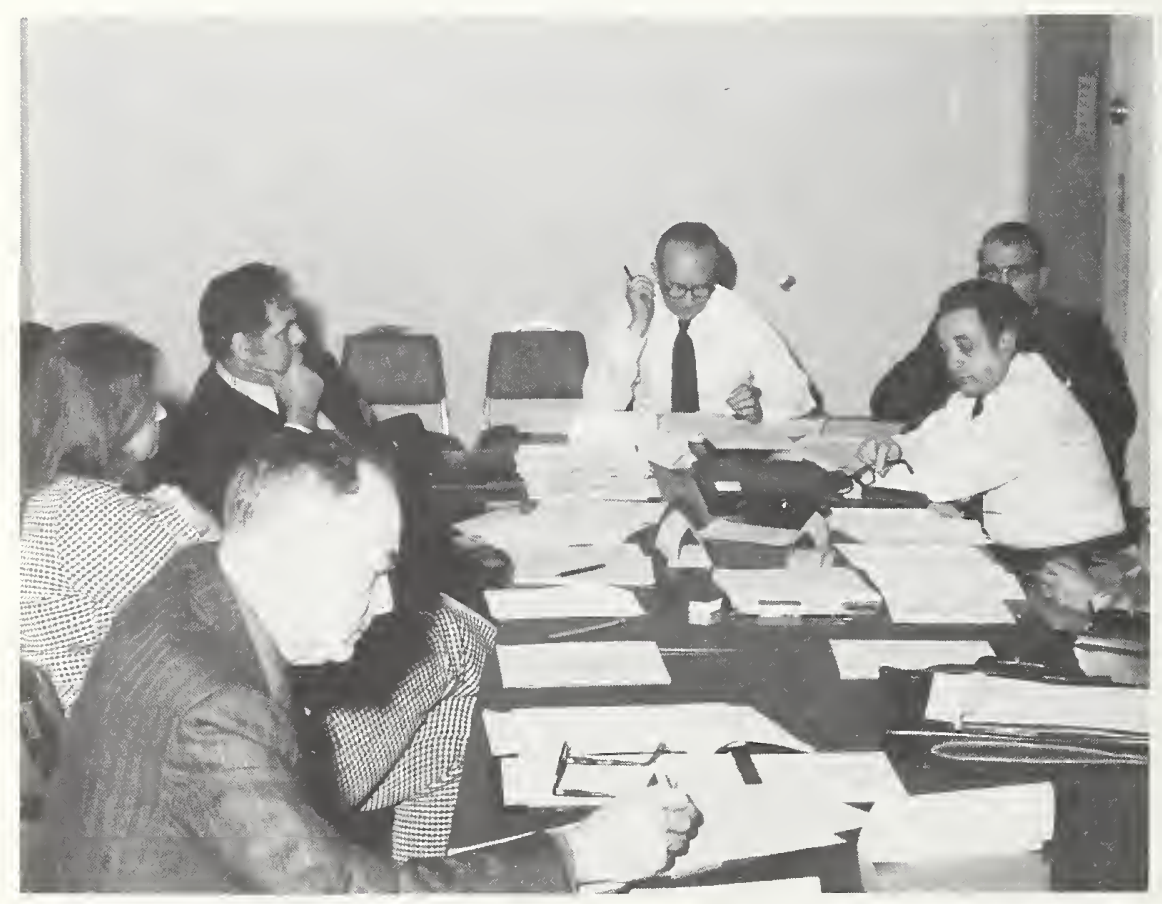

WORKSHOP $2 \mathrm{~B}$ 

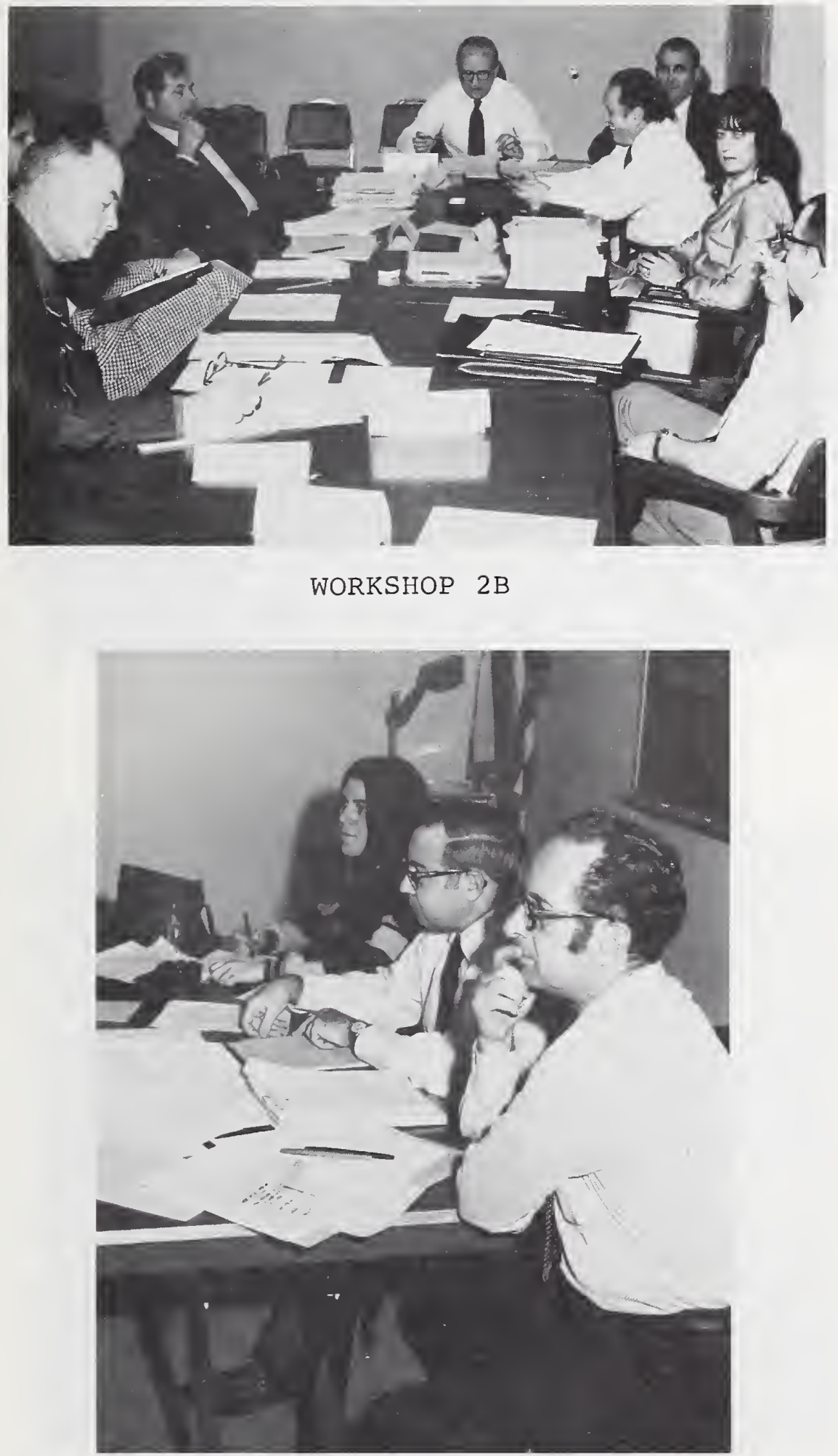

WORKSHOP 3 

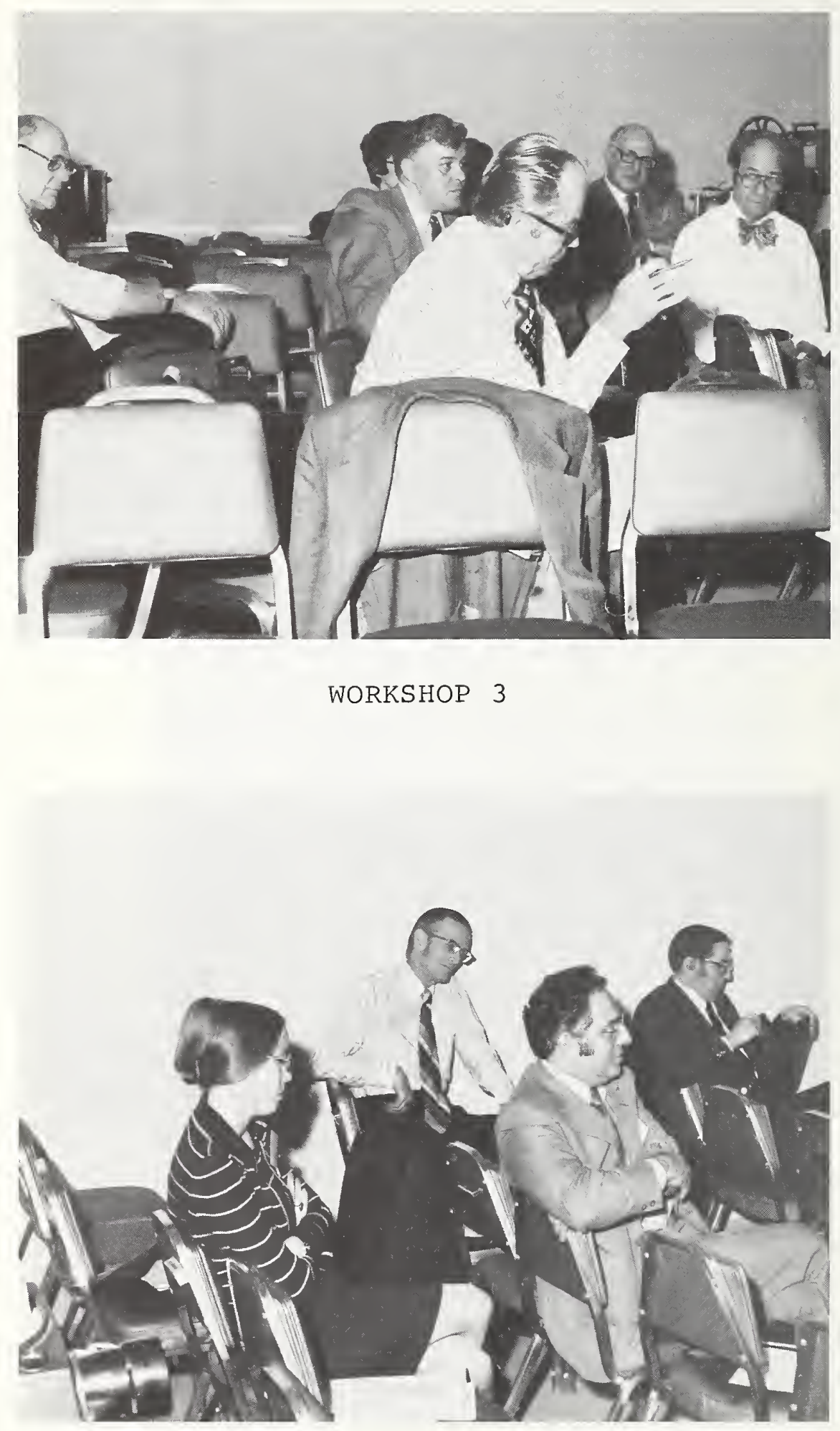

WORKSHOP 3 


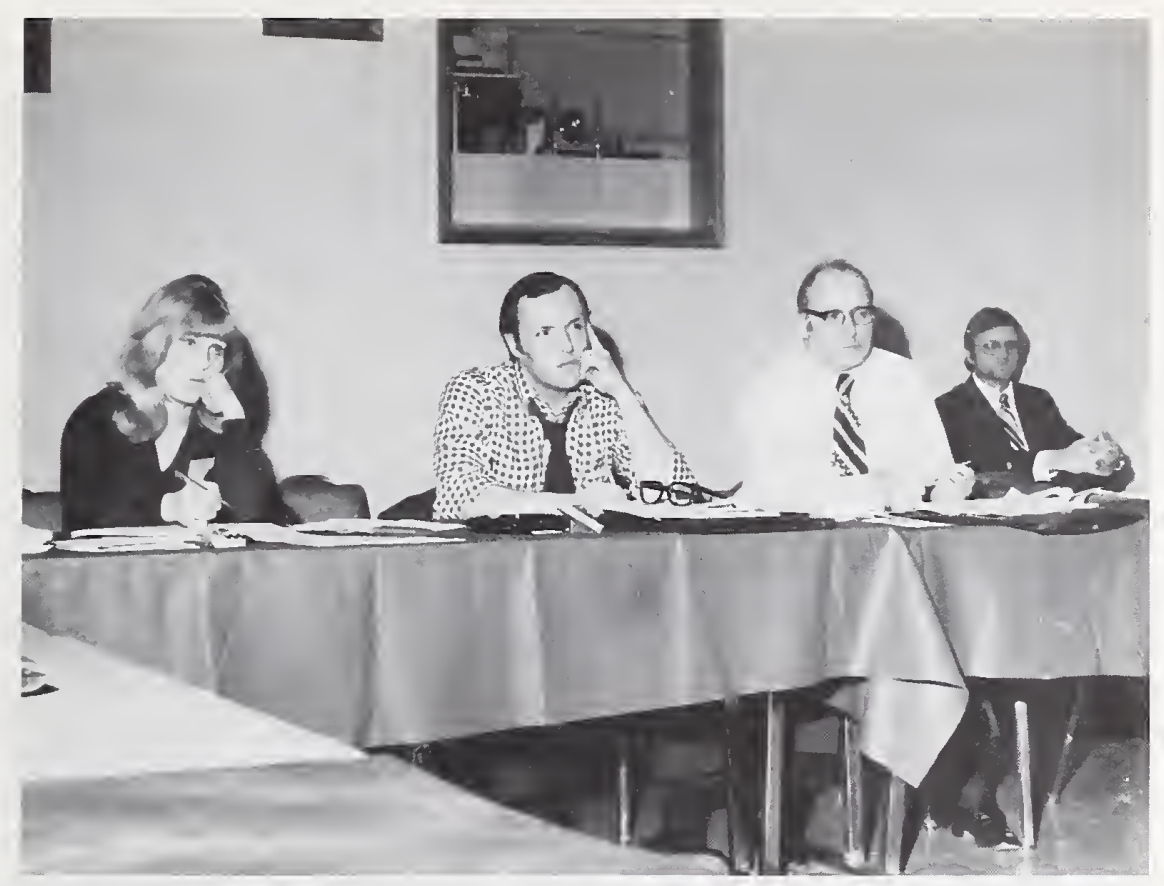

WORKSHOP 4

Co-Chairpersons

Jim Arnold

Roger Amorosi

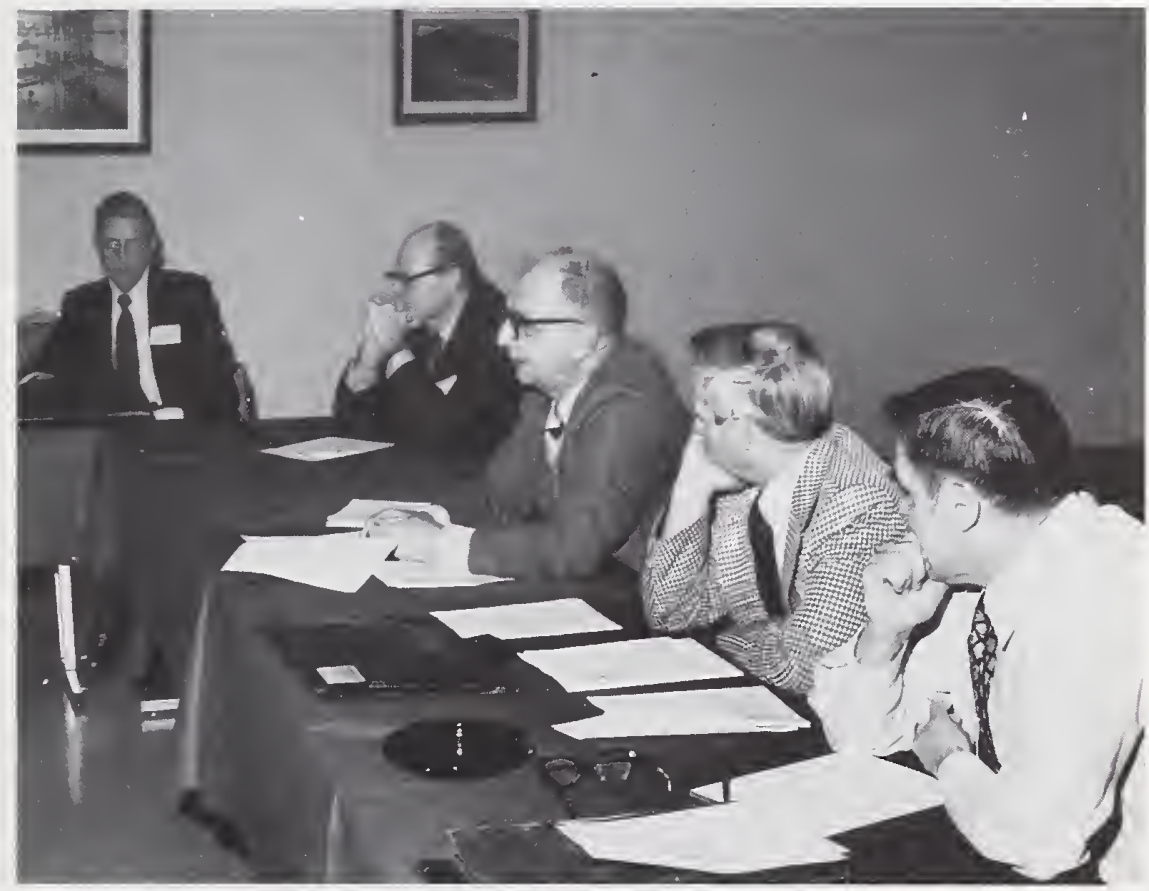

WORKSHOP 4 


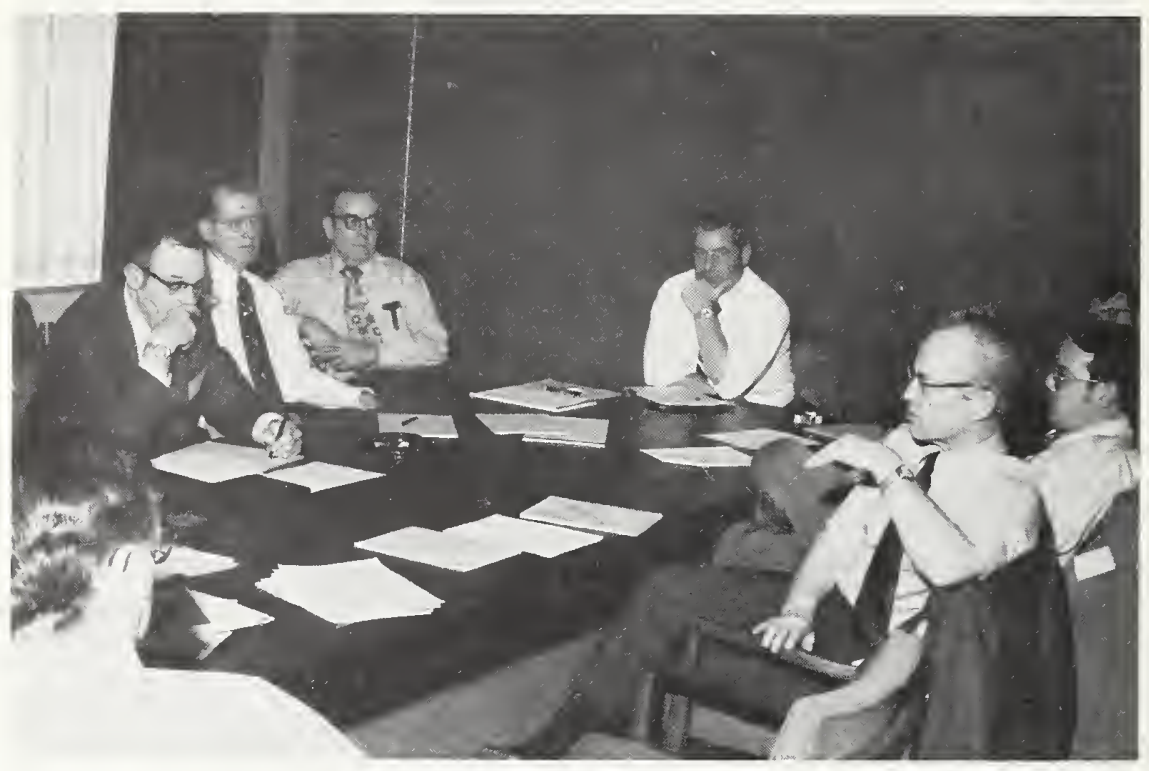

WORKSHOP 5

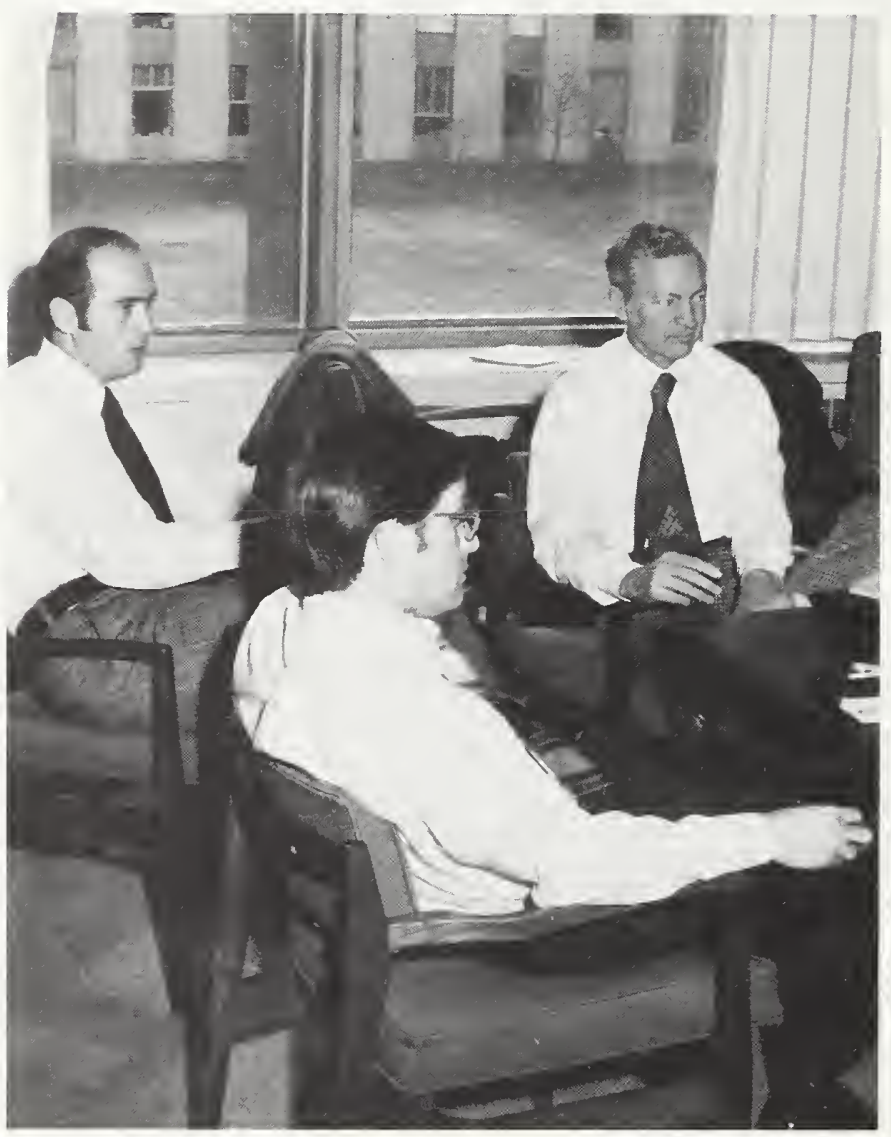

WORKSHOP 5 


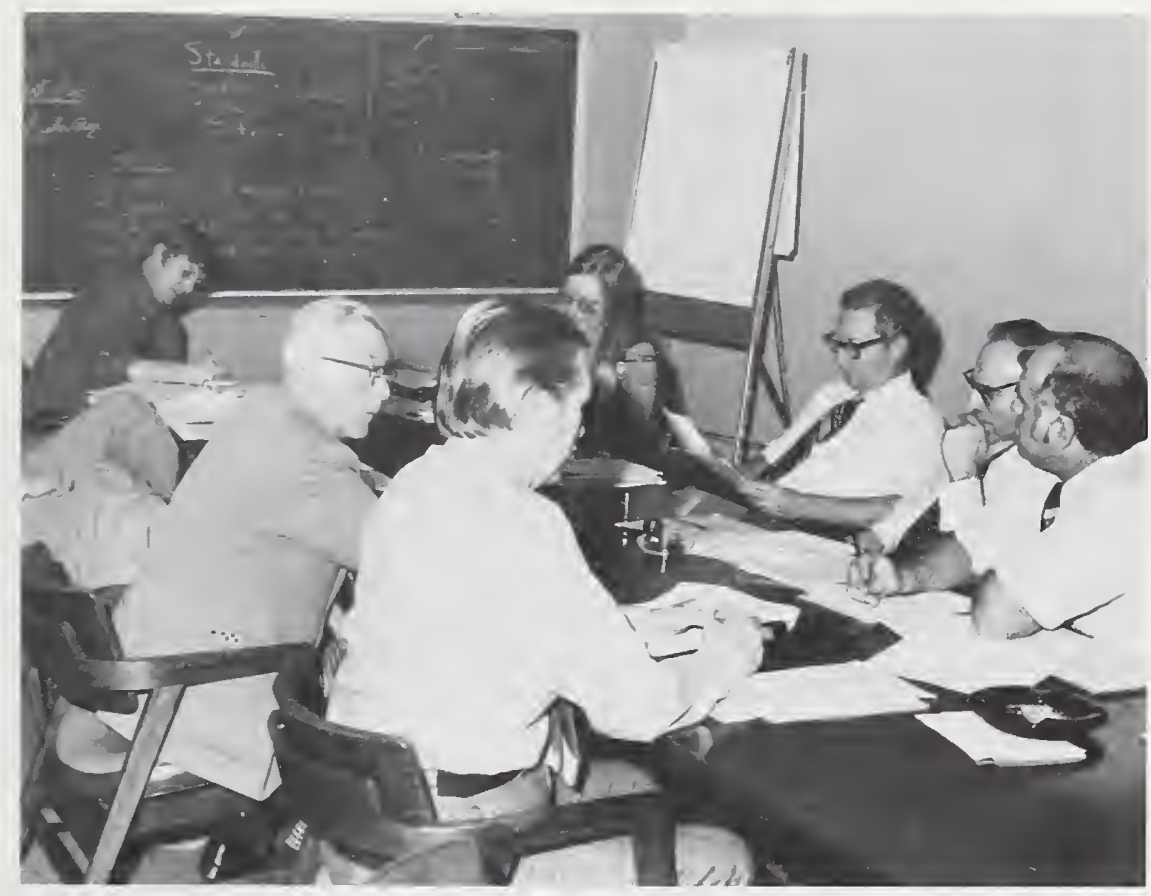

WORKSHOP 6

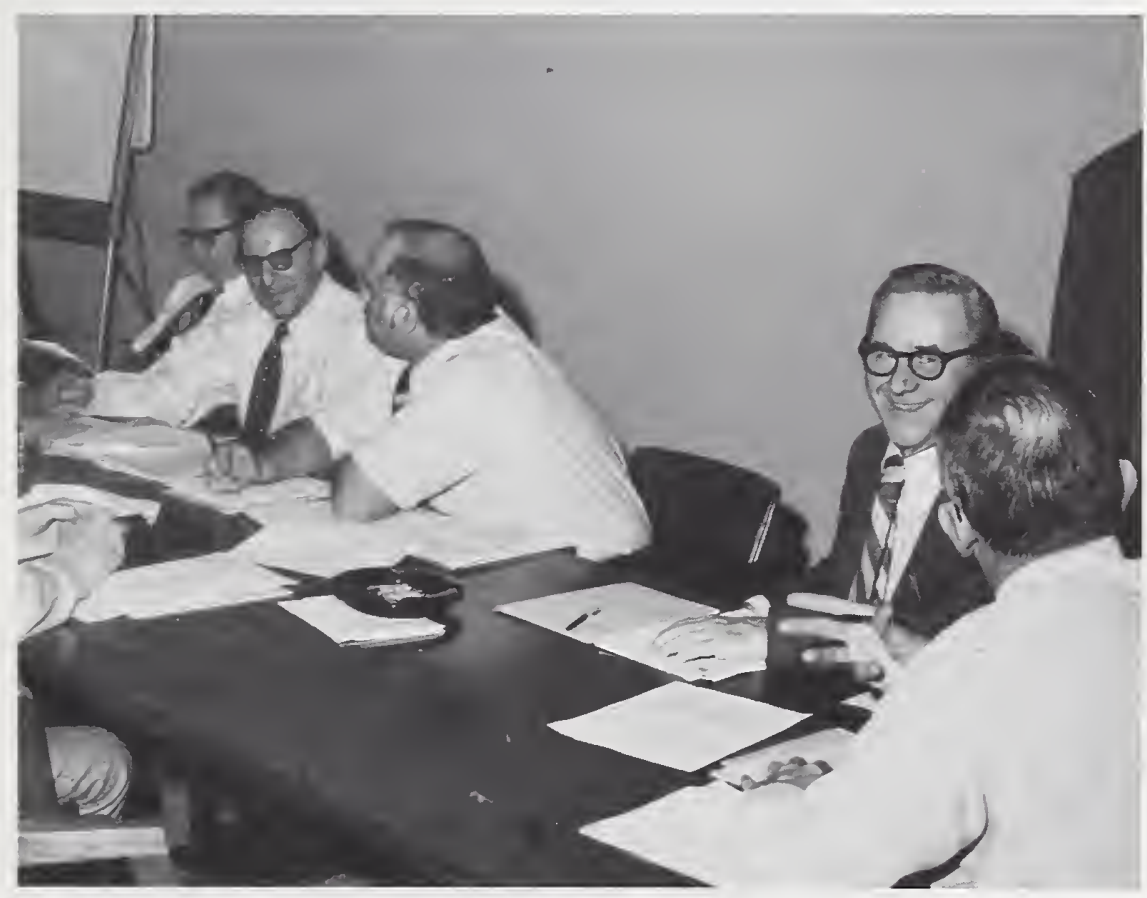

WORKSHOP 6 

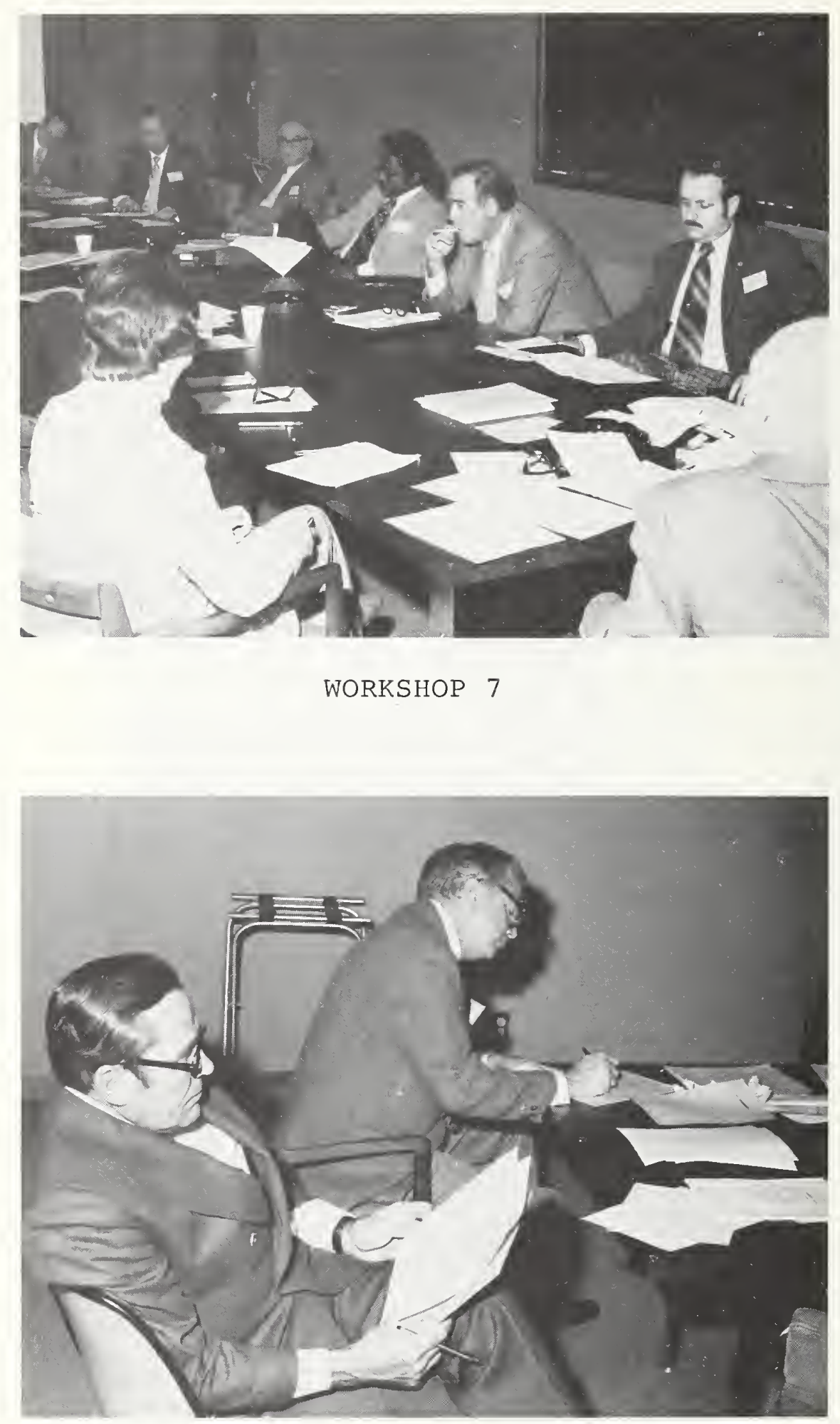

WORKSHOP 7 


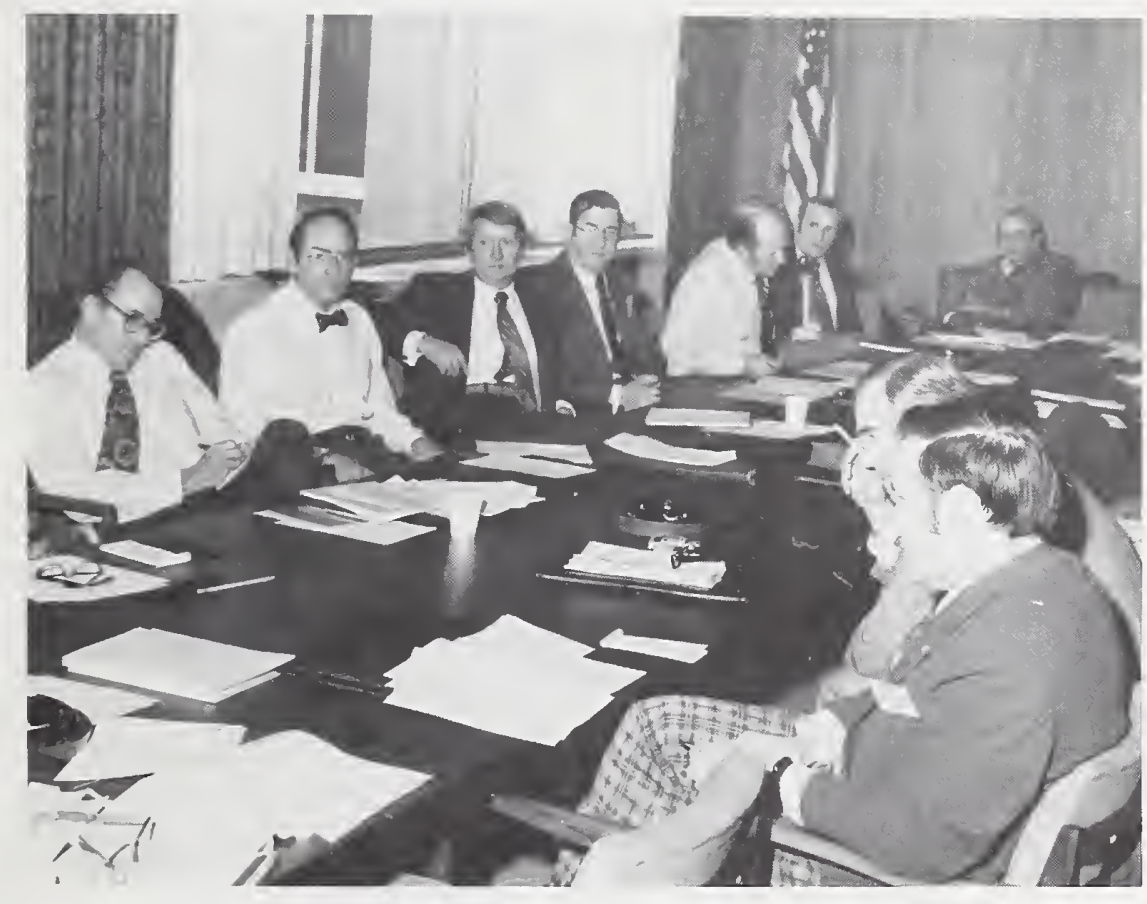

WORKSHOP 7 

NBS-114A (REV. 7-73)

\begin{tabular}{|c|c|c|c|}
\hline $\begin{array}{l}\text { U.S. DEPT. OF COMM. } \\
\text { BIBLIOGRAPHIC DATA } \\
\text { SHEET }\end{array}$ & $\begin{array}{l}\text { 1. PUBLICATION OR REPORT NO. } \\
\text { NBSIR } 75-716\end{array}$ & $\begin{array}{l}\text { 2. Gov"t Accession } \\
\text { No. }\end{array}$ & 3. Recipient's Accession No. \\
\hline \multicolumn{3}{|c|}{ Proceedings of Procurement Practices Symposium } & $\begin{array}{l}\text { 5. Publication Date } \\
\text { May } 30,1975\end{array}$ \\
\hline \multicolumn{3}{|c|}{$\begin{array}{c}\text { Federal, state and Local } \\
\text { January } 28-30,1975\end{array}$} & 6. Performing Organization Code \\
\hline \multicolumn{3}{|c|}{$\begin{array}{l}\text { 7. AUTHOR(S) } \\
\text { Theodore J. Fody Joseph G. Berke }\end{array}$} & 8. Performing Organ. Report No. \\
\hline \multicolumn{3}{|c|}{$\begin{array}{l}\text { 9. PERFORMING ORGANIZATION NAME AND ADDRESS } \\
\text { NATIONAL BUREAU OF STANDARDS } \\
\text { DEPARTMENT OF COMMERCE } \\
\text { WASHINGTON, D.C. } 20234\end{array}$} & 10. Project/Task/Work Unit No. \\
\hline \multirow{2}{*}{\multicolumn{3}{|c|}{$\begin{array}{l}\text { 12. Sponsoring Organization Name and Complete Address (Street, City, State, ZIP) } \\
\text { Experimental Technology Incentives Program, NBS } \\
\text { Federal Supply Service, Ceneral Services Administration } \\
\text { National Association of State Purchasing Officials (NASPO) } \\
\text { National Institute of Governmental Purchasing (NIGP) }\end{array}$}} & $\begin{array}{l}\text { 13. Type of Report \& Period } \\
\text { Covered } \\
\text { Final }\end{array}$ \\
\hline & & & 14. Sponsoring Agency Code \\
\hline
\end{tabular}

15. SUPPLEMENTARY NOTES

16. ABSTRACT (A 200-word or less factual summary of most significant information. If document includes a significant bibliography or literature survey, mention it here.)

The general objectives of the conference are to recommend ways to encourage information interchange and interaction between federal, state and local procurement levels and industry; to explore the use of special incentives such as life cycle costing, value incentives clauses, and unsolicited proposals as a means to promote innovation in products purchased by all levels of government; to establish the interrelationship between marketind, $R \& D$ and procurement and develop approaches to acquire the latest technolo $\$ y$ through the procurement process; to explore various product testing and evaluation efforts such as certification programs, tests by independent, company owned and association laboratories, university and government laboratories. Workshops were organized to consider procurement mechanisms, information interchange, testing and evaluation of products, and the interrelationship between marketing, R\&D and procurement. Workshops were grouped as follows: (1) Procurement Incentives, (2) Interaction and Information Interchange, (3) Marketing, R\&D and Government Procurement Cycles, (4) Product Testing and Evaluation, (5) Qualified Products Lists and Bid Samples, (6) Qualified Manufacturers, (7) Methods and Techniques of Contracting.

17. KEY WORDS (six to twelve entries; alphabetical order; capitalize only the first letter of the first key word unless a proper name; separated by semicolons)

Certification programs, ETIP; incentives; innovation; life cycle costing: procurement; product testing; specifications; unsolicited proposals

\begin{tabular}{|c|c|c|}
\hline $\begin{array}{l}\text { 18. AVAILABILITY } \quad \text { U UnIimited } \\
\square \text { For Official Distribution. Do Not Release to NTIS }\end{array}$ & $\begin{array}{l}\text { 19. SECURITY CLASS } \\
\text { (THIS REPURT) } \\
\text { UNCL ASSIFIED }\end{array}$ & $\begin{array}{l}\text { 21. NO. OF PAGES } \\
172\end{array}$ \\
\hline $\begin{array}{l}\text { Order From Sup. of Doc., U.S. Government Printing Office } \\
\text { Washington, D.C. } 20402, \text { SD Car. No. C13 }\end{array}$ & \multirow{2}{*}{$\begin{array}{l}\text { 20. SECURITY CLASS } \\
\text { (THIS PAGE) } \\
\text { UNCLASSIFIED }\end{array}$} & \multirow{2}{*}{$\begin{array}{r}\text { 22. Price } \\
\$ 6.25\end{array}$} \\
\hline $\begin{array}{l}\text { X Order From National Technical Information Service (NTIS) } \\
\text { Springfield, Virginia } 22151\end{array}$ & & \\
\hline
\end{tabular}



